\title{
POSSIBLE ROLE OF WETLANDS, PERMAFROST, AND METHANE HYDRATES IN THE METHANE CYCLE UNDER FUTURE CLIMATE CHANGE: A REVIEW
}

\author{
Fiona M. O'Connor, ${ }^{1}$ O. Boucher, ${ }^{1}$ N. Gedney, ${ }^{2}$ C. D. Jones, ${ }^{1}$ G. A. Folberth, ${ }^{1}$ R. Coppell, ${ }^{3}$ \\ P. Friedlingstein, ${ }^{4}$ W. J. Collins, ${ }^{1}{ }^{\text {J. Chappellaz, }}{ }^{5}$ J. Ridley, ${ }^{1}$ and C. E. Johnson ${ }^{1}$ \\ Received 11 January 2010; revised 27 May 2010; accepted 22 June 2010; published 23 December 2010.
}

[1] We have reviewed the available scientific literature on how natural sources and the atmospheric fate of methane may be affected by future climate change. We discuss how processes governing methane wetland emissions, permafrost thawing, and destabilization of marine hydrates may affect the climate system. It is likely that methane wetland emissions will increase over the next century. Uncertainties arise from the temperature dependence of emissions and changes in the geographical distribution of wetland areas. Another major concern is the possible degradation or thaw of terrestrial permafrost due to climate change. The amount of carbon stored in permafrost, the rate at which it will thaw, and the ratio of methane to carbon dioxide emissions upon decomposition form the main uncertainties. Large amounts of methane are also stored in marine hydrates, and they could be responsible for large emissions in the future. The time scales for destabilization of marine hydrates are not well understood and are likely to be very long for hydrates found in deep sediments but much shorter for hydrates below shallow waters, such as in the Arctic Ocean. Uncertainties are dominated by the sizes and locations of the methane hydrate inventories, the time scales associated with heat penetration in the ocean and sediments, and the fate of methane released in the seawater. Overall, uncertainties are large, and it is difficult to be conclusive about the time scales and magnitudes of methane feedbacks, but significant increases in methane emissions are likely, and catastrophic emissions cannot be ruled out. We also identify gaps in our scientific knowledge and make recommendations for future research and development in the context of Earth system modeling.

Citation: O'Connor, F. M., et al. (2010), Possible role of wetlands, permafrost, and methane hydrates in the methane cycle under future climate change: A review, Rev. Geophys., 48, RG4005, doi:10.1029/2010RG000326.

\section{INTRODUCTION TO THE METHANE CYCLE}

[2] Methane $\left(\mathrm{CH}_{4}\right)$ is an important greenhouse gas. Its atmospheric concentration in dry air mole fractions (nmol $\mathrm{mol}^{-1}$, abbreviated $\mathrm{ppb}$ ) has increased from $380 \mathrm{ppb}$ at the Last Glacial Maximum (LGM) [Monnin et al., 2001] to $715 \mathrm{ppb}$ in 1750 [Etheridge et al., 1998] and $1787 \mathrm{ppb}$ in 2008 [Dlugokencky et al., 2009]. It fluctuated between 320 and $780 \mathrm{ppb}$ (Antarctic concentration) over the last 800,000 years [Loulergue et al., 2008]. Ice core methane

\footnotetext{
${ }^{1}$ Met Office Hadley Centre, Exeter, UK.

${ }^{2}$ Joint Centre for Hydrometeorological Research, Met Office Hadley Centre, Crowmarsh Gifford, UK

${ }^{3}$ School of Geography, University of Leeds, Leeds, UK.

${ }^{4}$ College of Engineering, Mathematics and Physical Sciences, University of Exeter, Exeter, UK.

${ }^{5}$ Laboratoire de Glaciologie et Géophysique de l'Environnement, CNRS-University of Grenoble, Saint Martin d'Hères, France.
}

records also reveal abrupt changes concomitant with the abrupt warmings of the last glacial period recorded in Greenland [Chappellaz et al., 1993a], with a response reaching $16 \mathrm{ppb}$ per ${ }^{\circ} \mathrm{C}$ of Greenland warming [Huber et al., 2006] and increases of up to $200 \mathrm{ppb}$ within a century [Wolff et al., 2010]. The radiative efficiency of $\mathrm{CH}_{4}$ is 1 order of magnitude larger than that of carbon dioxide $\left(3.7 \times 10^{-4}\right.$ versus $1.548 \times 10^{-5} \mathrm{~W} \mathrm{~m}^{-2} \mathrm{ppb}^{-1}$ [Ramaswamy et al., 2001]). This is why $\mathrm{CH}_{4}$ is the second most important anthropogenic greenhouse gas with a radiative forcing of over $0.48 \mathrm{~W} \mathrm{~m}^{-2}$ in 2008 relative to preindustrial times (to be compared to $1.74 \mathrm{~W} \mathrm{~m}^{-2}$ for carbon dioxide $\left(\mathrm{CO}_{2}\right)$ based on a global mean concentration of 385 ppm for 2008 from Pieter Tans, Earth System Research Laboratory, NOAA, $\mathrm{http}: / /$ www.esrl.noaa.gov/gmd/ccgg/trends). The global mean atmospheric abundance of $\mathrm{CH}_{4}$ is determined by the interplay between emissions and sinks. $\mathrm{CH}_{4}$ emissions are very diverse, covering a wide range of natural (wetlands, termites, oceans, 
marine hydrates, geological sources, wild animals, and wildfires) and anthropogenic (energy, mining, landfills and waste treatment, ruminants, rice agriculture, and biomass burning) sources [Denman et al., 2007, Table 7.6]. It is widely accepted that reductions in anthropogenic $\mathrm{CH}_{4}$ emissions should play a role in a multigas strategy to mitigate climate change because reductions have a relatively large radiative payoff and can be economically beneficial (e.g., capturing $\mathrm{CH}_{4}$ from underground coal mines and marketing it). However, it is feared that the natural sources of $\mathrm{CH}_{4}$ may increase significantly in a warmer climate, through feedback loops that are not included in current climate models. The objective of this paper is to review the scientific literature in order to assess the importance and level of understanding of these potential feedback loops and to make some recommendations for future research.

[3] A prerequisite to the understanding of $\mathrm{CH}_{4}$ feedbacks is a quantitative understanding of the $\mathrm{CH}_{4}$ sources and sinks in the present-day climate. Estimates for individual sources can be obtained using "bottom-up" estimates, which involve a variety of techniques from field studies [e.g., Khalil et al., 1998; Mastepanov et al., 2008] and economic analyses [e.g., van Aardenne et al., 2001; Olivier et al., 2005] to processbased modeling [e.g., Walter et al., 2001a], or inversion modeling, the so-called "top-down" approach [e.g., Houweling et al., 1999; Wang et al., 2004; Bergamaschi et al., 2005]. In addition, ${ }^{13} \mathrm{C} /{ }^{12} \mathrm{C}$ isotopic ratios help constrain emissions sectorally [e.g., Mikaloff Fletcher et al., 2004a] and geographically [e.g., Mikaloff Fletcher et al., 2004b].

[4] The best estimates for individual source strengths are given by Denman et al. [2007] and, in turn, originate from a number of studies [e.g., Houweling et al., 2000; Wuebbles and Hayhoe, 2002; Olivier et al., 2005; Chen and Prinn, 2006]. Wetland emissions of $\mathrm{CH}_{4}$ are the largest single source. The estimated flux from Denman et al. [2007] to the atmosphere is given as $100-230 \mathrm{Tg} \mathrm{yr}^{-1}$. These uncertainty bounds indicate the remaining large level of uncertainty in their source strength. To balance sources, atmospheric $\mathrm{CH}_{4}$ is removed by oxidation with the hydroxyl $(\mathrm{OH})$ radical in the troposphere, biological oxidation in drier soil [Born et al., 1990; Ridgwell et al., 1999], reaction with chlorine and/or oxygen $\left(\mathrm{O}\left({ }^{1} D\right)\right)$ atoms in the stratosphere, and oxidation with chlorine atoms in the marine boundary layer [Platt et al., 2004; Allan et al., 2005]. Of these, oxidation with tropospheric $\mathrm{OH}$ is by far the most important and is responsible for removing $85 \%-90 \%$ of atmospheric $\mathrm{CH}_{4}$. The abundance of $\mathrm{OH}$ and, consequently, the $\mathrm{CH}_{4}$ lifetime depend on local concentrations of $\mathrm{CH}_{4}$ itself, nitrogen oxides $\left(\mathrm{NO}_{x}\right)$, carbon monoxide $(\mathrm{CO})$, and nonmethane volatile organic compounds (NMVOCs). For an overview of $\mathrm{OH}$ chemistry and its stability, the reader is referred to Lelieveld et al. [2002, 2004].

[5] Although there is uncertainty in individual source and sink estimates, the total global source of $\mathrm{CH}_{4}$ is relatively well constrained to within $\pm 15 \%$ [Prather et al., 2001] and largely reflects the uncertainty in the overall sink strength of $\pm 15 \%$ [Denman et al., 2007]. By knowing the atmospheric concentration and the loss rate, the global source is esti- mated to be approximately $582 \mathrm{Tg} \mathrm{CH}_{4} \mathrm{yr}^{-1}$ for the 2000 2004 period [Denman et al., 2007], of which $60 \%-70 \%$ is of anthropogenic origin. This emission rate is twice that estimated for the preindustrial period [Chappellaz et al., 1993b; Etheridge et al., 1998; Houweling et al., 2000; Ferretti et al., 2005; Valdes et al., 2005]. As a result, and predominantly because of the raised anthropogenic emissions breaking the near-balance between sources and sinks in preindustrial times, atmospheric $\mathrm{CH}_{4}$ concentrations have seen a dramatic increase since the 18th century from 715 to $1774 \mathrm{ppb}$ in 2005 [Forster et al., 2007]. Flask measurements for roughly the last 2 decades are shown in Figure 1a. Very recent concentrations of $\mathrm{CH}_{4}$ have increased even beyond the 2005 concentrations [Rigby et al., 2008; Dlugokencky et al., 2009] and are unprecedented in the past 800,000 years [Loulergue et al., 2008]. While the global increase in $\mathrm{CH}_{4}$ concentrations is unequivocal, the growth rate of $\mathrm{CH}_{4}$ and the processes controlling it are more poorly understood.

[6] The growth rate of atmospheric $\mathrm{CH}_{4}$, as shown in Figure $1 \mathrm{~b}$, represents the imbalance between sources and sinks. This was at a high of $16 \mathrm{ppb} \mathrm{yr}^{-1}$ in the late $1970 \mathrm{~s}$ and early 1980s [Blake and Rowland, 1988]. It then slowed significantly [Steele et al., 1992; Dlugokencky et al., 1998] until it came very close to zero in 1999 [Dlugokencky et al., 2003]. Since then and until very recently, $\mathrm{CH}_{4}$ concentrations have remained relatively stable. However, concerns have increased again during the last 3 years as very recent measurements show that renewed growth started in early 2007 [Rigby et al., 2008; Dlugokencky et al., 2009]. Numerous studies have examined the relative importance of changes in emissions and/or $\mathrm{OH}$ abundance to this trend. Prinn et al. [2005], for example, using an inversion model and methyl chloroform $\left(\mathrm{CH}_{3} \mathrm{CCl}_{3}\right)$ observations, found a small positive global trend in $\mathrm{OH}$ for the period 1984-2002 of $0.2 \% \mathrm{yr}^{-1}$, which appears consistent with the downward trend in $\mathrm{CH}_{4}$ growth rate, although the interannual variability is high. Other studies have also found a positive trend [Karlsdóttir and Isaksen, 2000; Dentener et al., 2003; Wang et al., 2004; Fiore et al., 2006] but differ in their explanations for the $\mathrm{OH}$ changes. Bousquet et al. [2005], however, found a negative trend in global mean $\mathrm{OH}$ of $0.7 \% \mathrm{yr}^{-1}$ for 1980-2000 but argued for improved $\mathrm{CH}_{3} \mathrm{CCl}_{3}$ emission inventory data to infer more robust long-term $\mathrm{OH}$ trends. Their argument appears to support possible incorrect assumptions about the temporal distribution of $\mathrm{CH}_{3} \mathrm{CCl}_{3}$ emissions [Krol and Lelieveld, 2003; Krol et al., 2003; Lelieveld et al., 2004]. On the other hand, the study of Manning et al. [2005] using ${ }^{14} \mathrm{CO}$ observations found no significant long-term trend in $\mathrm{OH}$ concentrations. Moreover, although changes in global mean $\mathrm{OH}$ may have been neutral or small in the past century, regional changes may have been more significant [Lelieveld et al., 2002, 2004].

[7] While the studies above have focused on $\mathrm{OH}$ and its $\mathrm{CH}_{4}$ removal properties, others have proposed that the decline in $\mathrm{CH}_{4}$ growth rate through the 1980 s and 1990 s can be partly or wholly attributed to reductions or stabilization of emissions. For example, Wang et al. [2004], in addition to a positive $\mathrm{OH}$ trend, found that decreasing anthropogenic 


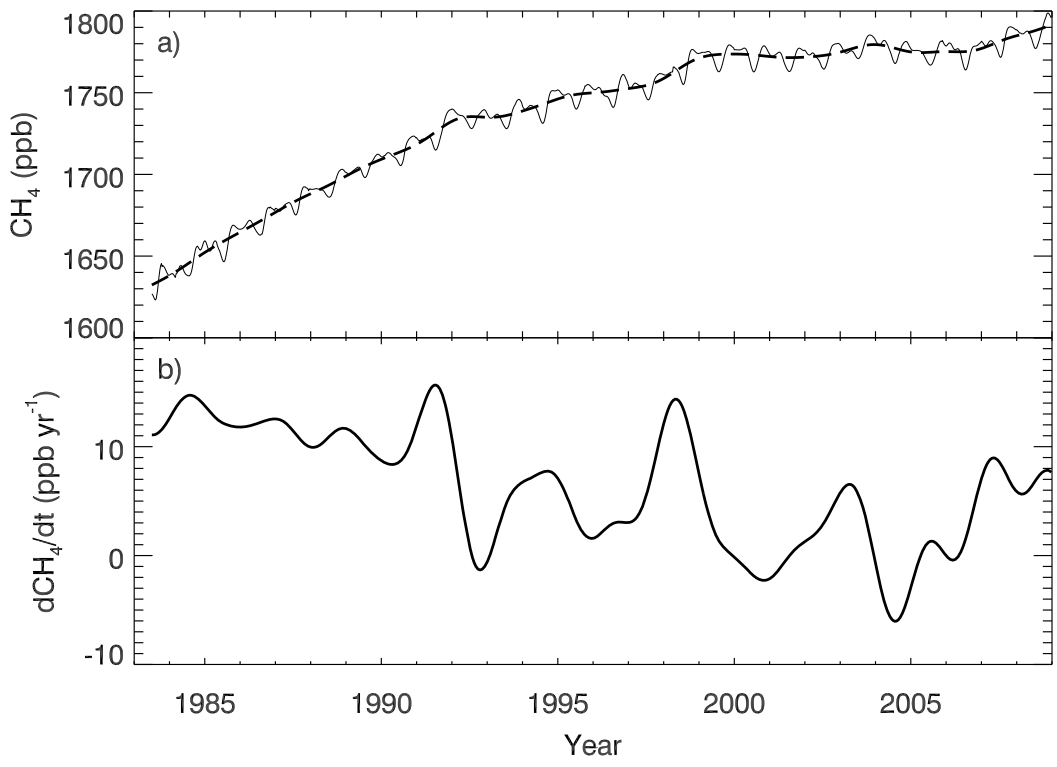

Figure 1. Time series of (a) globally averaged atmospheric $\mathrm{CH}_{4}$ concentrations in ppb and (b) instantaneous $\mathrm{CH}_{4}$ growth rate for globally averaged $\mathrm{CH}_{4}$ in $\mathrm{ppb} \mathrm{yr}^{-1}$ for the period 1983-2008 derived from observations from NOAA's global surface air sampling network. Adapted from Dlugokencky et al. [2009].

emissions (ruminants, gas leakage, and coal mining) from Eastern Europe and the former Soviet Union (FSU) contributed to the declining growth rate between 1988 and 1997. This reduction is supported by other studies [Dlugokencky et al., 2003; Bousquet et al., 2006; Chen and Prinn, 2006], although there may also be a contribution from wetlands [Walter et al., 2001b; Bousquet et al., 2006]. Furthermore, Cunnold et al. [2002] inferred from atmospheric $\mathrm{CH}_{4}$ measurements that net annual emissions from 1985 to 1997 were fairly constant, which is consistent with Dlugokencky et al. [1998]. While emissions from Eastern Europe and the FSU may have decreased in the late 1980s and early 1990s, global anthropogenic emissions increased during the entire 1970-1992 period, were fairly constant between 1993 and 2000, and have increased since 2000, according to the Emissions Database for Global Atmospheric Research (EDGAR4) database (http://edgar.jrc.ec.europa.eu). Since 1999, the increase in global anthropogenic emissions may have been masked by a coincident decrease in wetland emissions driven by extended droughts [Bousquet et al., 2006]. Bousquet et al. [2006] suggested that atmospheric $\mathrm{CH}_{4}$ may increase further if wetland emissions return to their 1990s level. Indeed, the very recent reversal to a positive $\mathrm{CH}_{4}$ growth rate has been attributed by Rigby et al. [2008] to increasing emissions globally or in the Northern Hemisphere alone, depending on the assumption regarding $\mathrm{OH}$ concentrations. Dlugokencky et al. [2009], more recently, indicated that the increase in 2007 was due to increased emissions from northern wetlands caused by anomalously high temperatures with a small contribution from the tropics. A further increase in atmospheric $\mathrm{CH}_{4}$ was evident in 2008, particularly in the tropics, and was attributed to increased emissions from tropical wetlands associated with positive anomalies in precipitation over Indonesia and the eastern Amazon typical of La Niña events [Dlugokencky et al., 2009]. Using satellite observations, an inversion model, and a simple $\mathrm{CH}_{4}$ wetland emissions model, Bloom et al. [2010] estimated a 7\% rise in wetland emissions over the 2003-2007 period as a result of midlatitude and high-latitude warming.

[8] From Figure 1b, there is significant variation in the atmospheric $\mathrm{CH}_{4}$ growth rate between years. This variation suggests a strong interannual variation in sources and/or sinks, but the main causes remain uncertain. For example, the anomalously low growth rate in 1992 following the Mount Pinatubo eruption has been attributed to aerosolinduced stratospheric ozone depletion and anomalously high $\mathrm{OH}$ concentrations [Bekki et al., 1994; Wang et al., 2004]. A more recent study by Telford et al. [2010] suggests that the low growth rate and enhanced $\mathrm{OH}$ could be attributed to reduced biogenic volatile organic compound (BVOC) emissions following the Mount Pinatubo eruption. On the other hand, other studies suggest that the anomaly was due to lower emissions from northern fossil fuel sources [Bousquet et al., 2006] and biomass burning [Lowe et al., 1997], with some contribution from lower wetland emissions [Wang et al., 2004]. The enhanced growth rate in the 1997-1998 El Niño year has been attributed to changes in emissions from wetlands [Dlugokencky et al., 2001; Mikaloff Fletcher et al., 2004a; Chen and Prinn, 2006; Morimoto et al., 2006], biomass burning [Langenfelds et al., 2002; Morimoto et al., 2006], and wildfires [Prinn et al., 2005; Bousquet et al., 2006]. An assessment of emissions for the period 1997-2004 clearly supports anomalous burning during the 1997-1998 El Niño year [van der Werf et al., 2006], and the enhancement in $\mathrm{CH}_{4}$ emissions alone accounts for approximately two thirds of the $\mathrm{CH}_{4}$ growth rate anomaly. In addition to $\mathrm{OH}$ and emission changes, the $\mathrm{CH}_{4}$ growth rate 
appears to be influenced by interannual variability in meteorology [Warwick et al., 2002].

[9] Despite the individual source strength uncertainties and the lack of understanding of the atmospheric $\mathrm{CH}_{4}$ growth rate, it is still widely accepted that reductions in anthropogenic $\mathrm{CH}_{4}$ emissions should play a role in a multigas strategy to mitigate climate change. However, as the climate warms, natural sources of $\mathrm{CH}_{4}$ may increase through feedback loops that are currently not represented in climate models. In sections 2-4, we examine the importance and level of understanding of potential feedback loops involving wetlands, permafrost, and marine hydrates, respectively.

\section{WETLANDS}

\subsection{Methane Emissions From Wetlands}

[10] Wetlands are the dominant natural source of $\mathrm{CH}_{4}$ over the globe and emit between 100 and $231 \mathrm{Tg} \mathrm{CH}_{4} \mathrm{yr}^{-1}$ globally [Denman et al., 2007] out of a total of about $582 \mathrm{Tg} \mathrm{CH}_{4} \mathrm{yr}^{-1}$ during the 2000-2004 period. This represents $\sim 17 \%-40 \%$ of the global present-day atmospheric $\mathrm{CH}_{4}$ budget, which is dominated by anthropogenic sources. As well as uncertainty in the global mean contribution of wetland $\mathrm{CH}_{4}$ emissions to the overall budget, there is considerable uncertainty over its geographical distribution.

[11] Methane is produced by the anaerobic respiration of methanogenic microbes. This occurs in saturated anoxic soil below the water table [Arneth et al., 2010]. The rate of $\mathrm{CH}_{4}$ production is dependent on soil temperature, the amount and quality of substrate available from vegetation primary production and organic matter decomposition [Christensen et al., 2003], and soil pH [Garcia et al., 2000]. The $\mathrm{CH}_{4}$ is transported out of the saturated zone either through diffusion, ebullition, or vegetation-mediated transfer in vascular plants. Ebullition is the formation and release of bubbles into the unsaturated soil pore space (or atmosphere if the water table is above the surface). Vegetation-mediated transport can also occur from the saturated zone through the roots of many species of wetland plants, thereby bypassing the unsaturated oxic soil above the water table.

[12] In non-vegetation-mediated transport, $\mathrm{CH}_{4}$ is oxidized in the oxic (unsaturated) region of the soil. Hence, the position of the water table defines the sizes of both the production and consumption zones. As the oxic region of the soil is highly efficient at oxidizing $\mathrm{CH}_{4}$, significant amounts of $\mathrm{CH}_{4}$ are generally only released from the soil into the atmosphere when the water table is relatively high [Roulet et al., 1992].

[13] The rates of $\mathrm{CH}_{4}$ production and oxidation are both strongly temperature dependent. Both the production and oxidation rates are often described by a $Q_{10}$ factor, where $Q_{10}$ is the factor by which a reaction rate increases with a $10 \mathrm{~K}$ increase in temperature. This observation-based value is an approximation to the Arrhenius equation, which describes the temperature dependence of a single biological process. Moreover, estimating $Q_{10}$ from observed $\mathrm{CH}_{4}$ emissions usually combines a number of processes (e.g., substrate production, $\mathrm{CH}_{4}$ production, and oxidation) and can thus generally be regarded as a semiempirical fitting parameter for simple models which lump these processes together. $Q_{10^{-}}$ derived values from observational studies give a range of 1.7-16 for $\mathrm{CH}_{4}$ emissions [Walter and Heimann, 2000]. However, much of this discrepancy is probably due to the difficulty in eliminating other environmental factors such as soil moisture variation [Khalil et al., 1998].

[14] The amount of $\mathrm{CH}_{4}$ emitted anaerobically from wetlands has been shown to be predominantly dependent on water table position, temperature, and the availability of carbonaceous substrate [Christensen et al., 2003; Moore et al., 1998]. However, the sensitivity of the emissions to these factors is still highly uncertain [Walter and Heimann, 2000]. The cause of the interannual variability in wetland $\mathrm{CH}_{4}$ emissions is also uncertain, with various studies showing differing temperature and hydrological sensitivities [Dlugokencky et al., 2001; Gedney et al., 2004; Bloom et al., 2010; Ringeval et al., 2010].

[15] Aerated soils can also take up atmospheric $\mathrm{CH}_{4}$ through oxidation by methanotrophic bacteria. Figure 2 shows modeled net $\mathrm{CH}_{4}$ fluxes to the atmosphere for the pan-Arctic region during the 1990s from Zhuang et al. [2004]. Although there are extensive areas with net uptake of $\mathrm{CH}_{4}$ from the atmosphere, this component is relatively small compared to the tropospheric $\mathrm{OH}$ sink.

[16] Estimates of present-day global wetland $\mathrm{CH}_{4}$ emissions are usually derived from process-based models (bottom-up approach [e.g., Cao et al., 1996; Walter et al., 2001a]) or global inverse models (top-down approach [e.g., Hein et al., 1997; Bousquet et al., 2006]). Process-based models tend to be calibrated at individual wetland sites and then applied across the globe. Some of these process-based models do not include all the different $\mathrm{CH}_{4}$ transport pathways from the soil to the atmosphere. Some schemes incorporate substrate availability through modeling the multiple soil carbon pools [e.g., Cao et al., 1996], whereas others use net primary productivity as a surrogate [e.g., Christensen and Cox, 1995; Walter et al., 2001a]. Most wetland $\mathrm{CH}_{4}$ emission models tend to use relatively simple hydrology models with the grid box mean water table depth estimated from a simple function of soil moisture [e.g., Cao et al., 1996].

[17] Regardless of the complexity of the process-based models, they are not globally constrained. This probably explains the large range in emissions estimates produced using this approach: e.g., $92 \mathrm{Tg} \mathrm{CH}_{4} \mathrm{yr}^{-1}$ with $\sim 64 \%$ from tropical wetlands [Cao et al., 1998] to $260 \mathrm{Tg} \mathrm{CH}_{4} \mathrm{yr}^{-1}$ with $\sim 75 \%$ from tropical wetlands [Walter et al., 2001a].

[18] Inverse models use a chemical transport model to estimate the most likely distribution of $\mathrm{CH}_{4}$ wetland emissions given the observed atmospheric chemistry and meteorology and estimates of anthropogenic $\mathrm{CH}_{4}$ emissions. These studies tend to rely on relatively simple models of $\mathrm{CH}_{4}$ emissions from wetlands [e.g., Hein et al., 1997]. More recent inversion studies have used isotopic $\mathrm{CH}_{4}$ data in order to constrain the model further by attempting to distinguish between biogenic and anthropogenic $\mathrm{CH}_{4}$ sources. 


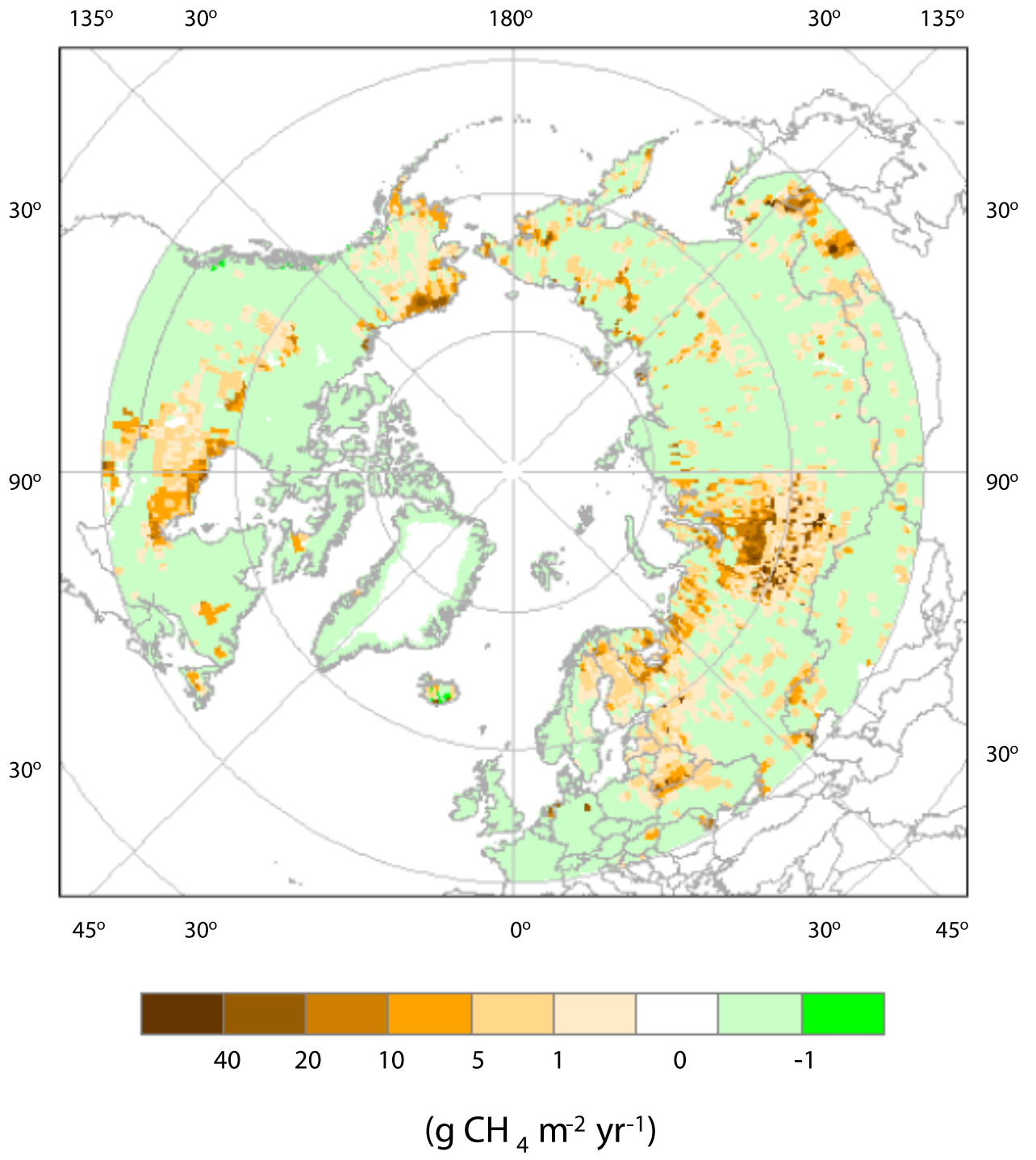

Figure 2. Simulated net $\mathrm{CH}_{4}$ fluxes (emissions and consumption) in the pan-Arctic region for the 1990s. Positive values indicate net emissions to the atmosphere, and negative values indicate net uptake from the atmosphere. Reproduced from Zhuang et al. [2004].

However, there is still considerable spread in global estimates from inversion models with a range of $145-231 \mathrm{Tg}$ $\mathrm{CH}_{4} \mathrm{yr}^{-1}$ [Denman et al., 2007]. Much of this spread is due to a lack of observations [Chen and Prinn, 2006]. A priori estimates of fluxes also play a significant role in determining the results of the inversion [Hein et al., 1997]. Another cause of uncertainty is in $\mathrm{OH}$, the global total of which is currently assumed to be known to within $10 \%$. Some of the emissions spread may also be explained by the difficulty in differentiating between rice and natural wetland emissions due to their close proximity in Southeast Asia. Indeed, Chen and Prinn [2006] merge their estimates of wetland and rice emissions over Southeast Asia as they state it would be difficult to separate them in an inversion model.

[19] Satellite estimates of total column $\mathrm{CH}_{4}$ from the Scanning Imaging Absorption Spectrometer for Atmospheric Chartography (SCIAMACHY) instrument have recently become available and have been used in inversion studies [e.g., Frankenberg et al., 2005; Bergamaschi et al., 2009].
Most inversion studies (regardless of whether they use SCIAMACHY data or not) produce a higher proportion of tropical emissions than the bottom-up studies: the percentages of emissions from tropical wetlands from a number of inversion studies are $81 \%, 85 \%, 88 \%$, and $76 \%$ for Hein et al. [1997], Wang et al. [2004], Mikaloff Fletcher et al. [2004a], and Chen and Prinn [2006], respectively. The bottom-up approaches have typically given more emphasis to the high latitudes where the majority of the wetlands occur (see above) and where most of the field experiment data are available [Walter et al., 2001a].

\subsection{Response of Methane Wetland Emissions to Changing Climate}

[20] Historical studies also have the potential to constrain wetland $\mathrm{CH}_{4}$ models; however, this constraint is not very strong. LGM and preindustrial atmospheric $\mathrm{CH}_{4}$ concentrations are highly correlated with rapid variations in the 
polar temperature records [Chappellaz et al., 1993a]. Methane concentrations have varied between 350 and $700 \mathrm{ppb}$ over this period. This suggests that there might be a strong feedback between temperature and wetland $\mathrm{CH}_{4}$ emissions. Precise measurements of the interpolar difference of the $\mathrm{CH}_{4}$ mixing ratio during the Holocene and back to the LGM have provided constraints on the latitudinal distribution of the source-sink changes through time [Chappellaz et al., 1997; Brook et al., 1999; Dällenbach et al., 2000]. These studies suggest that tropical wetlands played a key role in driving glacial-interglacial and Holocene $\mathrm{CH}_{4}$ changes but that abrupt $\mathrm{CH}_{4}$ increases accompanying the rapid DansgaardOeschger warmings mostly involved boreal wetland switch on/off. Recent isotopic $\left({ }^{13} \mathrm{C} /{ }^{12} \mathrm{C}\right.$ and $\left.\mathrm{D} / \mathrm{H}\right)$ mass balance of the $\mathrm{CH}_{4}$ budget between the LGM and the Holocene suggests that wetland changes (both in the tropics and at boreal latitudes) should have been key players to explain the $\mathrm{CH}_{4}$ doubling between glacial and interglacial conditions [Fischer et al., 2008]. Wetland extent and climate were considerably different during the LGM and are not well known [Chappellaz et al., 1993b; Kaplan, 2002]. Moreover, the atmospheric oxidizing capacity may have been influenced by other factors such as emissions of BVOCs (see also section 5.4).

[21] In the more recent past, increasing soil temperatures and draining land for agriculture [Chappellaz et al., 1993b; Houweling et al., 2000] are likely to have had opposing effects on emissions. Zhuang et al. [2004] estimate that emissions have increased by an average of $0.8 \mathrm{Tg} \mathrm{CH}_{4} \mathrm{yr}^{-1}$ over the 20th century across the pan-Arctic region. Houweling et al. [2000] suggest that wetland emissions would have decreased by roughly $10 \%$ since the beginning of industrialization.

[22] The overall change of wetland $\mathrm{CH}_{4}$ emissions in response to future climate is mainly dependent on the combined effect of geographical changes in temperature and precipitation. The largest warming is projected over the high latitudes [Meehl et al., 2007]. Christensen and Cox [1995] hypothesized that enhanced anaerobic decomposition of soil carbon and the associated increase in $\mathrm{CH}_{4}$ production could provide a significant positive feedback on the anthropogenic greenhouse effect. However, the height of the water table is strongly dependent on the extent of permafrost in the soil. Observations suggest that permafrost thawing has already been seen over large areas in the Arctic and subArctic [Stokstad, 2004]. This is discussed in more detail in section 3.3.

[23] As well as changes in climate, changes in sulfate deposition may also have a considerable impact on wetland emissions. Sulfur-reducing bacteria have a higher affinity for hydrogen and acetate (both of which are involved in methanogenesis). As a consequence, acid deposition may be suppressing $\mathrm{CH}_{4}$ emissions from peatlands by $\sim 15 \%$ in the present day [Gauci et al., 2004]. Acid deposition is likely to decrease in the future because of air quality control policies, thus unmasking the suppression in $\mathrm{CH}_{4}$ emissions that may have occurred in the recent past.
[24] The supply of substrate for $\mathrm{CH}_{4}$ production is also likely to change under climate change. In a dynamic global vegetation model comparison, the global vegetation productivity is predicted to decrease, and soil carbon decomposition is predicted to increase [Sitch et al., 2008]. The regional response is complex, however, with the extratropics predicting an increase in vegetation productivity.

[25] Cao et al. [1998] applied idealized changes to the climate in a process-based ecosystem model of natural wetlands and rice paddies. A uniform increase in temperature of $2^{\circ} \mathrm{C}$ and a $10 \%$ rise in precipitation resulted in a predicted increase in $\mathrm{CH}_{4}$ emissions of $19 \%$. Temperature increases above $4^{\circ} \mathrm{C}$, however, resulted in a reduced flux due to soil moisture depletion.

[26] Gedney et al. [2004] used a simple $\mathrm{CH}_{4}$ emissions model coupled to a version of the Met Office Surface Exchange Scheme [Gedney and Cox, 2003] to estimate the response of wetland emissions to future climate. The model had a temperature-dependent $Q_{10}$ which was equivalent to the Arrhenius equation, and the substrate availability is proportional to the soil carbon content. The model incorporated a prognostic water table depth and soil freezing and thawing. Hence, it could respond to both hydrological and thermodynamic changes caused by climate change. The $\mathrm{CH}_{4}$ model parameters $\left(Q_{10}\right.$ and a global rate factor constant) were first constrained using the observed interannual variability in global atmospheric $\mathrm{CH}_{4}$ concentrations. The best estimate of $Q_{10}$ was found to be $\sim 3.7$ at $0^{\circ} \mathrm{C}$ (equivalent to 3.3 at $25^{\circ} \mathrm{C}$ ) and total wetland and rice $\mathrm{CH}_{4}$ emissions of $300 \mathrm{Tg} \mathrm{CH}_{4} \mathrm{yr}^{-1}$. Gedney et al. [2004] predicted an increase of between $75 \%$ and $100 \%$ in wetland emissions over the 21 st century under the IS92A scenario. This is equivalent to a $\sim 25 \%-35 \%$ change in global wetland emissions per degree of global temperature change and amounts to a $4 \%$ $5 \%$ increase in the total predicted warming by 2100 . The dominant driving force in the model was found to be the increase in temperature, rather than changes in water table. The absolute increases in wetland emissions were largest over the tropics.

[27] Shindell et al. [2004] used the Goddard Institute for Space Studies climate model to predict the change in $\mathrm{CH}_{4}$ emissions due to climate change with both the emission rate and the geographic distribution of wetlands responding to climate. They simulated an increase in wetland $\mathrm{CH}_{4}$ emissions from 156 to $277 \mathrm{Tg} \mathrm{yr}^{-1}$ for a doubling of atmospheric $\mathrm{CO}_{2}$ with the bulk of the increase due to enhanced emissions from existing tropical wetlands. In most wetland regions, the increases were driven both by warmer temperatures and by enhanced precipitation.

[28] Eliseev et al. [2008] predicted future changes of wetland $\mathrm{CH}_{4}$ emissions for three scenarios $(\mathrm{A} 2, \mathrm{~A} 1 \mathrm{~B}$, and B2) from the Intergovernmental Panel on Climate Change (IPCC)'s Special Report on Emissions Scenarios (SRES) [Nakićenović et al., 2000] using the Institute of Applied Physics, Russian Academy of Sciences (IAP RAS), climate model of intermediate complexity. Wetland areas were fixed in time and prescribed from observations. Eliseev et al. [2008] also assumed that all wetland ecosystem soils were 
completely water saturated. The wetland $\mathrm{CH}_{4}$ model assumed a $Q_{10}$ temperature dependence of 2 with no account taken of substrate availability. Methane was incorporated into the atmosphere using a simple well-mixed approximation and decay time. The absolute increases in wetland emissions were largest over the high latitudes mainly because of the greater climatic change there. The global $\mathrm{CH}_{4}$ wetland emissions between preindustrial times and 2100 were predicted to change from $130-140$ to $170-200 \mathrm{Tg} \mathrm{CH}_{4} \mathrm{yr}^{-1}$ depending on the scenario used. This is approximately equal to $20-25 \mathrm{Tg} \mathrm{CH}_{4} \mathrm{yr}^{-1}$ per degree of global temperature change or $10 \%-15 \%$ change in global wetland emissions per degree of global temperature change. This results in approximately an additional $1 \%-2 \%$ additional warming between the preindustrial period and 2100 for the scenarios considered (A2, A1B, and B2).

[29] Volodin [2008] also used the IAP RAS climate model but with a more complex wetland model where the $\mathrm{CH}_{4}$ diffusion and ebullition as well as $\mathrm{CH}_{4}$ oxidation in the soil were explicitly modeled. The $\mathrm{CH}_{4}$ production was based on net primary productivity rather than soil organic matter. The $Q_{10}$ value for $\mathrm{CH}_{4}$ production was also much higher $\left(Q_{10}=\right.$ 6). The geographical distribution of wetland area was fixed, but the water table was modeled. The absolute increases in wetland emissions were largest over the tropics. Volodin [2008] predicted an increase from preindustrial times to 2100 for the A1B scenario run of $240-340 \mathrm{Tg} \mathrm{CH}_{4} \mathrm{yr}^{-1}$. This is equal to approximately a $12 \%$ change in global wetland emissions per degree of global temperature change due to both temperature and precipitation increases. Given the relatively high $Q_{10}$ value that was used, it is not surprising that Volodin predicts a much larger additional warming (8\%) due to interactive wetland $\mathrm{CH}_{4}$ than Eliseev et al. [2008]. Volodin also used a slightly different equation to calculate the $\mathrm{CH}_{4}$ concentration in the atmosphere, which may also partly explain this.

[30] The interactive wetland and atmospheric chemistry studies which predict the impact of changes in climate on $\mathrm{CH}_{4}$ and its subsequent climate feedback [Gedney et al., 2004; Eliseev et al., 2008; Volodin, 2008] predict very different present-day values and changes in future wetland emissions. The range of additional warming from wetland $\mathrm{CH}_{4}$ emissions from preindustrial times to 2100 is predicted to be between $\sim 1 \%$ and $8 \%$ for the SRES A2, A1B, and B2 scenarios [Eliseev et al., 2008; Volodin, 2008]. The Gedney et al. [2004] simulation, which started from 1990 and used the IS92a scenario, predicted a $4 \%-5 \%$ increase in warming between 1990 and 2100. The enhanced wetland emissions given by Shindell et al. [2004] and Volodin [2008] were due to both temperature and precipitation increases, whereas those given by Gedney et al. [2004] were dominated by temperature alone (Eliseev et al. [2008] fix the water content in their wetlands so their emissions increases must be due to temperature changes alone).

[31] All these interactive climate studies [Gedney et al., 2004; Eliseev et al., 2008; Volodin, 2008] predict presentday global wetland emissions that are within the range of (or very close to) current estimates [Denman et al., 2007]. In the
Eliseev et al. [2008] study, the modeled atmospheric $\mathrm{CH}_{4}$ concentrations agree well with observations between approximately 1960 and 2000 but are approximately 100 $150 \mathrm{ppb}$ too high between 1860 and 1960. In the Volodin [2008] study, the atmospheric $\mathrm{CH}_{4}$ concentration was too low $(\sim 50-100 \mathrm{ppb})$ from preindustrial times to 1990 . After this, the model simulation improved until 2000, where the model agrees well with the observations. Given the overall uncertainties in the historical $\mathrm{CH}_{4}$ budget, none of these studies can be obviously eliminated through their comparison against observations.

\subsection{Challenges and Prospects}

[32] There has been success in isolating the main controls of $\mathrm{CH}_{4}$ emissions from wetlands, namely, water table depth, soil temperature, and substrate availability and quality [Roulet et al., 1992; Khalil et al., 1998; Christensen et al., 2003]. However, the fundamental processes governing these and how they respond to changes in climate need to be modeled to an adequate level of complexity. In order to successfully model wetland $\mathrm{CH}_{4}$ emissions, the wetland hydrology and thermodynamics must first be adequately parameterized.

[33] Water table depth and inundation extent are strongly controlled by soil hydraulic properties, local topography, permafrost, and the active layer depth, in addition to climate. Presently, most models prescribe the inundated regions of the world from observations and use a simple hydrology model to estimate the height of the water table.

[34] The current global geographical distribution of wetlands is uncertain, however. There are a number of data sets available [e.g., Matthews and Fung, 1987; Aselmann and Crutzen, 1989; Prigent et al., 2007]. Most of the early data sets were based on regional charts and have differing levels of coverage. Prigent et al. [2007] used a multisatellite approach to indentify regions of surface inundation. This technique may underestimate small inundated areas especially under dense vegetation coverage. Also, it will fail to find noninundated wetlands by definition as here the water table is beneath the surface. However, unlike the map-based data sets, this approach produces monthly data which are helpful in the validation of modeled wetland hydrology.

[35] Some large-scale simple wetland models have been developed which combine subgrid-scale topographic statistical information and soil water content to predict the fractional inundation extent [e.g., Gedney and Cox, 2003; Decharme et al., 2008]. The Gedney and Cox [2003] model allowed for a saturated zone and water table to develop in the soil. This is dependent not only on climate but also on topography as the flatter the region, the slower the lateral water flow out of the soil column. The Decharme et al. [2008] model included a prognostic reservoir which fills when the river height exceeds a threshold. More sophisticated schemes are available which use spatially explicit subgrid-scale elevation data to model flow and inundation within the grid box [e.g., Dadson et al., 2010]. To date, these schemes have not been run in full Earth system models (ESMs). 
[36] Soil properties also impact the water table height significantly. The hydraulic properties of organic soils typically found in wetland areas are typified by high hydraulic conductivity near the soil surface which rapidly reduces with depth. These properties have not been incorporated into most climate models, although some land surface schemes do include them [e.g., Letts et al., 2000].

[37] The ability to model permafrost extent and the evolution of the active layer is discussed in detail in section 3 and is important in determining the water table depth. The exact nature of how permafrost thawing impacts water table height is likely to be highly significant but is still unclear as contrasting responses have been observed over the boreal regions [Jorgenson et al., 2001; Turetsky et al., 2002; Christensen et al., 2004; Stokstad, 2004]. Depending on the conditions, thawing may lead to enhanced soil drainage and therefore a lowering of the water table or landscape collapse leading to impeded drainage and a raised water table. More studies are therefore needed to clarify the relationship between permafrost thawing and change in the water table height.

[38] Another key driver of wetland $\mathrm{CH}_{4}$ emissions is temperature. Temperature not only affects the rate of production of $\mathrm{CH}_{4}$ emissions directly but also affects the quantity of substrate available through plant matter production and organic decomposition. However, there is considerable uncertainty in the response of plant productivity and soil decomposition to changes in climate [Sitch et al., 2008].

[39] Assuming the driving variables are adequately modeled, the level of detail that is required to model $\mathrm{CH}_{4}$ emissions at the large scale is still unclear. In order to fully constrain detailed process-based $\mathrm{CH}_{4}$ emission models and isolate production, transport pathways, and oxidation, detailed field data are required. However, the number of field experiments that have been carried out in order to validate these models is limited, especially over the tropics [Walter et al., 2001a]. Many wetland ecosystems have not been studied in sufficient detail to derive reliable parameterizations. Simpler models are easier to constrain as they tend to lump processes together, e.g., resulting in an overall model temperature dependence [e.g., Gedney et al., 2004; Ringeval et al., 2010]. However, they may lack processes which turn out to be important. All of these models would benefit from the availability of more field data, especially over the tropics.

[40] Given the general lack of calibration data, it is not surprising that there are widely differing results from the limited number of future climate change studies so far carried out. Some of this is likely to be partly due to differing temperature dependencies for $\mathrm{CH}_{4}$ production. This uncertainty is likely to decrease as wetland models become better constrained.

[41] Inverse modeling provides a helpful tool in reducing the uncertainty in large-scale emissions. Using historical studies to constrain wetland $\mathrm{CH}_{4}$ models is hampered by limited $\mathrm{CH}_{4}$ measurements and more limited knowledge of wetland extent and climate. Preindustrial studies have the advantage that anthropogenic sources are small, although their exact estimates are based on crude assumptions
[Houweling et al., 2000]. Also, it is not clear how wetland area changed because of drainage and cultivation between preindustrial times and the present day. Houweling et al. [2000] suggest that better isotopic measurements from ice cores would constrain preindustrial wetland emission estimates further.

[42] Modeling the trends in the recent historical $\mathrm{CH}_{4}$ budget and its interannual and seasonal variability is likely to be effective in constraining wetland emissions and their sensitivities to temperature and hydrological changes. The data required to constrain the system are better known over this time period. However, even over this time period, lack of observations, uncertainties in transport models, anthropogenic emissions, and the $\mathrm{OH}$ concentration distribution limit this technique.

[43] In the future, the use of total column $\mathrm{CH}_{4}$ estimates from satellite data [e.g., Frankenberg et al., 2005] and better emissions inventories should help to constrain wetland $\mathrm{CH}_{4}$ models further. The use of $\mathrm{CH}_{4}$ isotopes may also help in isolating different emission processes [e.g., Mikaloff Fletcher et al., 2004a]. Use of more complex wetland models in inversion studies may also help to provide better a priori data in top-down studies. Satellite-derived estimates of monthly wetland area [e.g., Prigent et al., 2007] could also be incorporated into inverse studies.

\section{TERRESTRIAL PERMAFROST}

\subsection{Definition and Description of Permafrost}

[44] Permafrost is defined as perennial sub $-0^{\circ} \mathrm{C}$ ground and covers approximately $20 \%$ of the terrestrial surface of the world [Davis, 2001], storing large quantities of carbon [Schuur et al., 2008]. Permafrost is up to $50 \mathrm{~m}$ deep in the "discontinuous" zone where a patchwork of permafrost and nonpermafrost occurs and 350-650 $\mathrm{m}$ deep in the "continuous" zone [Schuur et al., 2008]. Permafrost has a lower vertical limit owing to the Earth's geothermal gradient causing temperature to increase toward the Earth's core, at a rate of approximately $1^{\circ} \mathrm{C}$ per 30-60 m [Lachenbruch, 1968]. Permafrost in the discontinuous zone is especially vulnerable to environmental change as it typically comprises thinner soils and is already close to its thawing point. Permafrost also exists in the marine environment as subsea permafrost and is discussed in the context of $\mathrm{CH}_{4}$ hydrates in section 4.4.2.

[45] The layer of ground above permafrost which is subject to spring/summer thawing and winter refreezing is termed the active layer (Figure 3). This influences hydrology, plant rooting, and organic carbon storage and decomposition [Schuur et al., 2008]. In winter, the active layer is sandwiched between freezing air above and subzero permafrost below and loses heat both upward and downward, leading to progressive freezing. During such freezing along two fronts above and below (the "zero curtain effect") with liquid water migration prevented by the two fronts, the latent heat of fusion holds the temperature at the freezing point until the freeze or thaw is complete and raises hydraulic 


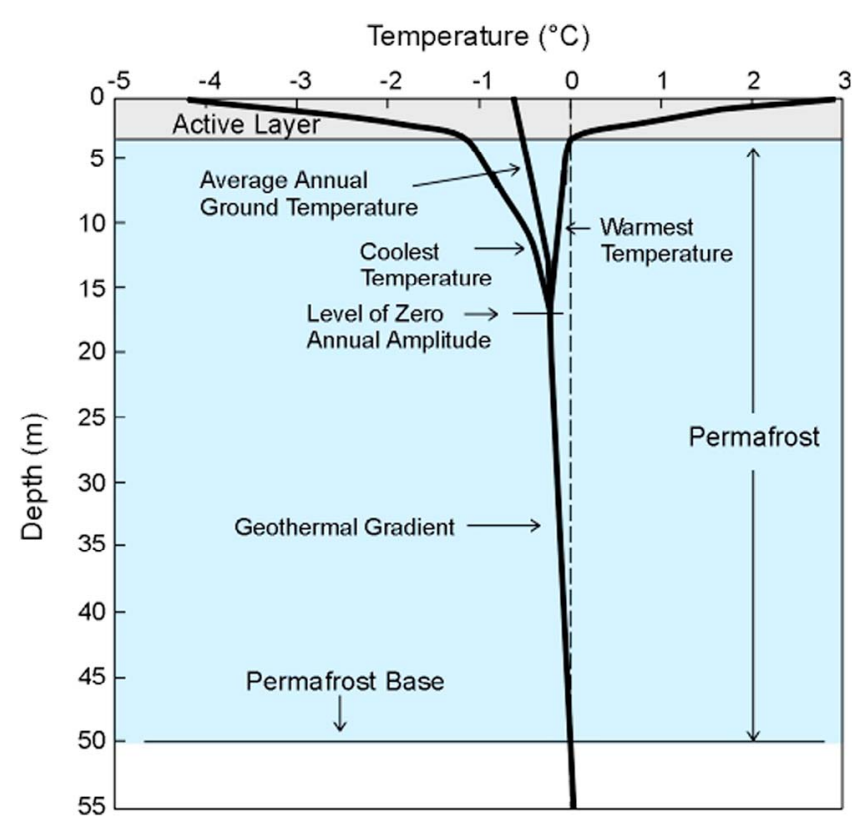

Figure 3. An illustration of the range in temperatures experienced at different depths in the ground during the year. The active layer above thaws each summer and freezes each winter, while the permafrost layer below remains below $0^{\circ} \mathrm{C}$. Reproduced with the permission of Natural Resources Canada 2010, courtesy of the Geological Survey of Canada (http://cgc.rncan.gc.ca/permafrost/whatis_e.php).

pressure [Putkonen, 2008; Williams and Smith, 1989]. Freeze-thaw cycles are now also thought to contribute to the seasonal cycle of emissions of $\mathrm{CH}_{4}$ [Mastepanov et al., 2008], but the mechanisms remain uncertain.

[46] Carbon stored in permafrost can be conceptually split into two categories: largely organic-rich carbon in frozen peatlands and carbon in mineral soils within the permafrost. Peatlands develop as highly organic soils because of reduced decomposition in saturated anoxic conditions. The physical accumulation of organic soil in peatland means that layers of carbon formerly in the active layer become increasingly deep and can hence become permanently frozen as permafrost. Where permafrost exists, basal decomposition may be halted, creating deeper peat structures incorporating ice [French, 2007]. Kuhry and Turonen [2006] identify early inception of peatlands following the last glacial in boreal areas over permafrost. Because this carbon has been deposited near the surface by biological activity, the surface tends to have high carbon density, but physical disturbance from cryoturbation (see below) can lead to significant carbon density at depth too.

[47] Lower carbon content mineral soils can also become buried in time because of deposition of wind-borne dust and silt (termed "loess"). Such deposits also result in carbon originally at the surface becoming increasingly deep and hence subject to permafrost freezing. Yedoma is relict grassland, incorporating root, plant, and animal matter buried deep under wind-borne or fluvial sediments. Such deep deposits of organic-rich material buried during the Pleistocene have survived for thousands of years in areas of
Alaska and Siberia by being preserved in permafrost [Zimov et al., 2006b]. Despite its lower organic carbon fraction, loess has more labile carbon because it has seen very little decomposition before freezing, whereas permafrost derived from bottom peat is entraining organic matter that has already been decomposing for hundreds or thousands of years so it is less labile, even if it is of higher carbon content. Additional deep carbon accumulations in permafrost have been identified in subpeat organic soils from cryoturbation or lake bed accumulation [Walter et al., 2007].

[48] Cryoturbation, or cryogenic mixing, of subsurface sediments from mechanical freezing processes leads to distribution of relatively high organic content in deeper mineral layers throughout permafrost regions with surface vegetation [Goryachkin et al., 2004; Schuur et al., 2008]. Local topography is also important, and north facing slopes in Arctic Canada have been found to exhibit permafrost, organic soil development, and inhibited drainage, whereas local south facing slopes did not [Carey and Woo, 1999]. The balance of mechanisms which have formed the permafrost (climate and/or ecosystem driven) will affect its stability and vulnerability to future climate change [Shur and Jorgenson, 2007].

\subsection{Distribution and Inventories}

[49] The carbon content in frozen deep peatlands ranges from $20 \%$ to $60 \%$ and is $<20 \%$ in frozen organic soil (peat or loess) mixed with mineral soil [Schuur et al., 2008]. The latter includes yedoma with its higher carbon lability. But the heterogeneous nature of permafrost regions has made upscaling local measurements to regional totals difficult and has led to uncertainties in estimates of carbon stored in peat and permafrost [Hugelius and Kuhry, 2009].

[50] Schuur et al. [2008] calculate a total northern circumpolar carbon pool in permafrost areas of $1672 \mathrm{Gt} \mathrm{C}$, split into $277 \mathrm{Gt} \mathrm{C}$ in frozen peatlands, $407 \mathrm{Gt} \mathrm{C}$ in Siberian yedoma, $747 \mathrm{Gt} \mathrm{C}$ in nonrelict organic/mineral soils, and $241 \mathrm{Gt} \mathrm{C}$ in deep alluvial sediments in major river deltas. This includes nonfrozen surface soil carbon overlying permafrost. Zimov et al. [2006a] estimate $450 \mathrm{Gt} \mathrm{C}$ in Siberian yedoma deposits, and Zimov et al. [2006b] estimate about $400 \mathrm{Gt} \mathrm{C}$ in nonyedoma, nonpeat permafrost.

[51] Increasing availability of new measurements and data sets has led to the recently updated Northern Circumpolar Soil Carbon Database estimates [Tarnocai et al., 2009]. Tarnocai et al. [2009] break down the estimates of Schuur et al. [2008] by regions, permafrost extent, depth, and soil types. Of the $18.8 \times 10^{3} \mathrm{~km}^{2}$ surveyed, $10.1 \times 10^{3} \mathrm{~km}^{2}$ was continuous permafrost with about $70 \%$ of this in Eurasia and the rest in North America. As in the work by Schuur et al. [2008], Tarnocai et al. [2009] estimate $1672 \mathrm{Gt} \mathrm{C}$ in total, with $1024 \mathrm{Gt} \mathrm{C}$ in the top $3 \mathrm{~m}$ of nonyedoma, nonalluvial carbon soil. This estimate is further broken down into 496 (191) Gt C estimated in the top $1 \mathrm{~m}(30 \mathrm{~cm})$ depth of soil. The continuous permafrost region accounts for $60 \%$ of this mass of carbon, and they estimate that $30 \%$ of it is in peat soils (see Figure 4). 

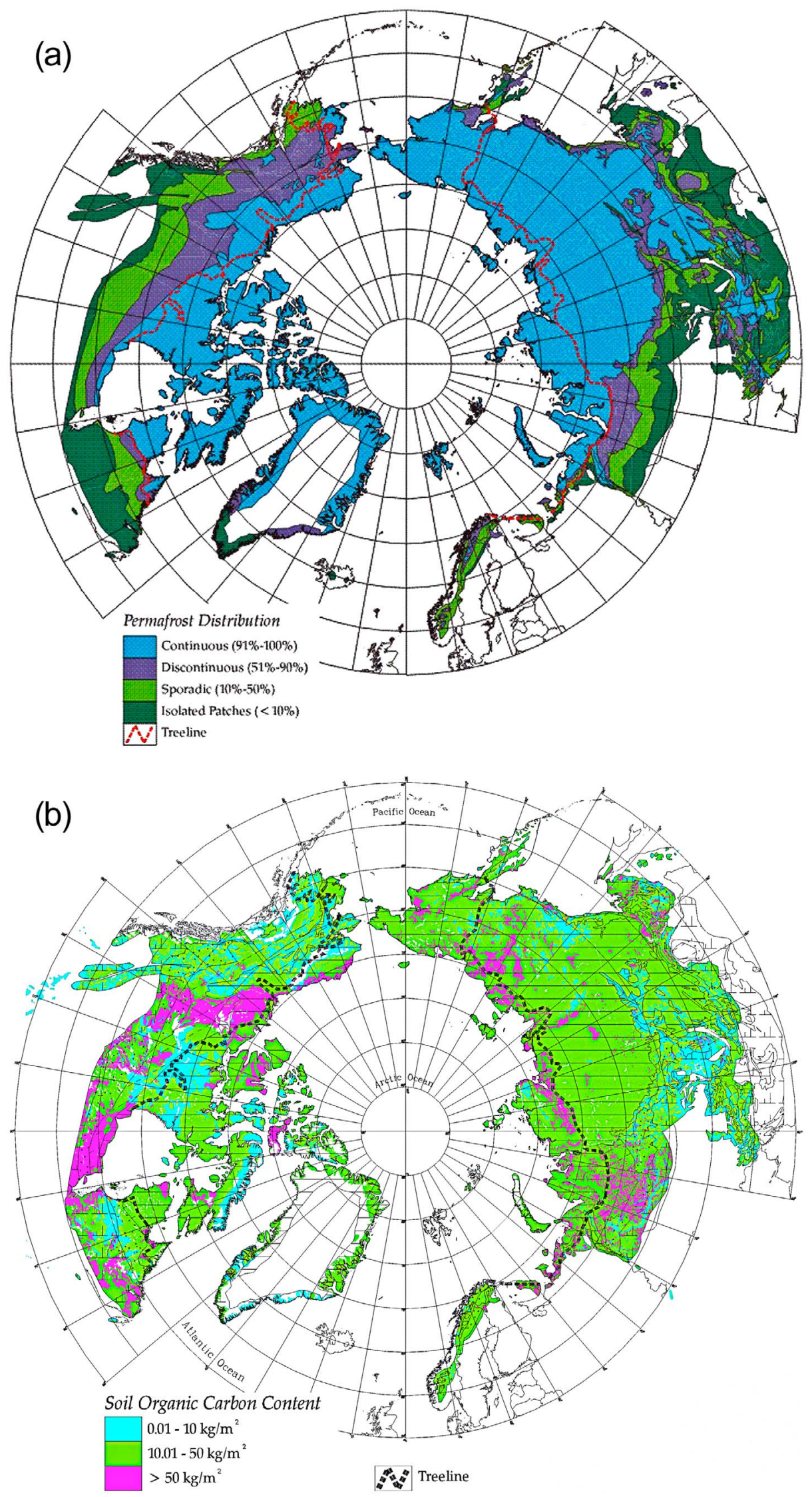

Figure 4. (a) Distribution of permafrost and (b) soil organic carbon content within the top $1 \mathrm{~m}$ in northern high latitudes. Reproduced from Tarnocai et al. [2009]. 


\subsection{Observed Changes and Processes Governing Permafrost Thawing}

[52] A major concern is the fate of permafrost that is currently near the surface and could face degradation or thaw due to climate change within the coming decades. Thawing of these high-latitude permafrost regions may result in a large source of carbon to the atmosphere [Goulden et al., 1998]. Recent observations suggest that such thawing is beginning to take place [Jorgenson et al., 2006] and that the active layer is increasing in depth [Oelke et al., 2004], although local conditions will influence the permafrost response to changes in air temperature [Smith et al., 2005]. A warmer climate and changes to soil drainage because of permafrost thawing may have a large impact on the carbon stored in high-latitude peatlands. Drying out of peatland areas has been shown to increase respiration [Bubier et al., 2003; Lafleur et al., 2003] and therefore release $\mathrm{CO}_{2}$ and may become a significant contribution to the climate-carbon cycle feedback [Schimel et al., 1994]. Permafrost thawing will not only increase amounts of active carbon available for decomposition and release to the atmosphere but also alter the soil's physical structure and hydrological properties, leading to changes in the extent of wetlands and lakes, which could increase $\mathrm{CH}_{4}$ emissions significantly [Zhuang et al., 2009].

[53] High latitudes are currently a sink of $\mathrm{CO}_{2}$ but a source of $\mathrm{CH}_{4}$ [Sitch et al., 2007a]. Future climate change could reverse the current carbon sink and significantly alter the production of $\mathrm{CH}_{4}$. This is driven primarily by a warmer, wetter climate and a longer thawing season, but the mechanisms by which climate change affects the carbon balance and $\mathrm{CH}_{4}$ emissions are complex, involving changes in both phase and amount of soil moisture governed by the physical impacts on permafrost and feedbacks with surface vegetation cover [Hinzman et al., 2005; Shur and Jorgenson, 2007]. The impacts of permafrost thawing therefore have to be viewed in the context of a vegetation and terrestrial carbon cycle response to regional climate change as well.

[54] The slow nature of soil accumulation, either by organic peat accumulation or by windblown deposition, means that growth of present-day carbon in permafrost has occurred over many thousands of years. Some ice wedges in North American permafrost have been dated back to 700,000 years before present [Froese et al., 2008]. This implies that at least some permafrost has survived several glacial-interglacial cycles, including prolonged periods warmer than today. However, Jorgenson et al. [2001] identify significant regions of permafrost degradation in Alaska that has occurred since 1700 , indicating sensitivity to periods of relatively warm climate.

[55] Processes governing vulnerability of permafrost carbon can be split into gradual changes such as active layer deepening and talik formation and sudden changes such as thermokarst or fire. These gradual and sudden changes will each be discussed in turn.

[56] Active layer deepening is a simple gradual thawing of successively deeper and deeper levels due to warmer tem- peratures (enhanced thawing in summer and reduced refreezing in winter) and longer above-freezing seasons. Soil moisture may increase from simple thawing, with moisture retention capacity further increasing with soil organic content as vegetation increases. An increase in soil moisture leads to a higher heat capacity of the soil, which makes it slower to refreeze. It also leads to higher thermal conductivity, increasing thermal coupling with the atmosphere, which counteracts the higher heat capacity. This leads to increased summer thawing that may not be balanced by winter refreezing. Increased snow cover in autumn (as predicted by some climate models) leads to increased insulation and hence reduced refreezing. This mechanism rather than air temperature has been identified as the most likely cause of recent observed increases in Arctic soil temperature. Schuur et al. [2008] contend that processes that thaw carbon from a perennially frozen state operate an order of magnitude quicker than direct temperature sensitivity of carbon release and are thus more important processes. Active layer deepening is the clearest such mechanism of carbon release by thawing. A further feedback occurs in that decomposition of soil organic matter releases heat energy and can further warm the soil. If this occurs at sufficient depth that the soil is well insulated from the atmosphere, then the warming can become self-sustaining as it leads to further decomposition [Khvorostyanov et al., 2008a].

[57] In dryland or upland areas, a longer growing season may induce further warming through a lower surface albedo because of increased shrub abundance or taiga-tundra feedback [Sturm et al., 2001]. Increased shrubs may also promote summer desiccation and wildfires. In wetland areas, however, mosses retain moisture well, and increased productivity can lead to increased soil organic content with greater moisture retention properties, feeding back into the thermal processes outlined above. The impact of overlying vegetation on soil moisture will influence whether decomposition proceeds aerobically (producing $\mathrm{CO}_{2}$ ) or anaerobically (producing $\mathrm{CH}_{4}$ ), but this influence may vary regionally in sign.

[58] Sudden changes to the landscape can occur because of the effects of thermokarst and fires. Thermokarst is the physical collapse of the ground surface due to thawing of the underlying permafrost. This occurs when the active layer increases because of a change in the thermal equilibrium and leads to heterogeneous subsidence features and lowland lake formation [Schuur et al., 2008] and possibly also the destruction of overlying forest [Osterkamp et al., 2000; Hinzman et al., 2005]. This is dependent on ice distribution and thaw, in turn dependent on soil properties, geomorphology, and topography [Shur and Jorgenson, 2007]. High ice content is necessary for thermokarst to occur, with high thermal coupling to the atmosphere and low heat capacity of the permafrost-affected ground. This favors soils and sediments in discontinuous permafrost and disfavors rocky areas, mountainous areas, and continuous permafrost areas [French, 2007]. Thawing can lead to both increased lakes if thermokarst collapses fill with water [Jorgenson et al., 2001] or decreased lakes if frozen soil forms the bottom 
of a lake, allowing it to drain [Yoshikawa and Hinzman, 2003]. Which of these happens upon thawing depends on location, extent, and ice content of the permafrost.

[59] Wildfires have a sudden and marked impact on the landscape. In addition to the impact on standing biomass, fire can consume the surface cover of dead litter which provided insulation to the soil prior to the fire. It can also reduce the albedo. Both the decrease in insulation of the soil and the subsequent warming due to reduced albedo can lead to an increase in active layer depth [Liljedahl et al., 2007]. North American boreal fires have been observed to increase over the second half of the 20th century in both burned area and extreme fire frequency [Kasischke and Turetsky, 2006]. This increase has been attributed to anthropogenic climate change [Gillett et al., 2004] and is also likely to be the case in Siberia, where Soja et al. [2007] report a recent increase in extreme fire seasons and a long-term upward trend in reported area burned. Changes in future fire regimes in boreal ecosystems will be determined by interactions between climate, soil moisture, and vegetation cover and composition, with longer projected fire seasons and increased seasonal severity [Stocks et al., 1998] both leading to likely increases in carbon released because of fires.

[60] Taliks generally refer to horizontal permanently unfrozen layers between the seasonally frozen active layer above and frozen permafrost below. They are common in marginal permafrost areas but uncommon in continuous permafrost zones [French, 2007]. As the active layer deepens and can no longer fully refreeze during winter, talik formation can occur as progressively thicker layers of ground are left permanently unfrozen year round. Taliks can influence subsurface runoff and drainage [Yoshikawa and Hinzman, 2003] and provide year-round moisture for soil respiration, meaning that $\mathrm{CO}_{2}$ and $\mathrm{CH}_{4}$ production from decomposition can proceed throughout the winter months.

[61] The most important determinant of whether release of frozen carbon happens as $\mathrm{CO}_{2}$ or $\mathrm{CH}_{4}$ is whether decomposition proceeds aerobically or anaerobically, which generally depends on whether the thawing permafrost is water saturated or not. This, in turn, depends on the subsurface soil structure and whether thawing has allowed increased drainage. In anaerobic conditions, a greater proportion of soil organic carbon decomposition is released as $\mathrm{CH}_{4}$, although not all of it necessarily reaches the atmosphere. Diffusion of oxygen in and $\mathrm{CH}_{4}$ out of the soil both occur through the soil profile and also through plant tissue. If $\mathrm{CH}_{4}$ percolates through enough depth of soil with sufficient oxygen levels, it can be oxidized to $\mathrm{CO}_{2}$ before reaching the atmosphere. If $\mathrm{CH}_{4}$ is produced in sufficiently high concentrations, then it can form bubbles and be released to the atmosphere through ebullition.

\subsection{Permafrost Modeling and Future Projections}

[62] Existing approaches for modeling permafrost use different models which give emphasis to different aspects from small to large scales and short to long time scales and which focus on physical or biogeochemical processes. Lawrence and Slater [2005] performed a future simulation of the fate of Arctic permafrost. They find a 90\% reduction in permafrost extent by 2100 for the SRES A2 scenario. As the model did not simulate carbon dynamics, there are no associated estimates of $\mathrm{CH}_{4}$ or $\mathrm{CO}_{2}$ release, but Lawrence et al. [2008b] did consider an additional feedback of local warming amplified by sea ice melt and subsequent albedo reduction. Burn and Nelson [2006] and Delisle [2007] claim that the Lawrence and Slater [2005] figure is an overestimate owing to limited simulation of deep soil thermal fluxes. Lawrence and Slater [2006] respond by acknowledging that deep permafrost below $3.5 \mathrm{~m}$ is not modeled and citing additional mechanisms that might increase the impact of permafrost thaw (carbon efflux from thawed soil, vegetation cover response, and wildfires). This simulation therefore highlights the potential for significant near-surface permafrost thaw, while showing deficiencies in permafrost representation in a general purpose land surface scheme.

[63] Citing model scenarios and risk assessments, Schuur et al. [2008] give a range of 50-100 Gt C release from thawing permafrost by 2100 . Consideration of self-sustaining biological warming from organic matter decomposition suggests that the higher figure is more likely [Khvorostyanov et al., 2008b]. Tarnocai and Stolbovoy [2006] give a similar volumetric estimate for permafrost peatland carbon release from Canada of $48 \mathrm{Gt} \mathrm{C}$ for the 21 st century consistent with lower lability of the peat carbon store.

[64] Zimov et al. [2006b] estimate that where thawing, yedoma could release all of its carbon content within a few decades. Dutta et al. [2006] calculate that 40 Gt C could be released this way over 4 decades if $10 \%$ of the Siberian yedoma thaws. This is dependent on the high lability of carbon in yedoma and decomposition leading to bacterial respiratory warming accelerating the thawing process. It further assumes a rate of thaw at the high order of magnitude simulated by Lawrence and Slater [2005], which has been questioned as being too high.

[65] Khvorostyanov et al. [2008a] developed a permafrost model specifically for the yedoma region, in eastern Siberia. Driving the model with an idealized linear warming trend, ranging from $3{ }^{\circ} \mathrm{C}$ to $8^{\circ} \mathrm{C}$ per century, the authors found a release of $75 \%$ of the $500 \mathrm{Gt} \mathrm{C}$ initial stock of frozen carbon within the next 3-4 centuries. The average release rate was estimated to be about $2.8 \mathrm{Gt} \mathrm{C} \mathrm{yr}^{-1}$; this is about one third of the current rate of $\mathrm{CO}_{2}$ emission from fossil fuel burning [Khvorostyanov et al., 2008c]. However, no fluxes of $\mathrm{CH}_{4}$ were reported in that study. In a separate study, Khvorostyanov et al. [2008b] used the SRES A2 warming scenario from the Institut Pierre-Simon Laplace climate model over the 21 st century, followed by stabilization to force the same model but for a single location, in the Yedoma Ice Complex $\left(59.3^{\circ} \mathrm{N}, 101.5^{\circ} \mathrm{E}\right)$. The amount of carbon released between 2100 and 2200 in the form of $\mathrm{CO}_{2}$ was about $236 \mathrm{~kg} \mathrm{C} \mathrm{m}^{-2}$ or $92 \%$, and $20 \mathrm{~kg} \mathrm{C} \mathrm{m}^{-2}$ or $8 \%$ was released in the form of $\mathrm{CH}_{4}$. In this case, anaerobic formation of $\mathrm{CH}_{4}$ is caused not by water saturation but by lack of oxygen diffusing to the deep levels where decomposition is occurring. No regional total estimate was reported as this was a site level study, but if this were to 
happen over an area of yedoma of 1 million $\mathrm{km}^{2}$ [Zimov et al., 2006b], it would equate to $236 \mathrm{Gt} \mathrm{C}$ released over a 100 year period.

[66] Ise et al. [2008] have coupled a one-dimensional cohort model with thermal and hydrological feedbacks, but not plant growth, under warming/thawing and drying conditions. They found that feedbacks between organic carbon content and soil thermal and hydrological properties could accelerate loss of peat, with particular sensitivity to extended dry periods in climate. In their simulations there is an initial pulse of $\mathrm{CH}_{4}$ release in response to warming, but the majority of the carbon is later released as $\mathrm{CO}_{2}$ as the soil column dries and decomposition can proceed aerobically.

[67] Wania et al. [2009a] tried to address both physical and biogeochemical model aspects by extending the Lund, Potsdam, and Jena vegetation model to include eight organic soil layers in the top $2 \mathrm{~m}$ and extend down to $10 \mathrm{~m}$ depth with an explicit treatment of peat and nonpeat hydrology and the influence of carbon content on soil properties. These changes allowed the model to better simulate soil temperature and permafrost extent and also improved the carbon balance in frozen ecosystems [Wania et al., 2009b]. When used to examine the impact of future climate change [Wania, 2007], this model simulated large losses $(>60 \%)$ of permafrost in the region $45^{\circ} \mathrm{N}-60^{\circ} \mathrm{N}$, even under the $\mathrm{B} 1$ emissions scenario. Significant losses also occurred in the region $60^{\circ} \mathrm{N}-75^{\circ} \mathrm{N}$, but north of $75^{\circ} \mathrm{N}$, despite rapid soil warming, soil temperatures remained sufficiently below freezing that no loss of permafrost occurred.

\subsection{Challenges and Prospects for Modeling in Global ESMs}

[68] Current climate carbon cycle models tend to treat soil organic content in mineral soils but not in organic soils. Organic soils have much higher content of organic matter, so the carbon itself affects their physical properties, unlike in mineral soils where the physical properties tend to be determined by the mineral soil itself with soil organic matter largely responding to, but not affecting, the environmental conditions. Feedbacks between hydrological and thermal conductivity and soil organic matter content can accelerate both peat accumulation and loss [Ise et al., 2008]. It is possible that the nature of the temperature response of heterotrophic respiration changes across the freeze-thaw boundary [Michaelson and Ping, 2003; Zhuang et al., 2003].

[69] Similarly, land surface schemes can typically treat freezing and thawing of soil moisture but only up to a limited depth, for example, $3 \mathrm{~m}$ in the Hadley Centre climate models and the Joint UK Land Environment Simulator land surface model [Essery et al., 2003]. But such shallow layers are unable to properly represent the temperature cycles and evolution of deeper soils and typically overestimate variability and rate of change [Lawrence et al., 2008a]. Alexeev et al. [2007] describe how at least $30 \mathrm{~m}$ depth of soil is required in the Community Land Model in order to capture permafrost dynamics. They also suggest that a thick permafrost slab below the explicitly resolved layers may be a computationally efficient solution without the need for explicit soil physics below this. Riseborough et al. [2008] review recent numerical deep permafrost models at regional and global spatial scales. The National Snow and Ice Data Center model; the Main Geophysical Observatory (St. Petersburg) model; the Northern Ecosystem Soil Temperature model; and University of Alaska Fairbanks-Geophysical Institute Permafrost Lab model, version 2 (UAF-GIPL v2), are uncoupled spatial permafrost models. These models adopt observed soil and snow properties and extent. UAFGIPL v2 [Marchenko et al., 2008] uses enthalpy to solve for vertical heat conservation, which gives implicit consideration of phase change dynamics in deeper soils or rocks. These models have been used to predict permafrost extent and active layer thickness at regional scales, driven by climate projections from a general circulation model.

[70] Deeper thermal physics can be addressed by including more layers within existing mineral soil models. Deeper organic soil development requires an explicit model. The peat decomposition model (PDM) of Frolking et al. [2001] represents and tracks individual cohorts of peat deposited over tens to thousands of years on an annual time scale and is used in the Peatland Carbon Simulator system [Frolking et al., 2002] to explicitly simulate the carbon balance of northern peatlands in a way which may be coupled to largescale land surface models and climate models. PDM explicitly includes belowground litter input from roots and the productivity of both vascular and nonvascular plants.

[71] An issue for large-scale modeling of permafrost response is the high level of spatial heterogeneity. Dynamic permafrost landforms such as peat palsas and plateaus, vertical ice wedge formation, and characteristic polygon patterns from frozen ground contraction exist on the meter scale. Subsurface hydrology may also be further complicated by networks of heterogeneous holes or "pipes" [Holden et al., 2009; Holden, 2005; Carey and Woo, 2000]. These issues cannot be explicitly represented in large-scale land surface models and so need to be parameterized. For example, cryoturbation processes from ice wedge freezethaw cycles can be represented as a simple diffusion of carbon content through model vertical levels, or thermokarst processes could be represented by changing surface roughness or topographical parameters. There is often no consensus between authors over their detailed interpretations of the geomorphological processes [e.g., Davis, 2001; French, 2007]. Models of these dynamic high-latitude geomorphologies tend to characterize individual features [e.g., Nixon, 1983], as a by-product of civil engineering models. Detailed fine-scale models and observations are required to enable this.

[72] Peatland and permafrost models are beginning to be incorporated into land surface and vegetation models but, to date, have not been run in coupled climate models. The complex interactions between climate, soil moisture, snow cover, ecosystems, fire, and permafrost provide a significant challenge; it is hard to study any of these aspects in isolation without a sound understanding of all of them. A key question is how permafrost thawing will have an impact on the water table depth as this is key to 
determining $\mathrm{CH}_{4}$ emissions. This remains a clear gap in Earth system modeling.

\section{OCEANIC METHANE HYDRATES}

\subsection{Definition of Methane Hydrates and the Gas Hydrate Stability Zone}

[73] Clathrates are a class of crystalline compounds which are formed from a regular arrangement of complex cage-like structures of molecules and which have "guest" atoms/ molecules trapped within the cages. When the cages are composed of water molecules, the compounds are called hydrates, and they can exist as several types (types I, II, and $\mathrm{H})$, depending on the number of water molecules in the cages and the sizes of the guest atoms/molecules present [Beauchamp, 2004; Sloan and Koh, 2008]. In general terms, hydrates are stable at high pressures and low temperatures and in the presence of sufficiently high concentrations of their guest atoms/molecules [Kvenvolden, 1993]. The most common hydrates on Earth are $\mathrm{CH}_{4}$ hydrates, with the $\mathrm{CH}_{4}$ coming from a variety of sources [Archer, 2007]: juvenile (volcanic gases and hydrothermal vents), biogenic (organic matter degradation by microorganisms), and thermogenic (produced from organic matter abiologically at higher temperatures than biogenic $\mathrm{CH}_{4}$ ). The various sources of $\mathrm{CH}_{4}$ can be distinguished by differences in carbon isotopic values, and by far, the largest source of $\mathrm{CH}_{4}$ in natural hydrates is of biogenic origin [Sloan, 2003].

[74] On Earth, hydrates are found mostly associated with deep permafrost and within marine sediments on the continental margins in water depths exceeding $500 \mathrm{~m}$ [Beauchamp, 2004] and can also occur along gravitationally unstable continental slopes. Assuming sufficient $\mathrm{CH}_{4}$ concentrations, estimates of in situ pressure and temperature can be used to define a theoretical gas hydrate stability zone (GHSZ), and this can be used to predict a volume of sediment where gas hydrates are theoretically stable and might potentially exist. Figure 5 shows schematics of the $\mathrm{CH}_{4}$ GHSZ associated with terrestrial permafrost, shallow water, and deep ocean water sediments. The volume occupied by the GHSZ is influenced by the geothermal gradient. Although it is thought to be in the range of $25-30 \mathrm{~K} \mathrm{~km}^{-1}$ in most of the world, this could vary substantially regionally. A recent study by Camps et al. [2009], for example, indicated that the average geothermal gradient off the coast of Scotland, U.K., was $45 \mathrm{~K} \mathrm{~km}^{-1}$ with a standard deviation of $11 \mathrm{~K} \mathrm{~km}^{-1}$. Sedimentation can cause some hydrate to dissociate below the base of the GHSZ. Some of the $\mathrm{CH}_{4}$ released migrates back into the GHSZ, but some remains as bubbles [Fleischer, 2001].

\subsection{Global Distribution and Inventories}

[75] Knowledge of the extent to which marine gas hydrates occur globally is still very incomplete and is obtained both directly and indirectly. Direct observation of gas hydrates has been obtained by drilling and associated well logs; Sloan and Koh [2008] reported 23 locations where hydrate samples were recovered: 3 in permafrost and 20 from the ocean. Indirectly, the presence of gas hydrates can be identified by the bottom-simulating reflector (BSR), which detects a sharp impedance contrast on seismic profiles between the hydrate zone and the free gas beneath it. However, there are a significant number of cases where hydrates are present but BSR did not indicate their presence [Sloan, 2003]. Gornitz and Fung [1994] have used Coastal Zone Color Scanner satellite imagery data to estimate regions of high seafloor organic matter on the basis of sea level chlorophyll concentrations and thus likely hydrate zones. Direct measurements of total organic carbon on the seafloor, however, show only a weak correlation with sea level phytoplankton [Klauda and Sandler, 2005].

[76] There have been large decreases in global estimates of $\mathrm{CH}_{4}$ within hydrates since the 1970s due to mapping and drilling estimates. Nevertheless, recent estimates still show quite large differences. The global estimate of $10^{4} \mathrm{Gt} C$ by Kvenvolden [1988] was based largely on the volume of sediments lying within the GHSZ in the oceans and permafrost areas and on extrapolations from a handful of known deposits. This estimate was considered as an early "consensus value" and suggests that the amount of energy in hydrates is equivalent to twice that of all other fossil fuels combined. However, a recent review by Milkov [2004] put the global estimate at 500-2500 Gt C. With this lower range, the size of the gas hydrate reservoir is comparable to other carbon reservoirs such as soil or dissolved organic matter in water

[77] A distinction can be made between passive and active margins in global inventory estimates of $\mathrm{CH}_{4}$ in marine hydrates [Gornitz and Fung, 1994]. In passive margins, sediment accumulation is the dominant source of organic material (and $\mathrm{CH}_{4}$ ) and hence limits the hydrate abundance. In active margins, on the other hand, hydrate abundance can be much higher as organic material (and $\mathrm{CH}_{4}$ ) is scavenged from a much larger area. Buffett and Archer [2004] used available observations to constrain the mechanisms responsible for hydrate formation and then used a quantitative model as the basis for extrapolation. They estimated a global inventory of 600 and $470 \mathrm{Gt} \mathrm{C}$ in hydrate and gas bubbles, respectively, for passive margins. For active margins, the corresponding estimates were 2200 and $930 \mathrm{Gt} \mathrm{C}$ in hydrate and bubbles, respectively. Their best global estimate was obtained by weighting these inventories by the fractional area of passive and active margins (75\% passive and $25 \%$ active) to give a total global estimate of $1600 \mathrm{Gt} \mathrm{C}$, with 1000 and $600 \mathrm{Gt} \mathrm{C}$ in hydrate and bubbles, respectively (these values have all been scaled down by a factor of 3 primarily because of an interpolation error, as reported by Archer et al. [2009]). This partitioning between hydrate and bubbles is consistent with observational estimates [Hornbach et al., 2004]. However, their global estimate is lower than that from Kvenvolden [1988] partly because that estimate assumed that $10 \%$ of the sediment pore volume was occupied by hydrates, whereas in the work by Buffett and Archer [2004], the active margins only yielded a peak value of 6\%. Archer [2007] argues that if observations from Blake Ridge or Hydrate Ridge are taken as represen- 
(a)

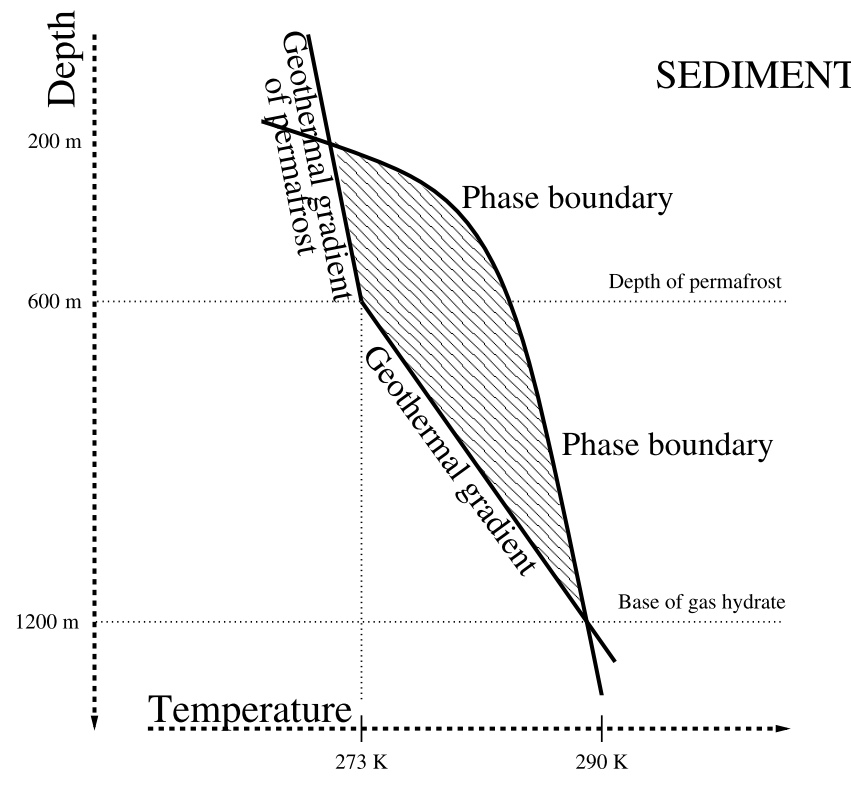

(c)

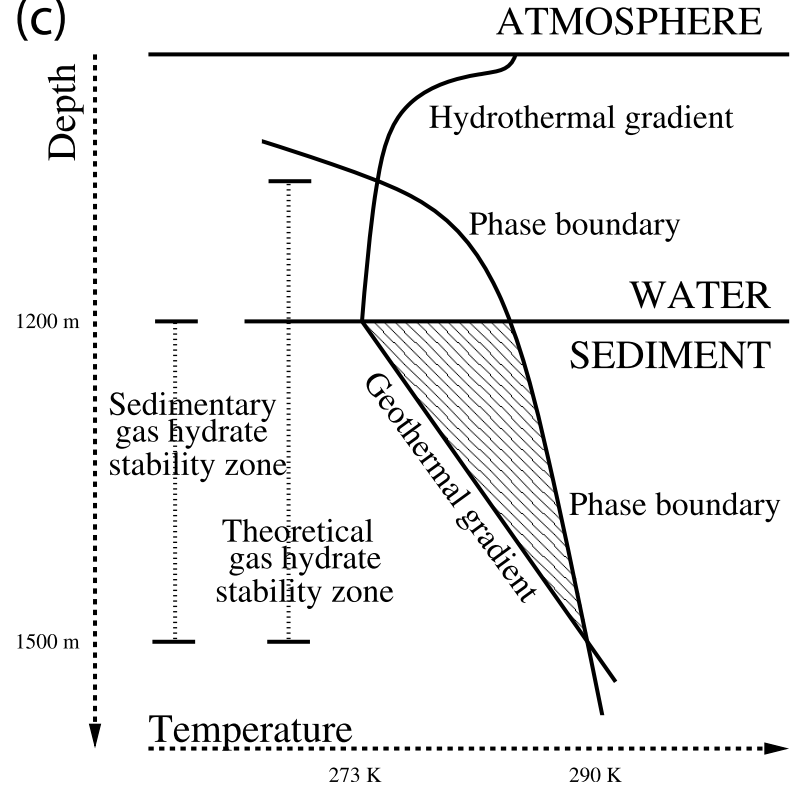

(b)

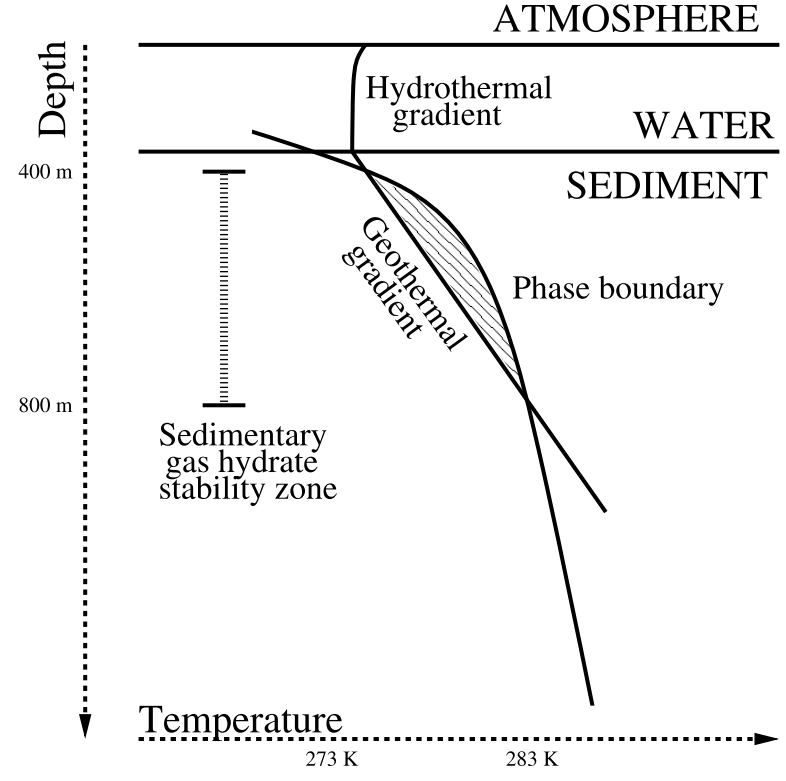

Figure 5. Illustration of the gas hydrate stability zone (a) associated with terrestrial permafrost, (b) in shallow offshore regions, and (c) in the deep ocean, adapted from Kvenvolden and Lorenson [2001].

tative of global hydrates, then the $10 \%$ volume fraction used by Kvenvolden [1988] was too high.

[78] As shown above, the amount of hydrate filling the pore volume presents a large uncertainty in global estimates. As a result, the recent study of Klauda and Sandler [2005] included a mass transfer model to estimate the pore volume occupied by hydrates. Their global estimate of $56 \times 10^{3} \mathrm{Gt} \mathrm{C}$ is larger than that of Kvenvolden [1988] and much higher than those of Milkov [2004] and Buffett and Archer [2004]. Archer [2007] suggested that the difference with Buffett and Archer [2004] could be attributed to differences in the sediment accumulation rate and carbon conversion efficiencies, with the Klauda and Sandler [2005] study using an accumulation rate of sediment which was far too high for the deep ocean. However, they argue that their estimate is large because they include inland seas and hydrates at greater ocean depths as well as continental margins. When considering seafloor depths of less than $3000 \mathrm{~m}$, they get an estimate of $20 \times 10^{3} \mathrm{Gt} \mathrm{C}$, which is comparable with the consensus value of Kvenvolden [1988]. However, it is still much higher than the estimate of Milkov [2004], but that study assumed that only $20 \%$ of the continental margins contained suitable conditions for hydrate growth and used a lower pore volume fraction than was calculated by Klauda and Sandler [2005]. 
[79] In the model study by Buffett and Archer [2004], the downward flux of organic matter (carbon rain) in the water column was prescribed as a function of water depth, i.e., maximum fluxes in shallow water with lower fluxes in deep water. However, they found that the rate at which organic carbon is buried in the ocean sediment is sensitive to the oxygen concentration in the overlying water. A decrease in oxygen concentration of $40 \mu \mathrm{M}$ in the deep ocean can increase the $\mathrm{CH}_{4}$ inventory by a factor of 2 and vice versa. They also found that an increase in carbon rain by $50 \%$ (using two different assumptions) resulted in the global $\mathrm{CH}_{4}$ inventory increasing by a factor of 2 , with the partitioning of the additional $\mathrm{CH}_{4}$ between clathrate and bubbles dependent on the assumption. This suggests that oxygen and the rate of carbon rain, as well as temperature, may be important for assessing the size of past and present-day hydrate inventories.

[80] The more recent review by Archer [2007] with a revision from Archer et al. [2009] suggests that a realistic consensus on the global estimate of the $\mathrm{CH}_{4}$ stored in marine hydrates is in the range of $170-1000 \mathrm{Gt} C$, with the inclusion of bubble $\mathrm{CH}_{4}$ adding a similar amount. Both the areal coverage of $\mathrm{CH}_{4}$ hydrate sediment and the average hydrate volume fraction contribute a factor of 3 to the uncertainty in the global estimate, thereby resulting in a factor of 10 in the overall uncertainty. This could be reduced by further $\mathrm{CH}_{4}$ hydrate sampling and by improving the techniques used for estimating the $\mathrm{CH}_{4}$ concentration.

[81] As mentioned above, there are also stores of $\mathrm{CH}_{4}$ in polar regions, held in terrestrial hydrates under ice sheets and within permafrost soils. Although the amount of $\mathrm{CH}_{4}$ held in such hydrates is lower than in marine hydrates and largely uncertain, it could still be quite large [Harvey and Huang, 1995, and references therein]. They are also vulnerable to climate change particularly given future expected temperature changes in high latitudes [Meehl et al., 2007]. For a full discussion on terrestrial hydrates, the mechanisms involved in their destabilization, and their potential to release $\mathrm{CH}_{4}$ to the atmosphere with anthropogenic warming, the reader is referred to Brook et al. [2008].

\subsection{Methane Hydrates and Past Climate Change}

[82] Hydrates are very sensitive to changes in temperature and pressure [Dickens and Quinby-Hunt, 1994; Brewer et al., 1997]. As a result, they have been implicated in past climate change [e.g., Dickens et al., 1995; Kennett et al., 2000].

[83] The Paleocene-Eocene thermal maximum (PETM), for example, occurred $55 \mathrm{Myr}$ ago and was characterized by a period of intense global warming and a rapid decrease (up to $-3 \%$ ) in the global mean carbon $\delta^{13} \mathrm{C}$ isotopic ratio [Kennett and Stott, 1991; Koch et al., 1992; Katz et al., 1999; Bains et al., 1999; Dickens, 1999]. Deep ocean warming of about $4^{\circ} \mathrm{C}-6^{\circ} \mathrm{C}$ has been inferred in many cores, with an ocean surface warming of $4^{\circ} \mathrm{C}-8^{\circ} \mathrm{C}$ [Katz et al., 1999]. The intense warming could have been driven by a massive $\mathrm{CH}_{4}$ release from hydrates along the continental margins [Dickens et al., 1995], the so-called "methane burp" hypothesis, in which the release involved 1500 2000 Gt C over a few thousand years [Norris and Röhl,
1999]. If Paleocene and present-day margins are considered as similar, then the global volume of the Paleocene GHSZ was approximately $43 \%$ of the present-day GHSZ (because of warmer water temperatures) and halved during the PETM [Dickens, 2001]. With the present-day global estimate of $\mathrm{CH}_{4}$ within gas hydrates of $500-2500 \mathrm{Gt} \mathrm{C}$ by Milkov [2004], for example, this would imply that there was an insufficient release of $\mathrm{CH}_{4}$ to account for the observed $\delta^{13} \mathrm{C}$ excursion at the PETM [Milkov et al., 2003].

[84] Quaternary climate change refers to brief atmospheric warming events, and there is evidence of corresponding large oscillations in atmospheric $\mathrm{CH}_{4}$ from polar ice cores on orbital, millennial, and decadal time scales [Lorius et al., 1990; Chappellaz et al., 1990; Loulergue et al., 2008]. Kennett et al. [2000] suggest, from the observation of carbon isotopic anomalies in benthic and planktic foraminifera, that thermal dissociation of $\mathrm{CH}_{4}$ hydrates repeatedly discharged large quantities of $\mathrm{CH}_{4}$ from marine sediments into the atmosphere, the so-called "clathrate gun hypothesis" [Kennett et al., 2002]. Dissociation has also been attributed to sea level falls [Paull et al., 1991]. However, an alternative hypothesis is that the increases in atmospheric $\mathrm{CH}_{4}$ could be attributed to enhanced methanogenesis (section 2.1) in tropical wetlands receiving greater precipitation during intense monsoon activity and the effect of temperature [Chappellaz et al., 1990]. Indeed, D/H isotopic ratios from ice cores measured over the rapid $\mathrm{CH}_{4}$ increases of the last deglaciation and during a single Dansgaard-Oeschger warm event of the last glacial period suggest that marine hydrates were stable during these abrupt warming episodes [Sowers, 2006].

\subsection{Methane Hydrate Sensitivity and Processes Governing Release of Methane to the Atmosphere}

[85] There is still some debate on the extent to which the decomposition of hydrates is responsible for past variations in atmospheric $\mathrm{CH}_{4}$ concentrations. Nevertheless, there is concern that future global warming may lead to hydrate instability and an enhanced $\mathrm{CH}_{4}$ flux to the atmosphere, thereby imposing a strong positive feedback that would amplify anthropogenic warming [Harvey and Huang, 1995; Prather et al., 2001].

[86] As atmospheric temperatures increase because of increasing greenhouse gases, higher temperatures will propagate into the deep ocean/seafloor, and the inventory of hydrate is expected to decrease. The time scale for changing the temperature of the ocean increases with depth, but there are significant regional variations in this time scale. In particular, the Arctic is expected to warm more strongly than the global mean. Dickens [2001] calculated that the volume of the GHSZ associated with marine hydrates halved during the PETM with a temperature increase of $5^{\circ} \mathrm{C}$. On the other hand, Buffett and Archer [2004] used their mechanistic model to predict the sensitivity of the steady state $\mathrm{CH}_{4}$ marine hydrate inventory. They found that an increase in temperature reduced the steady state global inventory because of a reduction in the GHSZ and an increase in the diffusive loss of $\mathrm{CH}_{4}$ from the sediments toward the seafloor. For an ocean temperature increase of $3^{\circ} \mathrm{C}$, their inventory of 
$\mathrm{CH}_{4}$ reduced to approximately $15 \%$ of the present-day inventory. Unfortunately, their calculated change is a steady state solution and does not reveal the time scale over which the transition could occur.

[87] The build up to a steady state hydrate inventory took several million years [Davie and Buffett, 2001]; its destabilization due to warming may be relatively rapid [Dickens, 2003]. However, this may still be slow compared to the time scale of anthropogenic global warming. Archer [2007] suggests that most hydrates are well insulated from the Earth's surface so that their decomposition will take place on time scales of millennia or longer. The heat conduction in a solid, such as ocean sediments, is proportional to thermal conductivity which has values of $0.65-1.2 \mathrm{~W} \mathrm{~m}^{-1} \mathrm{~K}^{-1}$ [Newson and Brunning, 2004; Sclater et al., 1969; Moqsud et al., 2008]. The response of such sediments to a transient thermal forcing can only be determined numerically and requires knowledge of the material density and heat capacity. Using typical values for ocean sediments, it takes about 2000 years for a $2^{\circ} \mathrm{C}$ positive anomaly to raise the temperature at $100 \mathrm{~m}$ depth by $1^{\circ} \mathrm{C}$. In addition, hydrate decomposition is an endothermic process and thus decreases ambient temperature, which slows down heat propagation in the medium even more.

[88] Because of the sensitivity of the GHSZ to temperature and pressure, several studies have investigated the effect of changes to sea level and seafloor temperature on the $\mathrm{CH}_{4}$ hydrate reservoir [Xu et al., 2001; Katz et al., 2001; Dickens, 2003]. However, these studies used idealized temperature and pressure changes over a single ocean sediment column, thereby neglecting regional variability. On the other hand, Fyke and Weaver [2006] used a global climate model in combination with a simple time-dependent GHSZ model to estimate potential spatial and temporal changes to the GHSZ volume in response to a range of climate model experiments. They found that along the continental margins, warming was significantly greater than the global average warming. Over half of the associated GHSZ loss occurred within the first 5000 years after initiation of the atmospheric $\mathrm{CO}_{2}$ increase, with the initial significant loss occurring within 200 years. This initial loss principally occurred in shallow water in midlatitude to high-latitude regions associated with sea ice loss. They also noted the sensitivity of the GHSZ volume decrease to thermal diffusivity of the seafloor.

[89] As can be seen from Figures $5 \mathrm{~b}$ and 5c, shallow water hydrates destabilize from the top and bottom parts of their stability zone, whereas deep ocean hydrates only destabilize from the bottom part of their stability zone, which is typically hundreds of meters below the seabed. Only when a sustained increase in seafloor temperature has propagated through the sediment column to the bottom of the GHSZ will it cause the deepest, most marginal hydrate to start to break down.

[90] Detailed models of $\mathrm{CH}_{4}$ hydrate destabilization have been developed (e.g., TOUGH+HYDRATE) initially with the aim to understand the risk of hydrate destabilization related to offshore oil drilling. These models resolve how a temperature and pressure perturbation propagates downward, including the effect of fluid motion within the sediment column, and how destabilized $\mathrm{CH}_{4}$ can move upward. Although these models have been tested and used locally, there is no assessment yet of the time scale associated with $\mathrm{CH}_{4}$ hydrate destabilization at the global scale.

[91] A recent study by Lamarque [2008] used the IPCC's fourth assessment report (AR4) $1 \%-\mathrm{CO}_{2}$ increase per year simulations to quantify the potential for $\mathrm{CH}_{4}$ hydrate destabilization with a doubling of $\mathrm{CO}_{2}$. He found the largest temperature increases occurred mostly in the Northern Hemisphere, particularly north of $50^{\circ} \mathrm{N}$. Using these temperature changes and on the assumption that the existence of hydrates is only dependent on depth (pressure) and temperature, he calculated a model mean release of $\mathrm{CH}_{4}$ at the bottom of the ocean of 560-2140 $\mathrm{Tg} \mathrm{CH}_{4} \mathrm{yr}^{-1}$ as an upper bound. This flux was reduced to $5-21 \mathrm{Tg} \mathrm{CH}_{4} \mathrm{yr}^{-1}$ to represent a flux reaching the atmosphere by applying an observed leakage rate of $1 \%$ from a large seepage zone [Mau et al., 2007]. The uncertainties on the fraction of $\mathrm{CH}_{4}$ emitted at the sea bottom reaching the atmosphere are discussed in section 4.4.3. Although the intermodel standard deviation was approximately $30 \%$, these estimates remain highly uncertain. No consideration was given to the global occurrence and/or depth of $\mathrm{CH}_{4}$ hydrates or the time scale associated with the propagation of a temperature anomaly at the seafloor into the sediment.

[92] Acoustic observations above the seabed west of Spitzbergen have recently revealed more than 250 plumes of $\mathrm{CH}_{4}$ bubbles in the water column above the GHSZ, coinciding with a recent warming of bottom waters by about $1{ }^{\circ} \mathrm{C}$ over the last 30 years [Westbrook et al., 2009]. Part of the escaping gas could correspond to free gas usually trapped below the GHSZ and migrating upward along the GHSZ lower boundary until it reaches the intersection between the sediment-water interface and the GHSZ. These observations suggest a close connection between bottom water warming and methane hydrate degassing under present conditions. More recently, Reagan and Moridis [2009] used TOUGH+HYDRATE to run a two-dimensional simulation of the conditions representative of the west Spitsbergen margin; their model results were remarkably consistent with Westbrook et al.'s [2009] observations and indicated that the observed $\mathrm{CH}_{4}$ plumes could have originated from temperature-driven dissociation of hydrates.

\subsubsection{Role of Pockmarks and Landslides}

[93] As well as deep ocean temperature change, $\mathrm{CH}_{4}$ could be released from hydrates through pockmarks [Archer, 2007]. These are holes in the sediment surface resulting from brutal escape of gas to the ocean. They range in size from meters to kilometers, with one on the crest of Blake Ridge being $700 \mathrm{~km}^{2}$ in size [Kvenvolden, 1999]. The amount of $\mathrm{CH}_{4}$ released through pockmarks is small compared to the atmospheric $\mathrm{CH}_{4}$ burden. If the Blake Ridge pockmark is the result of a large venting of gas in a single event, for example, it could only have released about $1 \mathrm{Gt} C$ as $\mathrm{CH}_{4}$ [Archer, 2007]. 
[94] Submarine landslides are an integral part of the ocean sedimentary system [Hampton et al., 1996] and are commonplace in river deltas. There have been regular landslides off the coast of Norway and in the Mediterranean Sea [Rothwell et al., 2000], with the potential for landslides off the east coast of the United States [Dugan and Flemings, 2000]. A drop in sea level or warming may trigger hydrate destabilization, leading to landslides [Kvenvolden, 1999; Driscoll et al., 2000; Vogt and Jung, 2002]. Such landslides individually could release up to $5 \mathrm{Gt} \mathrm{C}$ as $\mathrm{CH}_{4}$ [Archer, 2007]. A well-documented example is the large Storegga slide off Norway, which occurred in two steps since 50,000 years before present and could have released even more $\mathrm{CH}_{4}$ [Nisbet, 1992]. However, it is not known if future warming is sufficient to cause failure of continental slopes on a global scale, but isotopic evidence of rapid carbon release in the past is suggestive [Buffett and Archer, 2004].

[95] There have been other observations of $\mathrm{CH}_{4}$ bubbling through the seafloor. For instance, Are [2001] reports that release of gas bubbles was observed by Ivanov in the delta of the Yana River (Laptev Sea) as early as the 1960s. Paull et al. [2007] also recently documented methane-rich gas bubbles in the Beaufort Sea shelf. These gas bubbles originate from what they call "pingo-like features" on the Beaufort Sea shelf. Pingos are mounds of earth in the permafrost environment of the Arctic, sub-Arctic, and Antarctica that can reach up to $70 \mathrm{~m}$ in height and up to $2 \mathrm{~km}$ in diameter. Paull et al. [2007] hypothesized that growing submarine pingos result from gas pressure associated with gas hydrate decomposition. Shakhova et al. [2005] observed very large $\mathrm{CH}_{4}$ supersaturation of bottom waters on the Siberian shelf, in areas where $\mathrm{CH}_{4}$ hydrates are ubiquitous in sediments, thus suggesting a significant contribution of hydrate decomposition to the current $\mathrm{CH}_{4}$ balance of waters on this continental shelf. More recently, they have also reported on $\mathrm{CH}_{4}$ gas venting into the atmosphere [Shakhova et al., 2010].

[96] Emissions from pockmarks, landslides, and pingos contribute to the $\mathrm{CH}_{4}$ budget and may constitute the conduit for increased emissions in the future. However, there is no evidence that such emissions have yet increased because of global warming.

\subsubsection{Particular Case of the Arctic Ocean}

[97] Both models and geophysical data support the existence of subsea permafrost in large areas of the Arctic shelves down to a water depth of about $100 \mathrm{~m}$ [Rachold et al., 2007]. Subsea permafrost is the result of exposure of the seabed to cold temperatures during the LGM when sea level was much lower. Subsea permafrost is still poorly understood, mainly because of the lack of direct observations. However, it is known to be associated with gas hydrates, which can be stored below the subsea permafrost, and the stability of these hydrates is sustained by the existence of permafrost. It is unclear whether some $\mathrm{CH}_{4}$ hydrates can also be stored within the permafrost layer and, if so, how big this reservoir is.
[98] Since the hydrates are often several hundred meters under the sediments, it is likely that the heat diffusing through the sediments over the last 10,000 years (since the last deglaciation) is now just reaching them. For instance, Paull et al. [2007] offer a scenario where these thermal changes are caused by the continued warming associated with Holocene sea level rise and do not mention anthropogenic warming at all in their study. Both Weitemeyer and Buffett [2006] and Wadham et al. [2008] propose a mechanism by which $\mathrm{CH}_{4}$ hydrate accumulates below continental ice sheets during ice ages. The source of $\mathrm{CH}_{4}$ is microbial decomposition of organic material below the ice sheet. Deglaciation then releases the $\mathrm{CH}_{4}$ from hydrates into the atmosphere. Wadham et al. [2008] estimate the size of the subglacial reservoir of organic carbon and the amount that is available for microbial conversion. They conclude that the $\mathrm{CH}_{4}$ release (63 Gt $\mathrm{C}$ during a deglaciation) would have to be episodic to have a significant impact on atmospheric $\mathrm{CH}_{4}$ concentrations. However, Wadham et al. [2008] include a fairly shallow depth of ocean sediments in their estimates and do not examine the fraction of the $\mathrm{CH}_{4}$ reservoir that may respond on a longer time scale during a deglaciation.

[99] Anthropogenic warming is adding to the warming experienced in the Arctic since the LGM. Seawater temperature increases in response to increased atmospheric temperature, lack of insulation by disappearing sea ice, and warmer Atlantic water inflow. The Arctic Ocean temperatures at the seabed in a historical integration [Stott et al., 2006] of the Hadley Centre Global Environment Model, version 1 [Johns et al., 2006], have really only increased since preindustrial times in the last 25 years. The waters of the Barents and Kara seas (and to a lesser extent the Laptev Sea) have warmed by about $2.5 \mathrm{~K}$. The pattern of warming and salinity is entirely consistent with the cause being increased inflow of warm saline Atlantic waters. Elsewhere in the Arctic, the bottom temperatures have risen by about $0.1-0.2 \mathrm{~K}$ (up to $1 \mathrm{~K}$ in the West Spitzbergen Current), and this appears to be due to changes in buoyancy (with a gradual freshening of deeper water) resulting in slightly convective deeper mixing (although not to the seabed). Diffusion of heat would take the warming the rest of the way. The relative contributions of the Holocene warming and the recent anthropogenic warming to the diffusion of heat into the subsea permafrost and deep marine sediments at the origin of the $\mathrm{CH}_{4}$ emissions discussed previously are not known.

[100] We analyze here simulations from the AR4 multimodel ensemble [Meehl et al., 2007] which were forced with the SRES A1B emissions scenario [Nakićenović et al., 2000]. In the ensemble mean, the warming at the ocean bed, as defined by the physical temperature of each model's lowest ocean level, is greatest in the region of the western Barents Sea. We select this region $\left(20^{\circ} \mathrm{E}-30^{\circ} \mathrm{E}, 73^{\circ} \mathrm{N}-76^{\circ} \mathrm{N}\right)$ from each of the AR4 models to obtain a spread in model ocean floor temperatures and depths across the AR4 ensemble for 1860 and 2100. Figure 6 shows these modeled temperature profiles in relation to the hydrate stability curve. This stability curve is obtained from a corrected version of 


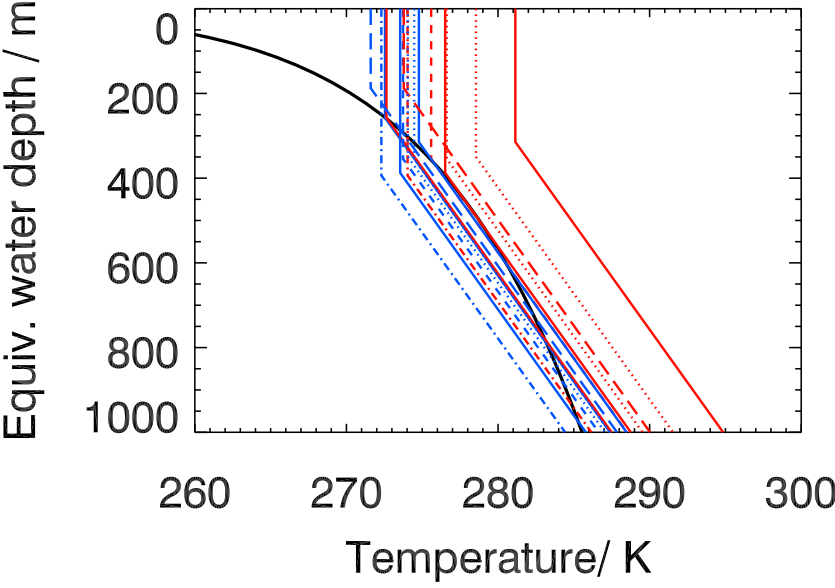

Figure 6. Illustration of the change in shallow water gas hydrate stability zone in the western Barents Sea. The stability curve (shown in black) is calculated from a corrected version of equation 1 from Dickens and Quinby-Hunt [1994]; the correction was required to be consistent with their Figure 1. The vertical temperature profiles are from the IPCC AR4 multimodel ensemble along with an assumed geothermal gradient of $0.02 \mathrm{~K} \mathrm{~m}^{-1}$ [Lachenbruch, 1968]. The majority of models show some hydrate stability back in 1860 (blue) but a reduction and/or disappearance of the stability zone by 2100 (red). The depth of the water appears to be different because of the different horizontal resolution of each model.

equation 1 from Dickens and Quinby-Hunt [1994] so that it is consistent with their Figure 1. All of the models except one show some hydrate stability in the western Barents Sea in 1860 but a reduction and/or disappearance of the stability zone by 2100 using the SRES A1B emissions scenario. Again, these are equilibrium results, and the dynamics of the sediment warming has yet to be modeled.

\subsubsection{Fate of Methane Emitted at the Seafloor}

[101] A less explored issue is the fate of $\mathrm{CH}_{4}$ emitted at the seafloor. $\mathrm{CH}_{4}$ solubility in seawater is small (it is much smaller than that of $\mathrm{CO}_{2}$ ). For a given temperature-pressure profile, Zhang [2003] estimated that $\mathrm{CH}_{4}$ solubility increases with depth to about $0.1 \mathrm{wt} \%$ at $500 \mathrm{~m}$ below sea level, using data from Duan et al. [1992]; note that the data have been updated by Duan and Mao [2006]. At low depths (low pressure), $\mathrm{CH}_{4}$ dissolves in water, and if the $\mathrm{CH}_{4}$ concentration exceeds the solubility, the excess $\mathrm{CH}_{4}$ would be in the gas phase. However, there might not be enough nucleation sites within the seawater to actually turn the excess $\mathrm{CH}_{4}$ into bubbles. The ocean can therefore be supersaturated with respect to $\mathrm{CH}_{4}$ in some places. At larger depths (high pressure), $\mathrm{CH}_{4}$ hydrates are stable, and any excess $\mathrm{CH}_{4}$ would be found in the hydrate phase. In the sediment column, $\mathrm{CH}_{4}$ hydrate stability decreases with increasing depth (because of increasing temperature), and $\mathrm{CH}_{4}$ solubility in pore water increases. The relatively high $\mathrm{CH}_{4}$ solubility at large depth suggests that the ocean could store large amounts of $\mathrm{CH}_{4}$ emitted at the seafloor, but decreasing solubility with decreasing pressure means that this $\mathrm{CH}_{4}$ would eventually turn into bubbles and outgas to the atmosphere when the water rises.

[102] Zhang [2003] reviewed what could happen following a release of $\mathrm{CH}_{4}$ at the seafloor. If $\mathrm{CH}_{4}$ is released as $\mathrm{CH}_{4}$ hydrate, since the density of $\mathrm{CH}_{4}$ hydrate is lower than that of seawater, whether released hydrate (e.g., from a submarine landslide or faulting) rises through the water column or not depends on how much sediment is mixed with it. If sediment mixing is small, then $\mathrm{CH}_{4}$ hydrate would rise through the water column and experience dissolution and dissociation during ascent. Zhang and $X u$ [2003] have estimated that hydrate chunks larger than $100 \mathrm{~mm}$ in radius would be able to survive dissociation through a $530 \mathrm{~m}$ surface layer. This is consistent with observations by Brewer et al. [2002], who revealed that hydrate pieces of $100 \mathrm{~mm}$ size easily survived transit from the seafloor $(780 \mathrm{~m})$ to the ocean surface. Paull et al. [2003] also report that marine slumping can release large pieces of solid gas hydrate that would float upward in the water column and reach the upper layers of the ocean before decomposing.

[103] If $\mathrm{CH}_{4}$ is released as bubbles, then the bubbles would rise through the water and expand as the pressure decreases. However, if the ocean is not saturated with respect to $\mathrm{CH}_{4}$, then dissolution would also happen, and whether the size of the bubble increases or not depends on the competition between expansion and dissolution. Zhang [2003] reported that the critical radius for a bubble to survive a $50 \mathrm{~m}$ rise is $0.9 \mathrm{~mm}$. If the $\mathrm{CH}_{4}$ bubble is released into deep water where hydrate is stable, then a hydrate shell would form around the bubble, which slows down dissolution. The hydrate shell will break and reform as the $\mathrm{CH}_{4}$ gas in the bubble expands during the rise of the bubble. Rehder et al. [2002] have observed the phenomenon of hydrate skin formation on $\mathrm{CH}_{4}$ bubbles. They found that the rise of $\mathrm{CH}_{4}$ and argon bubbles were similar above the $\mathrm{CH}_{4}$ hydrate stability zone (i.e., about $520 \mathrm{~m}$ depth). Below this, enhanced $\mathrm{CH}_{4}$ bubble lifetime was observed which they attributed to the formation of a hydrate skin. McGinnis et al. [2006] modeled the size of $\mathrm{CH}_{4}$ bubbles rising through the water column. They point out that even though the size of a bubble reaching the surface can be larger than its initial size, it would only contain a fraction of the $\mathrm{CH}_{4}$ that was initially released because of the difference in pressure. For instance, in the Black Sea a bubble released as a $12 \mathrm{~mm}$ bubble at 90 m depth would only contain $10 \%$ of the initial $\mathrm{CH}_{4}$, with the other $90 \%$ mainly dissolving in the water close to the seafloor. McGinnis et al. [2006] conclude that significant $\mathrm{CH}_{4}$ release to the atmosphere is only possible from shallow water depths (i.e., less than $100 \mathrm{~m}$ ). Zhang [2003] also notes that in the case of a major eruption bubbles would rise collectively as a bubbly water plume because bubbly water has a lower density than the surrounding seawater, which can lead to a rapid buoyant rise of the water plume. This process could considerably enhance the fraction of emitted $\mathrm{CH}_{4}$ that reaches the ocean surface.

[104] If $\mathrm{CH}_{4}$ dissolution is important, then it is important to determine what the fate of that dissolved $\mathrm{CH}_{4}$ is and whether it can leak into the atmosphere when the ocean is 
ventilated. There is evidence that $\mathrm{CH}_{4}$ is consumed in deep water by microbial oxidation. This phenomenon could explain why marine sediments record numerous episodes of $\mathrm{CH}_{4}$ hydrate decomposition during the Quaternary era, whereas ice core records suggest a minor contribution of such degassing on the atmospheric $\mathrm{CH}_{4}$ budget. Scranton and Brewer [1978] showed that dissolved $\mathrm{CH}_{4}$ concentrations rapidly decrease with depth in the North Atlantic and North Pacific oceans. However, they observed that $\mathrm{CH}_{4}$ consumption ceases within 100 years of isolation from the ocean surface. Rehder et al. [1999] deduced a time scale for $\mathrm{CH}_{4}$ oxidation in the North Atlantic Deep Water of about 50 years. This may have implications for the scenarios of hydrate release under climate change. While some regions of the ocean have low concentrations of $\mathrm{CH}_{4}$ because of $\mathrm{CH}_{4}$ oxidation, other regions exhibit larger $\mathrm{CH}_{4}$ concentrations because of natural sources of $\mathrm{CH}_{4}$ at the seafloor. It is therefore important to determine the extent to which the ocean is undersaturated, saturated, or supersaturated with respect to $\mathrm{CH}_{4}$. For example, Ward et al. [1987] show a vertical profile of $\mathrm{CH}_{4}$ in the western Cariaco Basin down to $1200 \mathrm{~m}$, which reveals an increase in $\mathrm{CH}_{4}$ concentration up to $12 \mu \mathrm{M}$ at $1300 \mathrm{~m}$. Ward et al. [1987] also estimated a $\mathrm{CH}_{4}$ oxidation rate of $0.4 \mathrm{nM} \mathrm{d}^{-1}$ below $600 \mathrm{~m}$ depth in the deep anoxic layer. Mau et al. [2007] observed a $\mathrm{CH}_{4}$ plume emitted at the seafloor from the Coal Oil Point on the Californian coast. They found that only $1 \%$ of the dissolved $\mathrm{CH}_{4}$ released at the seafloor enters the atmosphere within their study area of $280 \mathrm{~km}^{2}$. The rest of the dissolved $\mathrm{CH}_{4}$ emitted from the Coal Oil Point may enter the atmosphere farther away from the source or be oxidized by microbes in shallow coastal water or farther away in deep water where it has been mixed. Mau et al. [2007] argue that most of the dissolved $\mathrm{CH}_{4}$ seems to be transported and oxidized below the water surface.

[105] In addition to bubble and hydrate dynamics and physics, the sea surface microlayer is also important in both the consumption and production of atmospheric trace gases [Conrad and Seiler, 1988]. There is evidence that general microbial activity and metabolism at the air-sea interface can regulate air-sea gas exchange. In the tropical Atlantic Ocean, Conrad and Seiler [1988] found a significant mismatch between the invasive and evasive exchange of trace gases (e.g., $\mathrm{CH}_{4}$ and $\mathrm{CO}$ ) which they attributed to microbial gas consumption in the sea surface microlayer. Similarly, Frost [1999] found an invasion-evasion mismatch of up to $8 \%$ for $\mathrm{CH}_{4}$ in the coastal North Sea. Further work in a laboratory gas exchange tank with added methanotrophs confirmed the potential for active bacterioneuston control of trace gas exchange; air-water $\mathrm{CH}_{4}$ exchange differed by up to $10 \%$ relative to both nitrous oxide $\left(\mathrm{N}_{2} \mathrm{O}\right)$ and an inert tracer (sulfur hexafluoride), consistent with active metabolic control of $\mathrm{CH}_{4}$ exchange by the bacterioneuston [UpstillGoddard et al., 2003]. These studies collectively suggest that the bacterioneuston is intimately involved in the cycling of at least some climatically active trace gases, including $\mathrm{CH}_{4}$, and that it is potentially both a small gas source and a small gas sink dependent upon the prevailing microbial and biogeochemical regimes.

[106] In conclusion, the evidence for the importance of $\mathrm{CH}_{4}$ emission by hydrates to the atmosphere is contradictory. On the one hand, observations and calculations show that a significant fraction of the $\mathrm{CH}_{4}$ can reach the water surface and the atmosphere if the $\mathrm{CH}_{4}$ is emitted in large quantities or as large bubbles, especially from shallow water depths. On the other hand, $\mathrm{CH}_{4}$ dissolution, mixing with deeper water, and microbial $\mathrm{CH}_{4}$ oxidation could play an important role to significantly decrease the flux of $\mathrm{CH}_{4}$ to the atmosphere if the $\mathrm{CH}_{4}$ source is smaller, is more diffuse, happens through smaller bubbles, or takes place deeper in the ocean. There are few measurements of the $\mathrm{CH}_{4}$ concentration in the ocean and no global picture of the oceanic $\mathrm{CH}_{4}$ distribution. It seems important to investigate further the fate of $\mathrm{CH}_{4}$ in the ocean for different source locations, emission rates, and bubble size.

\subsection{Challenges and Prospects for Modeling in Global ESMs}

[107] A key challenge in $\mathrm{CH}_{4}$ hydrate research is improving our knowledge of the characterization of $\mathrm{CH}_{4}$ hydrates with a particular focus on their global occurrence, physical and chemical properties, and total $\mathrm{CH}_{4}$ inventory. Further data are also needed on the geothermal gradient and thermal diffusivity in the sediment column. Direct observations of gas hydrates have been obtained by drilling and associated well logs, but to date, there is still a relatively small number of locations where hydrate samples have been recovered. The overall uncertainty in the $\mathrm{CH}_{4}$ inventory is still quite high because of uncertainties in both the hydrate areal extent and the average hydrate volume fraction. This uncertainty could be reduced by further hydrate sampling and by improving the techniques used for estimating the $\mathrm{CH}_{4}$ concentration.

[108] As well as improving our knowledge on the occurrence, characteristics, and location of $\mathrm{CH}_{4}$ hydrates in the ocean sediments by field and laboratory-based studies, it is necessary to develop process-based models of hydratebearing sediments. Complex biological models describing the sedimentation and burial of biological material on the bed of shallow seas exist [e.g., Moll and Radach, 2003], but considerable development is required to translate these into models of clathrate formation. Some geological models also exist, but they are used largely in the oil and gas industries rather than in the context of climate change. By simulating the processes of hydrate formation and dissociation, it will be possible to use these models to examine how the GHSZ will change under different equilibrium conditions. A particular focus should also be on how the ocean warming will propagate through the sediment column, the time scale associated with it, and the transient rather than the steady state response of the hydrates. Given the long time scales associated with the deep ocean, it is recommended that these models be applied to shallow water hydrates in the Arctic Ocean, where substantial warming has already been observed and modeled. A case study for these models could well be the 
last interglacial period, 115,000-130,000 years before present. With about $50 \mathrm{~W} \mathrm{~m}^{-2}$ of additional insolation during summer months, the Arctic region experienced considerable warming, with surface summer temperature $4^{\circ} \mathrm{C}-5^{\circ} \mathrm{C}$ warmer than today [CAPE-Last Interglacial Project Members, 2006]. Detailed records of atmospheric $\mathrm{CH}_{4}$ and its carbon and hydrogen isotopic ratios measured in polar ice cores could disentangle the possible contribution of hydrate degassing under such critical conditions.

[109] Once destabilization occurs, the fate of the $\mathrm{CH}_{4}$ emitted from ocean sediments is also unclear. Process modeling of the ocean $\mathrm{CH}_{4}$ cycle will be required to understand the various processes in the ocean (bacterial oxidation of $\mathrm{CH}_{4}$, horizontal and vertical transport mechanisms for methane, and air-sea flux of $\mathrm{CH}_{4}$ ). This work could be extended to examine the sensitivity to the location and rate of $\mathrm{CH}_{4}$ emissions at the seafloor.

\section{METHANE PHOTOCHEMICAL FEEDBACKS ON CLIMATE}

\subsection{Methane Chemistry}

[110] As described in section 1, the principle destruction pathway for $\mathrm{CH}_{4}$ is via oxidation by the $\mathrm{OH}$ radical. The rate of this reaction includes a temperature term with the consequence that the loss of $\mathrm{CH}_{4}$ increases by approximately $2.3 \%$ for every $1^{\circ} \mathrm{C}$ increase in temperature. The principle source of $\mathrm{OH}$ is $\mathrm{UV}$ photolysis of ozone in the presence of water vapor. The densities of $\mathrm{OH}$ are highest where the sources are highest, i.e., in regions of high water vapor density such as the tropical lower troposphere. Under a changed climate where both temperature and water vapor density are expected to rise, the combined effect is to increase the removal rate of $\mathrm{CH}_{4}$ [Johnson et al., 1999, 2001]. A multimodel study by Stevenson et al. [2006] found that by 2030 climate change might be expected to reduce the $\mathrm{CH}_{4}$ lifetime by around $4 \%$ compared to the climate at the year 2000. Future changes in emissions of CO, hydrocarbons, and $\mathrm{NO}_{x}$ will affect the $\mathrm{OH}$ density and hence $\mathrm{CH}_{4}$ lifetime, with increases of $\mathrm{CO}$ and hydrocarbons decreasing $\mathrm{OH}$ and increases in $\mathrm{NO}_{x}$ increasing $\mathrm{OH}$.

[111] The chemistry that determines the $\mathrm{OH}$ radical concentration in the atmosphere can be complex and involves numerous reactions between various species. Detailed discussions are given, for instance, by Levy [1971], Rasmussen and Khalil [1984], Blake and Rowland [1988], Cicerone [1988], or Hough and Derwent [1990]. Essentially, though, $\mathrm{OH}$ is determined by the following reaction chain:

$$
\begin{gathered}
\mathrm{HO}_{2}\left(\mathrm{RO}_{2}\right)+\mathrm{NO} \rightarrow \mathrm{OH}+\mathrm{NO}_{2} \\
\mathrm{NO}_{2}+h \nu \rightarrow \mathrm{NO}+\mathrm{O}\left({ }^{3} P\right) \\
\mathrm{O}\left({ }^{3} P\right)+\mathrm{O}_{2}+\mathrm{M} \rightarrow \mathrm{O}_{3}+\mathrm{M} \\
\mathrm{O}_{3}+h \nu \rightarrow \mathrm{O}\left({ }^{1} D\right)+\mathrm{O}_{2}
\end{gathered}
$$

followed by

$$
\begin{gathered}
\mathrm{O}\left({ }^{1} D\right)+\mathrm{H}_{2} \mathrm{O} \rightarrow 2 \mathrm{OH} \\
\mathrm{O}_{3}+\mathrm{HO}_{2} \rightarrow \mathrm{OH}+2 \mathrm{O}_{2} \\
\mathrm{O}_{3}+\mathrm{OH} \rightarrow \mathrm{HO}_{2}+\mathrm{O}_{2} .
\end{gathered}
$$

Incidentally, reactions (R1)-(R3) lead to the formation of $\mathrm{O}_{3}$, and reactions (R4)-(R6) result in $\mathrm{O}_{3}$ destruction. Nitrogen oxides and hydrogen radicals are recycled through this catalytic reaction chain. Chain breaking occurs through the following reactions:

$$
\begin{gathered}
\mathrm{NO}_{2}+\mathrm{OH}+\mathrm{M} \rightarrow \mathrm{HNO}_{3}+\mathrm{M} \\
\mathrm{HO}_{2}+\mathrm{HO}_{2}+\mathrm{M} \rightarrow \mathrm{H}_{2} \mathrm{O}_{2}+\mathrm{M} \\
\mathrm{OH}+\mathrm{HO}_{2} \rightarrow \mathrm{H}_{2} \mathrm{O}+\mathrm{O}_{2},
\end{gathered}
$$

in which both $\mathrm{NO}_{x}$ and $\mathrm{OH}$ are eventually lost from the catalytic cycle. The reaction of $\mathrm{OH}$ with $\mathrm{CO}, \mathrm{CH}_{4}$, and NMVOCs produces peroxy radicals that feed into reaction (R1) and result in cycle closure:

$$
\begin{aligned}
& \mathrm{OH}+\mathrm{CO} \rightarrow\left(\mathrm{O}_{2}, \mathrm{M}\right) \rightarrow \mathrm{HO}_{2}+\mathrm{M} \\
& \mathrm{OH}+\mathrm{CH}_{4} \rightarrow\left(\mathrm{O}_{2}, \mathrm{M}\right) \rightarrow \mathrm{H}_{2} \mathrm{O}+\mathrm{CH}_{3} \mathrm{O}_{2} .
\end{aligned}
$$

The net effect will depend on the balance between $\mathrm{CO}$, NMVOC, and $\mathrm{NO}_{x}$ emissions in any particular scenario. Stevenson et al. [2006] found changes in $\mathrm{CH}_{4}$ lifetime of $0.0 \%,+1.4 \%$, and $+2.7 \%$ for three different emission scenarios for 2030 .

\subsection{Methane Feedback on Itself}

[112] Because $\mathrm{CH}_{4}$ changes its own loss rate, a perturbation to the $\mathrm{CH}_{4}$ distribution (such as an emission pulse) will not decay with the tropospheric lifetime but will last longer because of the reduced $\mathrm{OH}$ density. For the tropospheric chemistry models that contributed to the IPCC third assessment report [Prather et al., 2001], the average increase in lifetime was found to be a factor of 1.4. This means that for an atmospheric lifetime of 8.4 years (including dry deposition and stratospheric loss), the perturbation lifetime of an emission pulse is 12 years. In the steady state response to a step emission change, the fractional change in the $\mathrm{CH}_{4}$ burden due to the fractional change $(\delta)$ in the emissions is raised to the power of 1.4 (i.e., $\mathrm{CH}_{4} \rightarrow \mathrm{CH}_{4} \times(1+\delta)^{1.4}$ ). So a $1 \%$ increase in $\mathrm{CH}_{4}$ emissions would lead to an increase in the $\mathrm{CH}_{4}$ burden of $1.4 \%$.

\subsection{Methane Direct and Indirect Effects}

[113] $\mathrm{CH}_{4}$ concentrations have increased from values of around $715 \mathrm{ppb}$ in preindustrial times to $1787 \mathrm{ppb}$ in 2008 [Dlugokencky et al., 2009]. This gives a $\mathrm{CH}_{4}$ radiative forcing of over $0.48 \mathrm{~W} \mathrm{~m}^{-2}$. This change in $\mathrm{CH}_{4}$ is less than that expected because of the increase in $\mathrm{CH}_{4}$ emissions as 
concurrent increases in $\mathrm{NO}_{x}$ emissions have increased the rate of removal. The impact of $\mathrm{CH}_{4}$ emissions alone since preindustrial times is $0.59 \mathrm{~W} \mathrm{~m}^{-2}$ [Shindell et al., 2005].

[114] As well as a direct radiative forcing, $\mathrm{CH}_{4}$ emissions can change the concentrations of other greenhouse gases. $\mathrm{CH}_{4}$ is a precursor of tropospheric ozone, under atmospheric conditions rich in $\mathrm{NO}_{x}$. Shindell et al. [2005] estimate that $\mathrm{CH}_{4}$ emissions since the preindustrial era have contributed to a forcing by tropospheric ozone of $0.2 \mathrm{~W} \mathrm{~m}^{-2}$. Sitch et al. [2007b] suggest that the damage caused by ozone to vegetation could be to double the effective direct radiative forcing from an increase in tropospheric ozone alone by suppressing the land carbon sink. This results in additional anthropogenic $\mathrm{CO}_{2}$ emissions accumulating in the atmosphere and is therefore an indirect radiative forcing of climate.

[115] The impact of $\mathrm{CH}_{4}$ changes on stratospheric water vapor from 1880 to 2000 is estimated to be $+0.07 \pm$ $0.05 \mathrm{~W} \mathrm{~m}^{-2}$ [Hansen et al., 2005]. Finally, the ultimate degradation product from $\mathrm{CH}_{4}$ is $\mathrm{CO}_{2}$. The contribution from $\mathrm{CH}_{4}$ concentration changes to the $\mathrm{CO}_{2}$ forcing is $0.016 \mathrm{~W} \mathrm{~m}^{-2}$ [Forster et al., 2007]. The latter two contributions need to be scaled up by $20 \%$ to attribute the forcing to $\mathrm{CH}_{4}$ emissions in the absence of concurrent $\mathrm{NO}_{x}$ emissions. Therefore, the total radiative forcing from preindustrial times to the present day due to $\mathrm{CH}_{4}$ emissions (including the ozone damage effect) is $1.1 \pm 0.2 \mathrm{~W} \mathrm{~m}^{-2}$, and this estimate is even higher when the direct and indirect effects of nitrate and sulfate aerosols are also considered. Shindell et al. [2009] find a decrease in aerosol formation in response to an increase in $\mathrm{CH}_{4}$ due to the chemical feedback which leads to a net positive radiative forcing. This should be compared to a present-day radiative forcing of $1.74 \mathrm{~W} \mathrm{~m}^{-2}$ from anthropogenic $\mathrm{CO}_{2}$ emissions.

\subsection{Interplay of the Methane Cycle With Volatile Organic Compounds}

[116] Oxidation by $\mathrm{OH}$ radicals represents the main atmospheric sink not only for $\mathrm{CH}_{4}$ but also for many organic compounds of natural and anthropogenic origin. Once emitted into the atmosphere they compete for the available $\mathrm{OH}$ radicals, thereby altering the oxidizing capacity of the atmosphere [Levy, 1971; Hauglustaine et al., 1998; Bey et al., 2001; Collins et al., 2002; Folberth et al., 2006]. Through this interaction, NMVOCs have a significant impact on the chemical lifetime of $\mathrm{CH}_{4}$ in the atmosphere.

[117] Generally, it is expected that NMVOCs deplete $\mathrm{OH}$ in an unpolluted environment, thereby increasing the chemical lifetime of $\mathrm{CH}_{4}$ [Granier et al., 2000; Lelieveld et al., 2002; von Kuhlmann et al., 2004]. As outlined in section 5.2, this perturbation to the $\mathrm{CH}_{4}$ lifetime will be amplified by the $\mathrm{CH}_{4}$ feedback on its own lifetime. However, in a polluted environment where NMVOC emissions are generally collocated with pronounced emissions of $\mathrm{NO}_{x}$, NMVOC oxidation leads to a buildup of ozone and, consequently, $\mathrm{OH}$ by the catalytic action of $\mathrm{NO}_{x}$. This widely accepted picture has recently been challenged by Lelieveld et al. [2008], who indicate that oxidation of natural NMVOCs, notably isoprene, might provide a mechanism for $\mathrm{OH}$ recycling even in a pristine, low- $\mathrm{NO}_{x}$ environment. This proposed mechanism could effectively limit the impact of primary NMVOCs on the $\mathrm{CH}_{4}$ lifetime. Thus, it could have significant implications for the future evolution of the $\mathrm{CH}_{4}$ atmospheric burden, but the mechanism of $\mathrm{OH}$ recycling remains largely unclear.

[118] Using a dynamic global vegetation model, Lathière et al. [2005] have calculated that total BVOC emissions could increase from $725 \mathrm{Tg} \mathrm{C} \mathrm{yr}^{-1}$ at present-day conditions to $1250 \mathrm{Tg} \mathrm{C} \mathrm{yr}^{-1}$ at the end of the $21 \mathrm{st}$ century in response to climate change. This increase by $75 \%$ over the presentday source implies a significant increase in the $\mathrm{CH}_{4}$ lifetime and, consequently, its atmospheric concentration, adding further to a direct radiative forcing. The study by Lathière et al. [2005] did not take into account the inhibiting effect of increasing $\mathrm{CO}_{2}$ concentrations on isoprene formation [Monson et al., 2007]. However, further studies by Arneth et al. [2007] and Heald et al. [2009] have found little or no impact on future isoprene emissions as a consequence of the $\mathrm{CO}_{2}$ inhibition effect.

[119] It has to be pointed out, though, that the predictions of future NMVOC emissions from the biosphere are affected by extremely large uncertainties related to both the ecosystem adaptation and distribution in a changing climate as well as the actual emission magnitude itself. Effects that have been outlined include a reduced stomatal exchange rate with the atmosphere in response to elevated $\mathrm{CO}_{2}$ levels [Field et al., 1995], damage of plants due to exposure to surface ozone [Sitch et al., 2007b], inhibition of isoprene emissions on an intercellular level by elevated ambient $\mathrm{CO}_{2}$ concentrations which could partially counteract the longterm $\mathrm{CO}_{2}$ fertilization effects [Arneth et al., 2007; Heald et al., 2009], and reduced isoprene emissions as a consequence of drought [Pegoraro et al., 2004]. In addition, these processes depend on and interact with each other and the climate and atmospheric composition, implying a highly nonlinear response to future changes.

[120] The overall impact of these processes on future BVOC emissions is largely unknown at present, and most of the research is at a very early stage. Keeping in mind the very large uncertainties around all processes that govern BVOC emissions from the terrestrial biosphere, the most likely future scenario currently anticipated is one in which emissions of BVOCs which dominate over anthropogenic NMVOCs in the present-day atmosphere will increase substantially in response to a warmer climate and elevated atmospheric $\mathrm{CO}_{2}$ levels [Sanderson et al., 2003; Lathière et al., 2006; Monson et al., 2007] and, hence, will play a key role in the global $\mathrm{CH}_{4}$ budget.

[121] The future evolution of atmospheric $\mathrm{CH}_{4}$ concentrations may also be understood by turning to the past. The study of past atmospheric $\mathrm{CH}_{4}$ fluctuations from ice cores allows some of the vast uncertainties around the magnitude of the $\mathrm{CH}_{4}$-NMVOC feedback in future climate to be constrained. $\mathrm{CH}_{4}$ concentrations measured in gas 
bubbles that were preserved in the ice show that atmospheric concentrations of $\mathrm{CH}_{4}$ have increased from about $380 \mathrm{ppb}$ at the LGM 21,000 years before present to roughly $715 \mathrm{ppb}$ during the preindustrial era [Chappellaz et al., 1993b, 1997; Brook et al., 2000]. This increase in the atmospheric $\mathrm{CH}_{4}$ concentration by more than $65 \%$, which is similar to the one predicted to occur over the 21 st century, has been attributed to a substantial amount to the increase in BVOC emissions from a more productive tropical forest and the developing boreal forests as a consequence of the shrinking of the continental ice sheets [Valdes et al., 2005; Kaplan et al., 2006; Harder et al., 2007].

[122] Valdes et al. [2005] and Kaplan et al. [2006] have calculated an increase of the $\mathrm{CH}_{4}$ lifetime by approximately 1.3 years $(19 \%)$ and 2.1 years (29\%) from 7.1 and 7.3 years at LGM to 8.4 and 9.4 years, respectively, for the preindustrial Holocene (PIH) as a consequence of increasing BVOC emissions. In those studies, BVOC emissions were calculated to increase by $100 \%$ and $57 \%$. This increase in $\mathrm{CH}_{4}$ atmospheric lifetime would account for between $55 \%$ and $88 \%$ of the increase in the atmospheric $\mathrm{CH}_{4}$ concentration from LGM to PIH [Valdes et al., 2005; Kaplan et al., 2006]. However, these model studies have large uncertainties since many effects cannot be taken into account at the current stage of model development. Nevertheless, these modeling studies have found experimental support recently [Loulergue et al., 2008]. Because of its inherently nonlinear nature it is not possible to extrapolate the past feedback directly into a future atmosphere quantitatively. Nevertheless, it seems legitimate to assume that a similar feedback process in the past will result in a feedback of the same sign and possibly similar magnitude in the future. Furthermore, the available results at least allow us to speculate about how the future increase in BVOC emissions will affect the evolution of the $\mathrm{CH}_{4}$ burden over the 21st century. It can be hypothesized that a $75 \%$ increase in BVOC emissions is possible over the 21 st century [Lathière et al., 2005] with little impact from the $\mathrm{CO}_{2}$ inhibition effect [Arneth et al., 2007; Heald et al., 2009]. A similar increase in BVOC emissions from the LGM to the preindustrial period results in an increase of the $\mathrm{CH}_{4}$ lifetime by roughly 1-2 years [Valdes et al., 2005; Kaplan et al., 2006]. A simple reaction kinetic consideration implies a $2.3 \%$ or roughly 3 month decrease in $\mathrm{CH}_{4}$ chemical lifetime per ${ }^{\circ} \mathrm{C}$ increase in temperature at constant $\mathrm{OH}$ concentrations. The $\mathrm{CH}_{4}$ feedback on its own lifetime extends this lifetime decrease to $3.2 \%$ or almost 4 months per ${ }^{\circ} \mathrm{C}$ warming. A global warming of $2^{\circ} \mathrm{C}-$ $4^{\circ} \mathrm{C}$ by 2100 [Meehl et al., 2007] results in a decrease in the $\mathrm{CH}_{4}$ chemical lifetime due to temperature and humidity changes alone of between approximately 8 and 15 months.

[123] Consequently, this very rough comparison would indicate that the effect of a $75 \%$ increase in BVOC emissions on the $\mathrm{CH}_{4}$ lifetime and the chemical kinetic effect due to expected global warming are of the same order of magnitude but of opposite sign, potentially cancelling each other. However, very large uncertainties persist around these figures, and further model improvements are required to assess the importance of nonlinear chemical feedbacks in the Earth system.

\section{CONCLUSIONS AND RECOMMENDATIONS FOR FUTURE RESEARCH}

[124] We have made an assessment of the available scientific literature on $\mathrm{CH}_{4}$ feedbacks related to natural sources of $\mathrm{CH}_{4}$ from wetlands, permafrost, and ocean sediments. In summary, the complex and nonlinear processes governing the sources and atmospheric chemistry of $\mathrm{CH}_{4}$ cause a feedback loop between the climate, the terrestrial vegetation as the source of BVOCs, the oxidation capacity of the atmosphere, and the atmospheric $\mathrm{CH}_{4}$ burden. The feedback loop can be described in simple terms as follows: rising $\mathrm{CH}_{4}$ emissions from wetlands, thawing permafrost, and destabilizing marine hydrates increase atmospheric $\mathrm{CH}_{4}$ concentrations; this increase in $\mathrm{CH}_{4}$ concentration, amplified by the effect of $\mathrm{CH}_{4}$ on its own chemical lifetime, results in a greater radiative forcing on climate and terrestrial ecosystems. The ecosystems, given our current understanding, respond to the warmer, more humid conditions by an increase in BVOCs, which further augments the chemical lifetime of $\mathrm{CH}_{4}$. Finally, the resulting additional radiative forcing could lead to more or faster thawing of permafrost, further destabilization of marine hydrates, and potentially even larger wetland $\mathrm{CH}_{4}$ emissions. But this feedback loop could break down because of increased drought conditions resulting in a loss of global wetland area or a reduced BVOC emission efficiency in the terrestrial ecosystems under water stress or be limited by the speed of permafrost thawing and/or destabilization of marine hydrates. It is difficult, if not impossible, to predict if and when this breakdown occurs without simulating the entire feedback loop. Many of the processes involved are poorly understood or are only now being uncovered. The next generation of ESMs will provide the required framework to analyze the numerous interdependencies that contribute to the global $\mathrm{CH}_{4}$ cycle.

[125] Our main findings on future $\mathrm{CH}_{4}$ emissions are summarized in Figure 7, which shows cumulative emissions of $\mathrm{CH}_{4}$ as a function of the time scale of climate change. The diagram is semiquantitative and should be interpreted as such. The light blue line corresponds to present-day emissions of $\sim 600 \mathrm{Tg} \mathrm{CH}_{4} \mathrm{yr}^{-1}$ and can be used to assess the importance of the $\mathrm{CH}_{4}$ feedbacks on different time scales. Our review indicates an increase in wetland emissions of $10 \%-35 \%$ per ${ }^{\circ} \mathrm{C}$ warming, which we roughly translated into a range of cumulative emissions until 2100 (red lines). There are no studies looking at longer time scales, but emissions would be expected to continue, although permafrost thawing, changes in land use, and soil humidity all contribute to increase the uncertainty range. The change in $\mathrm{CH}_{4}$ lifetime due to changing BVOC emissions is fairly uncertain but can be translated into equivalent emissions as was done with the pink lines in Figure 7; it is thought to be a smaller effect than that from wetland emissions, especially if there is a $\mathrm{CO}_{2}$ inhibition effect on BVOC emissions. The change in $\mathrm{CH}_{4}$ lifetime due to the increase in temperature 


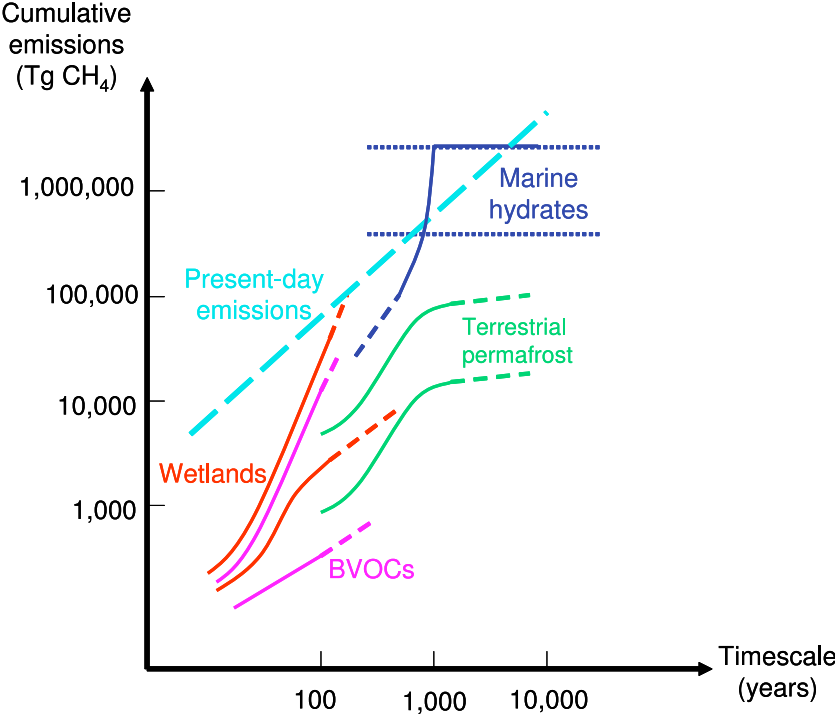

Figure 7. . Summary diagram of the relative sizes and time scales associated with methane feedbacks. See text for a discussion. Note that the diagram is semiquantitative. BVOCs, biogenic volatile organic compounds.

and humidity is expected to be of a similar magnitude but opposite sign (not shown in Figure 7). Thawing of the terrestrial permafrost will result in $\mathrm{CO}_{2}$ and $\mathrm{CH}_{4}$ emissions on time scales of a few decades to several centuries. Uncertainties in future emissions are dominated by the extent of carbon stores, the fractional area and volume of permafrost thawing, and the ratio of $\mathrm{CH}_{4}$ to $\mathrm{CO}_{2}$ emissions. We place a range in Figure 7 that reflects published estimates compiled in this review. We limit here the cumulative emissions of $\mathrm{CH}_{4}$ from terrestrial permafrost to a fraction of the carbon stores, but emissions can carry on as permafrost regions are transformed into wetlands with their own vegetation dynamics. Existing inventories on marine hydrates place an upper bound on cumulative $\mathrm{CH}_{4}$ emissions from this source; the blue dotted lines in Figure 7 show the range of $4 \times 10^{5}$ and $3 \times 10^{6} \mathrm{Tg} \mathrm{CH}_{4}$. Marine hydrates can only be fully destabilized on time scales of millennia because of the large inertia associated with the global oceanic circulation and heat propagation in sediments. It is difficult to put a lower bound on atmospheric $\mathrm{CH}_{4}$ emissions from hydrates because of the possibility of large quantities of $\mathrm{CH}_{4}$ being oxidized in oceanic water and the range of future climate projections. Likewise, it is not possible to give an estimate for emissions on shorter time scales. It is clear, however, that this is a very large reservoir of $\mathrm{CH}_{4}$ that could dominate other sources of $\mathrm{CH}_{4}$ even if emitted on long time scales. Methane has a lifetime of the order of 10 years so cumulative emissions, as presented in Figure 7, are only partially relevant for climate change. While the enhanced emissions from wetlands or the enhanced lifetime due to BVOC emissions would happen continuously, emissions from the terrestrial permafrost or marine hydrates could happen in a nonlinear way as various thresholds are crossed.

[126] A significant increase in $\mathrm{CH}_{4}$ emissions and atmospheric concentrations due to climate change is therefore a possible scenario for the next century. However, uncertainties are very large, and as discussed above, it is difficult to be very conclusive regarding the magnitude of $\mathrm{CH}_{4}$ feedbacks and their time scales. The following statements can nevertheless be made:

[127] 1. Natural emissions of $\mathrm{CH}_{4}$ are likely to increase in a warmer climate; however, the magnitude and rate of change of future emissions from natural sources are largely unknown.

[128] 2. There are large amounts of carbon stored as organic matter in permafrost or as $\mathrm{CH}_{4}$ hydrates in the ocean sediments. However, it is not clear how quickly these carbon stores can be released and how much would survive microbial oxidation between the source and the atmosphere. The risk of a rapid increase in $\mathrm{CH}_{4}$ emissions is real but remains largely unquantified.

[129] 3. Climate change will affect the $\mathrm{CH}_{4}$ lifetime. The anticipated increases in temperature and water vapor concentrations and emissions of BVOCs will have effects of opposite signs on the $\mathrm{CH}_{4}$ lifetime. In any case, the potential for increased $\mathrm{CH}_{4}$ emissions is larger than the potential for increased $\mathrm{CH}_{4}$ sinks.

[130] We also identify a number of gaps in our knowledge:

[131] 1. Our understanding of the present-day distribution, $\mathrm{CH}_{4}$ fluxes, and sensitivities associated with wetlands (including wetland spatial and seasonal distribution itself) needs to be improved, particularly in relation to tropical wetlands. Therefore, there is a requirement that ESMs successfully represent the wetland hydrology, permafrost processes, and vegetation as well as the processes for $\mathrm{CH}_{4}$ formation (including substrate supply), transfer, oxidation, and emission. Only by improving our understanding of these processes will we be able to quantify the climate feedback on wetland $\mathrm{CH}_{4}$ emissions with greater certainty.

[132] 2. The carbon stores in boreal regions are not well known, although some recent inventories of soil organic pools in permafrost regions constitute a good starting point for global-scale modeling. It is of fundamental importance to understand the horizontal and vertical distributions of the carbon stored as organic matter in the land permafrost and $\mathrm{CH}_{4}$ hydrates in the ocean sediments. Land $\mathrm{CH}_{4}$ hydrates and subsea permafrost may also play a role. Better inventories of carbon stores will benefit from more observations and better integration of existing observations, as well as modeling of paleoclimatic ecosystems and sediment formation (notably by considering past warmer interglacials as a case study).

[133] 3. It is timely to develop models of permafrost dynamics. The modeling needs to focus on accurately representing heat and water transfer within a deep soil layer with potentially high content of organic matter. The sensitivity of permafrost thawing to global warming will need to be investigated. It is also important to understand to what extent permafrost thawing will result in changes in the water table depth and wetland area in order to predict the relative strengths of $\mathrm{CH}_{4}$ and $\mathrm{CO}_{2}$ emissions associated with the decomposition of the organic matter present in the permafrost. 
[134] 4. It is not just sufficient to know the location of $\mathrm{CH}_{4}$ hydrates in the ocean sediments and how the $\mathrm{CH}_{4}$ hydrate stability zone would move for different equilibrium conditions; we need to understand how and how quickly the ocean warming will propagate through the sediment column. Further data are needed on the geothermal gradient and thermal diffusivity in the sediment column. It is important that modeling focuses on understanding the transient rather than steady state response of marine hydrates to climate change. Some geological models exist but have hardly been used in the context of climate change. Given the long time scales associated with the deep ocean and that $\mathrm{CH}_{4}$ is not likely to enter the atmosphere from the deep ocean, it is recommended that research focuses on ocean shelves with a particular emphasis on the Arctic Ocean where substantial warming has been observed and modeled. A particular challenge in modeling hydrates in ESMs will be the different time scales associated with hydrate formation, heat propagation, etc.

[135] 5. The fate of $\mathrm{CH}_{4}$ emitted from ocean sediments is unclear. Some simple modeling of the ocean $\mathrm{CH}_{4}$ cycle should be initiated to understand the various processes at play in the ocean (bacterial oxidation of $\mathrm{CH}_{4}$, horizontal and vertical transport mechanisms for methane, and air-sea flux of $\mathrm{CH}_{4}$ ). Sensitivity studies on the location and rate of $\mathrm{CH}_{4}$ emissions at the seafloor should be performed.

[136] 6. The atmospheric response to a large emission rate of $\mathrm{CH}_{4}$ is not well known. The sensitivity of the oxidizing capacity of the atmosphere to large emissions of $\mathrm{CH}_{4}$ should be investigated. This is in the context of changes in the oxidizing capacity of the atmosphere driven by expected changes in atmospheric temperature, water vapor, VOC emissions from the biosphere, and the $\mathrm{CH}_{4}$ feedback on itself. Earth system models will provide further insight into the importance of the numerous feedbacks that are involved.

[137] This research should be done collaboratively, pulling together the relevant multidisciplinary expertise, and should be quickly incorporated into scientific advice that is provided to governments regarding safe levels of climate change.

[138] ACKNOWLEDGMENTS. The Met Office Hadley Centre is funded by the Joint DECC and Defra Integrated Climate Programme, DECC/Defra (GA01101). R. Coppell is supported by a NERC scholarship, NE/F008341/1, supported by the Met Office Hadley Centre as a CASE partner. J. Chappellaz was supported by the French ANR project IMPACT-BOREAL under the Vulnérabilité 2006 program and also by the INSU-QUEST British-French project DESIRE. We also wish to acknowledge Philip Cameron-Smith, Michael Cunliffe, Chris Huntingford, Mike Lovell, Andy Ridgwell, and Chris Rochelle for useful discussions and comments.

[139] The Editor for this paper was Mark Moldwin. He thanks reviewer Rita Wania and two additional anonymous reviewers.

\section{REFERENCES}

Alexeev, V. A., D. J. Nicolsky, V. E. Romanovsky, and D. M. Lawrence (2007), An evaluation of deep soil configurations in the CLM3 for improved representation of permafrost, Geophys. Res. Lett., 34, L09502, doi:10.1029/2007GL029536.
Allan, W., D. C. Lowe, A. J. Gomez, H. Struthers, and G. W. Brailsford (2005), Interannual variation of ${ }^{13} \mathrm{C}$ in tropospheric methane: Implications for a possible atomic chlorine sink in the marine boundary layer, J. Geophys. Res., 110, D11306, doi:10.1029/2004JD005650.

Archer, D. (2007), Methane hydrate stability and anthropogenic climate change, Biogeosciences, 4, 521-544, doi:10.5194/bg-4521-2007.

Archer, D., B. Buffett, and V. Brovkin (2009), Ocean methane hydrates as a slow tipping point in the global carbon cycle, Proc. Natl. Acad. Sci. U. S. A., 106(49), 20,596-20,601.

Are, F. E. (2001), The problem of the emission of deep-buried gases to the atmosphere, in Permafrost Response on Economic Development, Environmental Security and Natural Resources, edited by R. Paepe and V. Melnikov, pp. 497-509, Kluwer Acad., Dordrecht, Netherlands.

Arneth, A., P. A. Miller, A. Scholze, T. Hickler, G. Schurges, B. Smith, and I. C. Prentice (2007), $\mathrm{CO}_{2}$ inhibition of global terrestrial isoprene emissions: Potential implications for atmospheric chemistry, Geophys. Res. Lett., 34, L18813, doi:10.1029/ 2007GL030615.

Arneth, A., et al. (2010), From biota to chemistry and climate: Towards a comprehensive description of trace gas exchange between the biosphere and atmosphere, Biogeosciences, 7, 121-149, doi:10.5194/bg-7-121-2010.

Aselmann, I., and P. J. Crutzen (1989), Global distribution of natural fresh-water wetlands and rice paddies, their net primary productivity, seasonality and possible methane emissions, J. Atmos. Chem., 8(4), 307-358.

Bains, S., R. M. Corfield, and R. D. Norris (1999), Mechanisms of climate warming at the end of the Paleocene, Science, 285, 724-727, doi:10.1126/science.285.5428.724.

Beauchamp, B. (2004), Natural gas hydrates: Myths, facts and issues, C. R. Geosci., 336, 751-765, doi:10.1016/j.crte.2004.04. 003.

Bekki, S., K. S. Law, and J. A. Pyle (1994), Effect of ozone depletion on atmospheric $\mathrm{CH}_{4}$ and $\mathrm{CO}$ concentrations, Nature, 371, 595-597, doi:10.1038/371595a0.

Bergamaschi, P., M. Krol, F. Dentener, A. Vermeulen, F. Meinhardt, R. Graul, M. Ramonet, W. Peters, and E. J. Dlugokencky (2005), Inverse modelling of national and European $\mathrm{CH}_{4}$ emissions using the atmospheric zoom model TM5, Atmos. Chem. Phys., 5, 2431-2460, doi:10.5194/acp-5-2431-2005.

Bergamaschi, P., et al. (2009), Inverse modeling of global and regional $\mathrm{CH}_{4}$ emissions using SCIAMACHY satellite retrievals, J. Geophys. Res., 114, D22301, doi:10.1029/2009JD012287.

Bey, I., D. J. Jacob, R. M. Yantosca, J. A. Logan, B. D. Field, A. M. Fiore, Q. B. Li, H. G. Y. Liu, L. J. Mickley, and M. G. Schultz (2001), Global modeling of tropospheric chemistry with assimilated meteorology: Model description and evaluation, J. Geophys. Res., 106, 23,073-23,095, doi:10.1029/2001JD000807.

Blake, D. R., and F. S. Rowland (1988), Continuing worldwide increase in tropospheric methane, 1978 to 1987, Science, 239, 1129-1131, doi:10.1126/science.239.4844.1129.

Bloom, A. A., P. I. Palmer, A. Fraser, D. S. Reay, and C. Frankenberg (2010), Large-scale controls of methanogenesis inferred from methane and gravity spaceborne Data, Science, 327, 322-325, doi:10.1126/science. 1175176 .

Born, M., H. Dorr, and I. Levin (1990), Methane consumption in aerated soils of the temperate zone, Tellus, Ser. B, 42, $2-8$.

Bousquet, P., D. A. Hauglustaine, P. Peylin, C. Carouge, and P. Ciais (2005), Two decades of $\mathrm{OH}$ variability as inferred by an inversion of atmospheric transport and chemistry of methyl chloroform, Atmos. Chem. Phys., 5, 2635-2656, doi:10.5194/ acp-5-2635-2005.

Bousquet, P., et al. (2006), Contribution of anthropogenic and natural sources to atmospheric methane variability, Nature, 443, 439-443, doi:10.1038/nature05132. 
Brewer, P. G., F. M. Orr Jr., G. Friederich, K. A. Kvenvolden, D. L. Orange, J. McFarlane, and W. Kirkwood (1997), Deepocean field test of methane hydrate formation from a remotely operated vehicle, Geology, 25, 407-410, doi:10.1130/00917613(1997)025<0407:DOFTOM >2.3.CO;2.

Brewer, P. G., C. Paull, E. T. Peltzer, W. Ussler, G. Rehder, and G. Friederich (2002), Measurements of the fate of gas hydrates during transit through the ocean water column, Geophys. Res. Lett., 29(22), 2081, doi:10.1029/2002GL014727.

Brook, E. J., S. Harder, J. Severinghaus, and M. Bender (1999), Atmospheric methane and millennial-scale climate change, in Mechanisms of Global Climate Change at Millennial Time Scale, Geophys. Monogr. Ser., vol. 112, edited by P. U. Clark, R. S. Webb, and L. D. Keigwin, pp. 165-175, AGU, Washington, D. C.

Brook, E. J., S. Harder, J. Severinghaus, E. J. Steig, and C. M. Sucher (2000), On the origin and timing of rapid changes in atmospheric methane during the last glacial period, Global Biogeochem. Cycles, 14, 559-572, doi:10.1029/1999GB001182.

Brook, E., D. Archer, E. Dlugokencky, S. Frolking, and D. Lawrence (2008), Potential for abrupt changes in atmospheric methane, in Abrupt Climate Change. A Report by the U.S. Climate Change Science Program and the Subcommittee on Global Change Research, pp. 360-452, U.S. Geol. Surv., Reston, Va.

Bubier, J. L., G. Bhatia, T. R. Moore, N. T. Roulet, and P. M. Lafleur (2003), Spatial and temporal variability in growing season net ecosystem carbon dioxide exchange at a large peatland in Ontario, Canada, Ecosystems, 6, 353-367.

Buffett, B., and D. Archer (2004), Global inventory of methane clathrate: Sensitivity to changes in the deep ocean, Earth Planet. Sci. Lett., 227, 185-199, doi:10.1016/j.epsl.2004.09.005.

Burn, C. R., and F. E. Nelson (2006), Comment on "A projection of severe near-surface permafrost degradation during the $21 \mathrm{st}$ century" by David M. Lawrence and Andrew G. Slater, Geophys. Res. Lett., 33, L21503. doi:10.1029/2006GL027077.

Camps, A. P., D. Long, C. A. Rochelle, and M. A. Lovell (2009), Mapping hydrate stability zones offshore Scotland, in SedimentHosted Gas Hydrates: New Insights on Natural and Synthetic Systems, Geol. Soc. Spec. Publ., 319, 81-91, doi:10.1144/SP319.7.

Cao, M., S. Marshall, and K. Gregson (1996), Global carbon exchange and methane emissions from natural wetlands: Application of a process-based model, J. Geophys. Res., 101(D9), 14,399-14,414, doi:10.1029/96JD00219.

Cao, M., K. Gregson, and S. Marshall (1998), Global methane emission from wetlands and its sensitivity to climate change, Atmos. Environ., 32, 3293-3299, doi:10.1016/S1352-2310(98) 00105-8.

CAPE-Last Interglacial Project Members (2006), Last Interglacial Arctic warmth confirms polar amplification of climate change, Quat. Sci. Rev., 25, 1383-1400, doi:10.1016/j.quascirev.2006. 01.033 .

Carey, S. K., and M. K. Woo (1999), Hydrology of two slopes in subarctic Yukon, Canada, Hydrol. Processes, 13, 2549-2562, doi:10.1002/(SICI)1099-1085(199911)13:16<2549::AIDHYP938>3.0.CO;2-H.

Carey, S. K., and M. K. Woo (2000), The role of soil pipes as a slope runoff mechanism, Subarctic Yukon, Canada, J. Hydrol., 233, 206-222, doi:10.1016/S0022-1694(00)00234-1.

Chappellaz, J., J. M. Barnola, D. Raynaud, Y. S. Korotkevich, and C. Lorius (1990), Ice-core record of atmospheric methane over the past 160,000 years, Nature, 345, 127-131, doi:10.1038/ $345127 \mathrm{a} 0$.

Chappellaz, J., T. Blunier, D. Raynaud, J. M. Barnola, J. Schwander, and B. Stauffer (1993a), Synchronous changes in atmospheric $\mathrm{CH} 4$ and Greenland climate between 40 and $8 \mathrm{Kyr}$ BP, Nature, 366, 443-445, doi:10.1038/366443a0.

Chappellaz, J. A., I. Y. Fung, and A. M. Thompson (1993b), The atmospheric $\mathrm{CH}_{4}$ increase since the Last Glacial Maximum (1) Source estimates, Tellus, Ser. B, 45, 228-241.
Chappellaz, J. A., T. Blunier, S. Kints, A. Dallenbach, J.-M. Barnola, J. Schwander, D. Raynaud, and B. Stauffer (1997), Changes in the atmospheric $\mathrm{CH}_{4}$ gradient between Greenland and Antarctica during the Holocene, J. Geophys. Res., 102, 15,987-15,997, doi:10.1029/97JD01017.

Chen, Y.-H., and R. G. Prinn (2006), Estimation of atmospheric methane emissions between 1996 and 2001 using a threedimensional global chemical transport model, J. Geophys. Res., 111, D10307, doi:10.1029/2005JD006058.

Christensen, T. R., and P. Cox (1995), Response of methane emission from arctic tundra to climatic change: Results from a model simulation, Tellus, Ser. B, 47, 301-309, doi:10.1034/ j.1600-0889.47.issue3.2.x.

Christensen, T. R., A. Ekberg, L. Ström, M. Mastepanov, N. Panikov, M. Öquist, B. H. Svensson, H. Nykänen, P. J. Martikainen, and H. Oskarsson (2003), Factors controlling large scale variations in methane emissions from wetlands, Geophys. Res. Lett., 30(7), 1414, doi:10.1029/2002GL016848.

Christensen, T. R., T. Johansson, H. J. Aakerman, M. Mastepanov, N. Malmer, T. Friborg, P. Crill, and B. H. Svensson (2004), Thawing sub-arctic permafrost: Effects on vegetation and methane emissions, Geophys. Res. Lett., 31, L04501, doi:10.1029/ 2003GL018680.

Cicerone, R. J. (1988), How has the atmospheric concentration of CO changed?, in The Changing Atmosphere, edited by F. S. Rowland and I. S. A. Isaksen, pp. 44-61, John Wiley, New York. Collins, W. J., R. G. Derwent, C. E. Johnson, and D. S. Stevenson (2002), The oxidation of organic compounds in the troposphere and their global warming potentials, Clim. Change, 52, 453-479, doi:10.1023/A:1014221225434.

Conrad, R., and W. Seiler (1988), Influence of the surface microlayer on the flux of nonconservative trace gases $\left(\mathrm{CO}, \mathrm{H}_{2}, \mathrm{CH}_{4}\right.$, $\mathrm{N}_{2} \mathrm{O}$ ) across the ocean-atmosphere interface, J. Atmos. Chem., 6, 83-94, doi:10.1007/BF00048333.

Cunnold, D. M., et al. (2002), In situ measurements of atmospheric methane at GAGE/AGAGE sites during 1985-2000 and resulting source inferences, J. Geophys. Res., 107(D14), 4225, doi:10.1029/2001JD001226

Dadson, S. J., I. Ashpole, P. Harris, H. N. Davies, D. B. Clark, E. Blyth, and C. M. Taylor (2010), Wetland inundation dynamics in a model of land-surface climate: Evaluation in the Niger inland Delta region, J. Geophys. Res., doi:10.1029/2010JD014474, in press.

Dällenbach, A., T. Blunier, J. Flückiger, B. Stauffer, J. Chappellaz, and D. Raynaud (2000), Changes in the atmospheric $\mathrm{CH}_{4}$ gradient between Greenland and Antarctica during the last glacial and the transition to the Holocene, Geophys. Res. Lett., 27(7), 1005-1008, doi:10.1029/1999GL010873.

Davie, M. K., and B. A. Buffett (2001), A numerical model for the formation of gas hydrate below the seafloor, J. Geophys. Res., 106(B1), 497-514, doi:10.1029/2000JB900363.

Davis, N. (2001), Permafrost: A Guide to Frozen Ground in Transition, Univ. of Alaska Press, Fairbanks.

Decharme, B., H. Douville, C. Prigent, F. Papa, and F. Aires (2008), A new river flooding scheme for global climate applications: Off-line evaluation over South America, J. Geophys. Res., 113, D11110, doi:10.1029/2007JD009376.

Delisle, G. (2007), Near-surface permafrost degradation: How severe during the 21 st century?, Geophys. Res. Lett., 34, L09503, doi:10.1029/2007GL029323.

Denman, K., et al. (2007), Couplings between changes in the climate system and biogeochemistry, in Climate Change 2007: The Physical Science Basis. Contribution of Working Group I to the Fourth Assessment Report of the Intergovernmental Panel on Climate Change, edited by S. Solomon et al., pp. 499-587, Cambridge Univ. Press, Cambridge, U. K.

Dentener, F., W. Peters, M. Krol, M. van Weele, P. Bergamaschi, and J. Lelieveld (2003), Interannual variability and trend of $\mathrm{CH}_{4}$ lifetime as a measure for $\mathrm{OH}$ changes in the 1979-1993 time 
period, J. Geophys. Res., 108(D15), 4442, doi:10.1029/ 2002JD002916.

Dickens, G. R. (1999), The blast in the past, Nature, 401, 752-755, doi:10.1038/44486.

Dickens, G. R. (2001), The potential volume of oceanic methane hydrates with variable external conditions, Org. Geochem., 32, 1179-1193, doi:10.1016/S0146-6380(01)00086-9.

Dickens, G. R. (2003), Rethinking the global carbon cycle with a large, dynamic and microbially mediated gas hydrate capacitor, Earth Planet. Sci. Lett., 213, 169-183, doi:10.1016/S0012821X(03)00325-X.

Dickens, G. R., and M. S. Quinby-Hunt (1994), Methane hydrate stability in seawater, Geophys. Res. Lett., 21, 2115-2118, doi:10.1029/94GL01858.

Dickens, G. R., J. R. O’Neil, D. K. Rea, and R. M. Owen (1995), Dissociation of oceanic methane hydrate as a cause of the carbon isotope excursion at the end of the Paleocene, Paleoceanography, 10, 965-971, doi:10.1029/95PA02087.

Dlugokencky, E. J., K. A. Masarie, P. M. Lang, and P. P. Tans (1998), Continuing decline in the growth rate of the atmospheric methane burden, Nature, 393, 447-450, doi:10.1038/30934.

Dlugokencky, E. J., B. P. Walter, K. A. Masarie, P. M. Lang, and E. S. Kasischke (2001), Measurements of an anomalous global methane increase during 1998, Geophys. Res. Lett., 28(3), 499-502, doi:10.1029/2000GL012119.

Dlugokencky, E. J., S. Houweling, L. Bruhwiler, K. A. Masarie, P. M. Lang, J. B. Miller, and P. P. Tans (2003), Atmospheric methane levels off: Temporary pause or a new steady-state?, Geophys. Res. Lett., 30(19), 1992, doi:10.1029/2003GL018126.

Dlugokencky, E. J., et al. (2009), Observational constraints on recent increases in the atmospheric $\mathrm{CH}_{4}$ burden, Geophys. Res. Lett., 36, L18803, doi:10.1029/2009GL039780.

Driscoll, N. W., J. K. Weissel, and J. A. Goff (2000), Potential for large-scale submarine slope failure and tsunami generation along the US mid-Atlantic coast, Geology, 28(5), 407-410, doi:10.1130/0091-7613(2000)28<407:PFLSSF>2.0.CO;2.

Duan, Z., and S. Mao (2006), A thermodynamic model for calculating methane solubility, density and gas phase composition of methane-bearing aqueous fluids from 273 to $523 \mathrm{~K}$ and from 1 to 2000 bar, Geochimica, 70, 3369-3386, doi:10.1016/j. gca.2006.03.018.

Duan, Z. H., N. Moller, and J. H. Weare (1992), Molecular dynamics simulation of PVT properties of geological fluids and a equation of state of nonpolar and weakly polar gases up to $2000 \mathrm{~K}$ and 20,000 bar, Geochim. Cosmochim. Acta, 56, 3839-3845, doi:10.1016/0016-7037(92)90175-I.

Dugan, B., and P. B. Flemings (2000), Overpressure and fluid flow in the New Jersey continental slope: Implications for slope failure and cold seeps, Science, 289, 288-291, doi:10.1126/science. 289.5477.288.

Dutta, K., E. A. G. Schuur, J. C. Neff, and S. A. Zimov (2006), Potential carbon release from permafrost soils of northeastern Siberia, Global Change Biol., 12, 2336-2351, doi:10.1111/ j.1365-2486.2006.01259.x.

Eliseev, A. V., I. I. Mokhov, M. M. Arzhanov, P. F. Demchenko, and S. N. Denisov (2008), Interaction of the methane cycle and processes in wetland ecosystems in a climate model of intermediate complexity, Izv. Russ. Acad. Sci. Atmos. Oceanic Phys., Engl. Transl., 44, 139-152, doi:10.1134/S0001433808020011.

Essery, R. L. H., M. J. Best, R. A. Betts, P. M. Cox, and C. M. Taylor (2003), Explicit representation of subgrid heterogeneity in a GCM land-surface scheme, J. Hydrometeorol., 4(3), 530-543, doi:10.1175/1525-7541(2003)004<0530:EROSHI >2.0.CO;2.

Etheridge, D. M., L. P. Steele, R. J. Francey, and R. L. Langenfelds (1998), Atmospheric methane between 1000 A.D. and present: Evidence of anthropogenic emissions and climatic variability, J. Geophys. Res., 103(D13), 15,979-15,993, doi:10.1029/ 98JD00923.
Ferretti, D. F., et al. (2005), Unexpected changes to the global methane budget over the past 2000 years, Science, 309, 1714-1717, doi:10.1126/science.1115193.

Field, C., R. Jackson, and H. Mooney (1995), Stomatal responses to increased $\mathrm{CO}_{2}$ : Implications from the plant to the global scale, Plant Cell Environ., 18, 1214-1225, doi:10.1111/j.13653040.1995.tb00630.x.

Fiore, A. M., L. W. Horowitz, E. J. Dlugokencky, and J. J. West (2006), Impact of meteorology and emissions on methane trend, 1990-2004, Geophys. Res. Lett., 33, L12809, doi:10.1029/ 2006 GL026199.

Fischer, H., et al. (2008), Changing boreal methane sources and constant biomass burning during the last termination, Nature, 452, 864-867, doi:10.1038/nature06825.

Fleischer, P. (2001), Distribution of free gas in marine sediments: A global overview, Geo Mar. Lett., 21, 103-122, doi:10.1007/ s003670100072.

Folberth, G. A., D. A. Hauglustaine, J. Lathière, and F. Brocheton (2006), Interactive chemistry in the Laboratoire de Météorologie Dynamique general circulation model: Model description and impact analysis of biogenic hydrocarbons on tropospheric chemistry, Atmos. Chem. Phys., 6, 2273-2319, doi:10.5194/acp-62273-2006.

Forster, P., et al. (2007), Changes in atmospheric constituents and in radiative forcing, in Climate Change 2007: The Physical Science Basis. Contribution of Working Group I to the Fourth Assessment Report of the Intergovernmental Panel on Climate Change, edited by S. Solomon et al., pp. 129-234, Cambridge Univ. Press, Cambridge, U. K.

Frankenberg, C., J. F. Meirink, M. van Weele, U. Platt, and T. Wagner (2005), Assessing methane emission from global space-borne observation, Science, 308, 1010-1014, doi:10.1126/ science. 1106644.

French, H. M. (2007), The Periglacial Environment, John Wiley, Chichester, U. K.

Froese, D. G., J. A. Westgate, A. V. Reyes, R. J. Enkin, and S. J. Preece (2008), Ancient permafrost and a future, warmer Arctic, Science, 321, 1648, doi:10.1126/science.1157525.

Frolking, S., N. T. Roulet, T. R. Moore, P. J. H. Richard, M. Lavoie, and S. D. Muller (2001), Modeling northern peatland decomposition and peat accumulation, Ecosystems, 4, 479-498, doi:10.1007/s10021-001-0105-1.

Frolking, S., N. T. Roulet, T. R. Moore, P. M. Lafleur, J. L. Bubier, and P. M. Crill (2002), Modeling seasonal to annual carbon balance of Mer Bleue Bog, Ontario, Canada, Global Biogeochem. Cycles, 16(3), 1030, doi:10.1029/2001GB001457.

Frost, T. (1999), Environmental control of air-water gas exchange, Ph.D. thesis, Newcastle Univ., Newcastle upon Tyne, U. K.

Fyke, J. G., and A. J. Weaver (2006), The effect of potential future climate change on the marine methane hydrate stability zone, J. Clim., 19, 5903-5917, doi:10.1175/JCLI3894.1.

Garcia, J. L., B. K. C. Patel, and B. Ollivier (2000), Taxonomic, phylogenetic, and ecological diversity of methanogenic Archaea, Anaerobe, 6, 205-226, doi:10.1006/anae.2000.0345.

Gauci, V., E. Matthews, N. Dise, B. Walter, D. Koch, and G. Granberg (2004), Sulfur pollution suppression of the wetland methane source in the 20th and 21st centuries, Proc. Natl. Acad. Sci. U. S. A., 101(34), 12,583-12,587, doi:10.1073/pnas.0404412101.

Gedney, N., and P. M. Cox (2003), The sensitivity of global climate model simulations to the representation of soil moisture heterogeneity, J. Hydrometeorol., 4, 1265-1275, doi:10.1175/1525-7541 (2003)004<1265:TSOGCM $>2.0$. CO;2.

Gedney, N., P. M. Cox, and C. Huntingford (2004), Climate feedback from wetland methane emissions, Geophys. Res. Lett., 31, L20503, doi:10.1029/2004GL020919.

Gillett, N. P., A. J. Weaver, F. W. Zwiers, and M. D. Flannigan (2004), Detecting the effect of climate change on Canadian forest fires, Geophys. Res. Lett., 31, L18211, doi:10.1029/ 2004GL020876. 
Gornitz, V., and I. Fung (1994), Potential distribution of methane hydrates in the worlds oceans, Global Biogeochem. Cycles, 8(3), 335-347, doi:10.1029/94GB00766.

Goryachkin, S. V., H. P. Blume, L. Beyer, I. Campbell, G. Claridge, J. G. Bockheim, N. A. Karavaeva, V. Targulian, and C. Tarnocai (2004), Similarities and differences in Arctic and Antarctic soil zones, in Cryosols, Permafrost-Affected Soils, edited by J. M. Kimble, pp. 49-70, Springer, Berlin.

Goulden, M. L., et al. (1998), Sensitivity of boreal forest carbon balance to soil thaw, Science, 279, 214-217, doi:10.1126/science. 279.5348.214.

Granier, C., G. Petron, J.-F. Müller, and G. Brasseur (2000), The impact of natural and anthropogenic hydrocarbons on the tropospheric budget of carbon monoxide, Atmos. Environ., 34, 52555270, doi:10.1016/S1352-2310(00)00299-5.

Hampton, M. A., H. J. Lee, and J. Locat (1996), Submarine landslides, Rev. Geophys., 34(1), 33-59, doi:10.1029/95RG03287.

Hansen, J., et al. (2005), Efficacy of climate forcings, J. Geophys. Res., 110, D18104, doi:10.1029/2005JD005776.

Harder, S. L., D. T. Shindell, G. A. Schmidt, and E. J. Brook (2007), A global climate model study of $\mathrm{CH}_{4}$ emissions during the Holocene and glacial-interglacial transitions constrained by ice core data, Global Biogeochem. Cycles, 21, GB1011, doi:10.1029/2005GB002680.

Harvey, L. D. D., and Z. Huang (1995), Evaluation of the potential impact of methane clathrate destabilization on future global warming, J. Geophys. Res., 100, 2905-2926, doi:10.1029/ 94JD02829.

Hauglustaine, D. A., G. P. Brasseur, S. Walters, P. J. Rasch, J.-F. Muller, L. K. Emmons, and C. A. Carroll (1998), MOZART, a global chemical transport model for ozone and related chemical tracers: 2. Model results and evaluation, J. Geophys. Res., 103, 28,291-28,335, doi:10.1029/98JD02398.

Heald, C. L., M. J. Wilkinson, R. K. Monson, C. A. Alos, G. Wang, and A. Guenther (2009), Response of isoprene emission to ambient $\mathrm{CO}_{2}$ changes and implications for global budgets, Global Change Biol., 15, 1127-1140, doi:10.1111/j.13652486.2008.01802.x.

Hein, R., P. J. Crutzen, and M. Heimann (1997), An inverse modeling approach to investigate the global atmospheric methane cycle, Global Biogeochem. Cycles, 11, 43-76, doi:10.1029/ 96GB03043.

Hinzman, L. D., et al. (2005), Evidence and implications of recent climate change in Northern Alaska and other Arctic regions, Clim. Change, 72, 251-298, doi:10.1007/s10584-005-5352-2.

Holden, J. (2005), Peatland hydrology and carbon cycling: Why small-scale process matters, Philos. Trans. R. Soc. A, 363 , 2891-2913, doi:10.1098/rsta.2005.1671.

Holden, J., R. Smart, P. J. Chapman, A. J. Baird, and M. Billett (2009), The role of natural soil pipes in water and carbon transfer in and from peatlands, in Northern Peatlands and Carbon Cycling, Geophys. Monogr. Ser., vol. 184, edited by A. J. Baird et al., pp. 251-264, AGU, Washington, DC.

Hornbach, M. J., D. M. Saffer, and W. S. Holbrook (2004), Critically pressured free-gas reservoirs below gas hydrate provinces, Nature, 427, 142-144, doi:10.1038/nature02172.

Hough, A. M., and R. G. Derwent (1990), Changes in the global concentration of tropospheric ozone due to human activities, Nature, 344, 645-648, doi:10.1038/344645a0.

Houweling, S., T. Kaminski, F. Dentener, J. Lelieveld, and M. Heimann (1999), Inverse modelling of methane sources and sinks using the adjoint of a global transport model, J. Geophys. Res., 104(D21), 26,137-26,160, doi:10.1029/1999JD900428.

Houweling, S., F. Dentener, and J. Lelieveld (2000), Simulation of preindustrial atmospheric methane to constrain the global source strength of natural wetlands, J. Geophys. Res., 105(D13), 17,243-17,255, doi:10.1029/2000JD900193.

Huber, C., M. Leuenberger, R. Spahni, J. Flückiger, J. Schwander, T. F. Stocjer, S. Johnsen, A. Landais, and J. Jouzel (2006), Iso- tope calibrated Greenland temperature record over Marine Isotope Stage 3 and its relation to $\mathrm{CH}_{4}$, Earth Planet. Sci. Lett., 243, 504-519, doi:10.1016/j.epsl.2006.01.002.

Hugelius, G., and P. Kuhry (2009), Landscape partitioning and environmental gradient analyses of soil organic carbon in a permafrost environment, Global Biogeochem. Cycles, 23, GB3006, doi:10.1029/2008GB003419.

Ise, T., A. L. Dunn, S. C. Wofsy, and P. R. Moorcroft (2008), High sensitivity of peat decomposition to climate change through water-table feedback, Nat. Geosci., 1, 763-766, doi:10.1038/ ngeo331.

Johns, T. C., et al. (2006), The new Hadley Centre climate model HadGEM1: Evaluation of coupled simulations, J. Clim., 19, 1327-1353, doi:10.1175/JCLI3712.1.

Johnson, C. E., W. J. Collins, D. S. Stevenson, and R. G. Derwent (1999), Relative roles of climate and emissions changes on future tropospheric oxidant concentrations, J. Geophys. Res., 104(D15), 18,631-18,645, doi:10.1029/1999JD900204.

Johnson, C. E., D. S. Stevenson, W. J. Collins, and R. G. Derwent (2001), Role of climate feedback on methane and ozone studied with a coupled Ocean-Atmosphere-Chemistry model, Geophys. Res. Lett., 28, 1723-1726, doi:10.1029/2000GL011996.

Jorgenson, M. T., C. H. Racine, J. C. Walters, and T. E. Osterkamp (2001), Permafrost degradation and ecological changes associated with a warming climate in central Alaska, Clim. Change, 48, 551-579, doi:10.1023/A:1005667424292.

Jorgenson, M. T., Y. L. Shur, and E. R. Pullman (2006), Abrupt increase in permafrost in Arctic Alaska, Geophys. Res. Lett., 33, L02503, doi:10.1029/2005GL024960.

Kaplan, J. O. (2002), Wetlands at the Last Glacial Maximum: Distribution and methane emissions, Geophys. Res. Lett., 29(6), 1079, doi:10.1029/2001GL013366.

Kaplan, J. O., G. Folberth, and D. A. Hauglustaine (2006), Role of methane and biogenic volatile organic compound sources in late glacial and Holocene fluctuations of atmospheric methane concentrations, Global Biogeochem. Cycles, 20, GB2016, doi:10.1029/2005GB002590.

Karlsdóttir, S., and I. S. A. Isaksen (2000), Changing methane lifetime: Possible cause for reduced growth, Geophys. Res. Lett., 27, 93-96, doi:10.1029/1999GL010860.

Kasischke, E. S., and M. R. Turetsky (2006), Recent changes in the fire regime across the North American boreal region-Spatial and temporal patterns of burning across Canada and Alaska, Geophys. Res. Lett., 33, L09703, doi:10.1029/2006GL025677.

Katz, M. E., D. K. Pak, G. R. Dickens, and K. G. Miller (1999), The source and fate of massive carbon input during the latest Paleocene Thermal Maximum, Science, 286, 1531-1533, doi:10.1126/science.286.5444.1531.

Katz, M. E., B. S. Cramer, G. S. Mountain, S. Katz, and K. G. Miller (2001), Uncorking the bottle: What triggered the Paleocene/ Eocene thermal maximum methane release?, Paleoceanography, 16, 549-562, doi:10.1029/2000PA000615.

Kennett, J., and L. D. Stott (1991), Abrupt deep sea warming, paleoceanographic changes and benthic extinctions at the end of the Paleocene, Nature, 353, 225-229, doi:10.1038/353225a0.

Kennett, J. P., K. G. Cannariato, I. L. Hendy, and R. J. Behl (2000), Carbon isotopic evidence for methane hydrate instability during Quaternary interstadials, Science, 288, 128-133, doi:10.1126/science.288.5463.128.

Kennett, J. P., K. G. Cannariato, I. L. Hendy, and R. J. Behl (2002), Methane Hydrates in Quaternary Climate Change: The Clathrate Gun Hypothesis, AGU, Washington, D. C.

Khalil, M., R. Rasmussen, M. Shearer, R. Dalluge, L. Ren, and C.-L. Duan (1998), Factors affecting methane emissions from rice fields, J. Geophys. Res., 103(D19), 25,219-25,231, doi:10.1029/ 98JD01115.

Khvorostyanov, D., G. Krinner, P. Ciais, M. Heimann, and S. A. Zimov (2008a), Vulnerability of permafrost carbon to global warming. Part I: Model description and role of heat generated 
by organic matter decomposition, Tellus, Ser. B, 60(2), 250-264, doi:10.1111/j.1600-0889.2007.00333.x.

Khvorostyanov, D., P. Ciais, G. Krinner, S. A. Zimov, C. Corradi, and G. Guggenberger (2008b), Vulnerability of permafrost carbon to global warming. Part II. Sensitivity of permafrost carbon stock to global warming, Tellus, Ser. B, 60(2), 265-275, doi:10.1111/j.1600-0889.2007.00336.x.

Khvorostyanov, D., P. Ciais, G. Krinner, and S. A. Zimov (2008c), Vulnerability of East Siberia's frozen carbon stores to future warming, Geophys. Res. Lett., 35, L10703, doi:10.1029/ 2008 GL033639.

Klauda, J. B., and S. I. Sandler (2005), Global distribution of methane hydrate in ocean sediment, Energy Fuels, 19, 459-470, doi:10.1021/ef049798o.

Koch, P. L., J. C. Zachos, and P. Gingerich (1992), Correlation between isotope record in marine and continental carbon reservoirs near the Palaeocene/Eocene boundary, Nature, 358, 319-322, doi:10.1038/358319a0.

Krol, M. C., and J. Lelieveld (2003), Can the variability in tropospheric $\mathrm{OH}$ be deduced from measurements of 1,1,1-trichloroethane (methyl chloroform)?, J. Geophys. Res., 108(D3), 4125, doi:10.1029/2002JD002423.

Krol, M. C., J. Lelieveld, D. E. Oram, G. A. Sturrock, S. A. Penkett, C. A. M. Brenninkmeijer, V. Gros, J. Williams, and H. A. Scheeren (2003), Continuing emissions of methyl chloroform from Europe, Nature, 421, 131-135, doi:10.1038/nature01311.

Kuhry, P., and J. Turonen (2006), The postglacial development of boreal and subarctic peatlands, in Boreal Peatland Ecosystems, pp. 25-46, doi:10.1007/978-3-540-31913-9_3, Springer, Berlin.

Kvenvolden, K. A. (1988), Methane hydrate-A major reservoir of carbon in the shallow geosphere?, Chem. Geol., 71, 41-51, doi:10.1016/0009-2541(88)90104-0.

Kvenvolden, K. A. (1993), Gas hydrates - Geological perspective and global change, Rev. Geophys., 31(2), 173-187, doi:10.1029/ 93RG00268.

Kvenvolden, K. A. (1999), Potential effects of gas hydrate on human welfare, Proc. Natl. Acad. Sci. U. S. A., 96, 3420-3426, doi:10.1073/pnas.96.7.3420.

Kvenvolden, K. A., and T. D. Lorenson (2001), The global occurrence of natural gas hydrates, in Natural Gas Hydrates: Occurrence, Distribution, and Detection, Geophys. Monogr. Ser., vol. 124, edited by C. K. Paull and W. P. Dillon, pp. 3-18, AGU, Washington, D. C.

Lachenbruch, A. H. (1968), Rapid estimation of the topographic disturbance to superficial thermal gradients, Rev. Geophys., 6, 365-400, doi:10.1029/RG006i003p00365.

Lafleur, P. M., N. T. Roulet, J. L. Bubier, S. Frolking, and T. R. Moore (2003), Interannual variability in the peatland-atmosphere carbon dioxide exchange at an ombrotrophic bog, Global Biogeochem. Cycles, 17(2), 1036, doi:10.1029/2002GB001983.

Lamarque, J.-F. (2008), Estimating the potential for methane clathrate instability in the $1 \%-\mathrm{CO}_{2}$ IPCC AR-4 simulations, Geophys. Res. Lett., 35, L19806, doi:10.1029/2008GL035291.

Langenfelds, R. L., R. J. Francey, B. C. Pak, L. P. Steele, J. Lloyd, C. M. Trudinger, and C. E. Allison (2002), Interannual growth rate variations of atmospheric $\mathrm{CO}_{2}$ and its $\delta^{13} \mathrm{C}, \mathrm{H}_{2}, \mathrm{CH}_{4}$, and CO between 1992 and 1999 linked to biomass burning, Global Biogeochem. Cycles, 16(3), 1048, doi:10.1029/2001GB001466.

Lathière, J., D. A. Hauglustaine, N. de Noblet-Ducoudré, G. Krinner, and G. A. Folberth (2005), Past and future changes in biogenic volatile organic compound emissions simulated with a global dynamic vegetation model, Geophys. Res. Lett., 32, L20818, doi:10.1029/2005GL024164.

Lathière, J., D. A. Hauglustaine, A. D. Friend, N. de NobletDucoudré, N. Viovy, and G. A. Folberth (2006), Impact of climate variability and land use changes on global biogenic volatile organic compound emissions, Atmos. Chem. Phys., 6, 21292146, doi:10.5194/acp-6-2129-2006.
Lawrence, D. M., and A. G. Slater (2005), A projection of severe near-surface permafrost degradation during the 21 st century, Geophys. Res. Lett., 32, L24401, doi:10.1029/2005GL025080.

Lawrence, D. M., and A. G. Slater (2006), Reply to comment by C. R. Burn and F. E. Nelson on "A projection of near surface permafrost degradation during the 21st century", Geophys. Res. Lett., 33, L21504, doi:10.1029/2006GL027955.

Lawrence, D. M., A. G. Slater, V. E. Romanovsky, and D. J. Nicolsky (2008a), Sensitivity of a model projection of nearsurface permafrost degradation to soil column depth and representation of soil organic matter, J. Geophys. Res., 113, F02011, doi:10.1029/2007JF000883.

Lawrence, D. M., A. G. Slater, R. A. Tomas, M. M. Holland, and C. Deser (2008b), Accelerated Arctic land warming and permafrost degradation during rapid sea ice loss, Geophys. Res. Lett., 35, L11506, doi:10.1029/2008GL033985.

Lelieveld, J., W. Peters, F. J. Dentener, and M. C. Krol (2002), Stability of tropospheric hydroxyl chemistry, J. Geophys. Res., 107(D23), 4715, doi:10.1029/2002JD002272.

Lelieveld, J., F. J. Dentener, W. Peters, and M. C. Krol (2004), On the role of hydroxyl radicals in the self-cleansing capacity of the troposphere, Atmos. Chem. Phys., 4, 2337-2344, doi:10.5194/ acp-4-2337-2004.

Lelieveld, J., et al. (2008), Atmospheric oxidation capacity sustained by a tropical forest, Nature, 452, 737-740, doi:10.1038/ nature 06870.

Letts, M. G., N. T. Roulet, N. T. Comer, M. R. Skarupa, and D. L. Verseghy (2000), Parametrization of peatland hydraulic properties for the Canadian Land Surface Scheme, Atmos. Ocean, 38, $141-160$

Levy, H., II (1971), Normal atmosphere: Large radical and formaldehyde concentrations predicted, Science, 173, 141-143, doi:10.1126/science.173.3992.141.

Liljedahl, A., L. Hinzman, R. Busey, and K. Yoshikawa (2007), Physical short-term changes after a tussock fire, Seward Peninsula, Alaska, J. Geophys. Res., 112, F02S07, doi:10.1029/ 2006JF000554.

Lorius, C., J. Jouzel, D. Raynaud, J. Hansen, and H. Le Treut (1990), The ice-core record: Climate sensitivity and future greenhouse warming, Nature, 347, 139-145, doi:10.1038/347139a0.

Loulergue, L., A. Schilt, R. Spahni, V. Masson-Delmotte, T. Blunier, B. Lemieux, J.-M. Barnola, D. Raynaud, T. F. Stocker, and J. E. Chappellaz (2008), Orbital and millennial-scale features of atmospheric $\mathrm{CH}_{4}$ over the past 800,000 years, Nature, 453, 383-386, doi:10.1038/nature 06950

Lowe, D. C., M. R. Manning, G. W. Brailsford, and A. M. Bromley (1997), The 1991-1992 atmospheric methane anomaly: Southern Hemisphere ${ }^{13} \mathrm{C}$ decrease and growth rate fluctuations, Geophys. Res. Lett., 24(8), 857-860, doi:10.1029/97GL00830.

Manning, M. R., D. C. Lowe, R. C. Moss, G. E. Bodeker, and W. Allan (2005), Short-term variations in the oxidizing power of the atmosphere, Nature, 436, 1001-1004, doi:10.1038/nature03900.

Marchenko, S., V. E. Romanovsky, and G. Tipenko (2008), Numerical modeling of spatial permafrost dynamics in Alaska, in Ninth International Conference on Permafrost, edited by D. L. Kane and K. M. Hinkel, pp. 1125-1130, Inst. of North. Eng., Univ. of Alaska Fairbanks, Fairbanks.

Mastepanov, M., C. Sigsgaard, E. J. Dlugokencky, S. Houweling, L. Ström, M. P. Tamstorf, and T. R. Christensen (2008), Large tundra methane burst during onset of freezing, Nature, 456, 628-630, doi:10.1038/nature07464.

Matthews, E., and I. Fung (1987), Methane emission from natural wetlands: Global distribution, area, and environmental characteristics of sources, Global Biogeochem. Cycles, 1(1), 61-86, doi:10.1029/GB001i001p00061.

Mau, S., D. L. Valentine, J. F. Clark, J. Reed, R. Camilli, and L. Washburn (2007), Dissolved methane distributions and air-sea flux in the plume of a massive seep field, Coal Oil Point, California, Geophys. Res. Lett., 34, L22603, doi:10.1029/2007GL031344. 
McGinnis, D. F., J. Greinert, Y. Artemov, S. E. Beaubien, and A. Wüest (2006), Fate of rising methane bubbles in stratified waters: How much methane reaches the atmosphere?, J. Geophys. Res., 111, C09007, doi:10.1029/2005JC003183.

Meehl, G. A., et al. (2007), Global climate projections, in Climate Change 2007: The Physical Science Basis-Contribution of Working Group I to the Fourth Assessment Report of the Intergovernmental Panel on Climate Change, edited by S. Solomon et al., pp. 747-845, Cambridge Univ. Press, Cambridge, U. K.

Michaelson, G. J., and C. L. Ping (2003), Soil organic carbon and $\mathrm{CO}_{2}$ respiration at subzero temperature in soils of Arctic Alaska, J. Geophys. Res., 108(D2), 8164, doi:10.1029/2001JD000920.

Mikaloff Fletcher, S. E., P. P. Tans, L. M. Bruhwiler, J. B. Miller, and M. Heimann (2004a), $\mathrm{CH}_{4}$ sources estimated from atmospheric observations of $\mathrm{CH}_{4}$ and its ${ }^{13} \mathrm{C} /{ }^{12} \mathrm{C}$ isotopic ratios: 1. Inverse modeling of source processes, Global Biogeochem. Cycles, 18, GB4004, doi:10.1029/2004GB002223.

Mikaloff Fletcher, S. E., P. P. Tans, L. M. Bruhwiler, J. B. Miller, and M. Heimann (2004b), $\mathrm{CH}_{4}$ sources estimated from atmospheric observations of $\mathrm{CH}_{4}$ and its ${ }^{13} \mathrm{C} /{ }^{12} \mathrm{C}$ isotopic ratios: 2. Inverse modeling of $\mathrm{CH}_{4}$ fluxes from geographical regions, Global Biogeochem. Cycles, 18, GB4005, doi:10.1029/ 2004GB002224.

Milkov, A. V. (2004), Global estimates of hydrate-bound gas in marine sediments: How much is really out there?, Earth Sci. Rev., 66, 183-197, doi:10.1016/j.earscirev.2003.11.002.

Milkov, A. V., G. E. Claypool, Y.-J. Lee, W. Xu, G. R. Dickens, W. S. Borowski, and ODP Leg 204 Scientific Party (2003), In situ methane concentrations, at Hydrate Ridge, offshore Oregon: New constraints on the global gas hydrate inventory from an active margin, Geology, 31(10), 833-836.

Moll, A., and G. Radach (2003), Review of three-dimensional ecological modelling related to the North Sea shelf system: Part 1: Models and their results, Prog. Oceanogr., 57(2), 175-217, doi:10.1016/S0079-6611(03)00067-3.

Monnin, E., A. Indermühle, A. Dällenbach, J. Flückiger, B. Stauffer, T. F. Stocker, D. Raynaud, and J.-M. Barnola (2001), Atmospheric $\mathrm{CO}_{2}$ concentrations over the last glacial termination, Science, 291, 112-114, doi:10.1126/science.291.5501.112.

Monson, R. K., et al. (2007), Isoprene emissions from terrestrial ecosystems in response to global change: Minding the gap between models and observations, Philos. Trans. R. Soc., 365 , 1677-1695, doi:10.1098/rsta.2007.2038.

Moore, T. R., N. T. Roulet, and J. M. Waddington (1998), Uncertainty in predicting the effect of climatic change on the carbon cycling for Canadian peatlands, Clim. Change, 40, 229-245, doi:10.1023/A:1005408719297.

Moqsud, M. A., S. Hayashi, Y. J. Du, and D. Suetsugu (2008), Appraisal of thermal properties of mud in the Ariake Sea, Japan, Am. J. Environ. Sci., 4, 129-135, doi:10.3844/ajessp.2008.129. 135.

Morimoto, S., S. Aoki, T. Nakazawa, and T. Yamanouchi (2006), Temporal variations of the carbon isotopic ratio of atmospheric methane observed at Ny Ålesund, Svalbard from 1996 to 2004, Geophys. Res. Lett., 33, L01807, doi:10.1029/2005GL024648.

Nakićenović, N., et al. (2000), IPCC Special Report on Emissions Scenarios, 599 pp., Cambridge Univ. Press, Cambridge, U. K.

Newson, T. A., and P. Brunning (2004), Thermal conductivity of deepwater offshore sediments, Int. J. Offshore Polar Eng., 14, 310-314.

Nisbet, E. G. (1992), Sources of atmospheric $\mathrm{CH}_{4}$ in early Postglacial time, J. Geophys. Res., 97(D12), 12,859-12,867.

Nixon, J. F. (1983), Practical applications of a geothermal simulator, J. Energy Resour. Technol., 105, 442-447, doi:10.1115/ 1.3230950

Norris, R. D., and U. Röhl (1999), Carbon cycling and chronology of climate warming during the Palaeocene/Eocene transition, Nature, 401, 775-778, doi:10.1038/44545.
Oelke, C., T. Zhang, and M. C. Serreze (2004), Modeling evidence for recent warming of the Arctic soil thermal regime, Geophys. Res. Lett., 31, L07208, doi:10.1029/2003GL019300.

Olivier, J. G. J., J. A. van Aardenne, F. J. Dentener, V. Pagliari, L. N. Ganzeveld, and J. A. H. W. Peters (2005), Recent trends in global greenhouse emissions: Regional trends 1970-2000 and spatial distribution of key sources in 2000, Environ. Sci., 2, 81-99, doi:10.1080/15693430500400345.

Osterkamp, T. E., L. Viereck, Y. Shur, M. T. Jorgenson, C. Racine, A. Doyle, and R. D. Boone (2000), Observations of thermokarst and its impact on boreal forests in Alaska, USA, Arct. Antarct. Alp. Res., 32, 303-315, doi:10.2307/1552529.

Paull, C. K., W. Ussler, and W. P. Dillon (1991), Is the extent of glaciation limited by marine gas-hydrates?, Geophys. Res. Lett., 18, 432-434, doi:10.1029/91GL00351.

Paull, C. K., P. Brewer, W. Ussler, E. Peltzer, G. Rehder, and D. Clague (2003), An experiment demonstrating that marine slumping is a mechanism to transfer methane from seafloor gas-hydrate deposits into the upper ocean and atmosphere, Geo Mar. Lett., 22, 198-203, doi:10.1007/s00367-002-0113-y.

Paull, C. K., W. Ussler III, S. R. Dallimore, S. M. Blasco, T. D. Lorenson, H. Melling, B. E. Medioli, F. M. Nixon, and F. A. McLaughlin (2007), Origin of pingo-like features on the Beaufort Sea shelf and their possible relationship to decomposing methane gas hydrates, Geophys. Res. Lett., 34, L01603, doi:10.1029/ 2006GL027977.

Pegoraro, E., A. Rey, J. Greenberg, P. Harley, J. Grace, Y. Malhi, and A. Guenther (2004), Effect of drought on isoprene emission rates from leaves of Quercus virginiana Mill, Atmos. Environ., 38(36), 6149-6156, doi:10.1016/j.atmosenv.2004.07.028.

Platt, U., W. Allan, and D. Lowe (2004), Hemispheric average Cl atom concentration from ${ }^{13} \mathrm{C} /{ }^{12} \mathrm{C}$ ratios in atmospheric methane, Atmos. Chem. Phys., 4, 2393-2399, doi:10.5194/acp-4-23932004.

Prather, M. J., et al. (2001), Atmospheric chemistry and greenhouse gases, in Climate Change 2001: The Scientific BasisContributions of Working Group I to the Third Assessment Report of the IPCC, edited by J. T. Houghton et al., pp. 239287, Cambridge Univ. Press, New York.

Prigent, C., F. Papa, F. Aires, W. B. Rossow, and E. Matthews (2007), Global inundation dynamics inferred from multiple satellite observations, 1993-2000, J. Geophys. Res., 112, D12107, doi:10.1029/2006JD007847.

Prinn, R. G., et al. (2005), Evidence for variability of atmospheric hydroxyl radicals over the past quarter century, Geophys. Res. Lett., 32, L07809, doi:10.1029/2004GL022228.

Putkonen, J. (2008), What dictates the occurrence of zero curtain effect?, in Ninth International Conference on Permafrost, edited by D. L. Kane and K. M. Hinkel, pp. 1451-1455, Inst. of North. Eng., Univ. of Alaska Fairbanks, Fairbanks.

Rachold, V., D. Y. Bolshyanov, M. N. Grigoriev, H.-W. Hubberten, R. Junker, V. V. Kunitsky, F. Merker, P. Overduin, and W. Schneider (2007), Nearshore Arctic subsea permafrost in transition, Eos Trans. AGU, 88(13), 149, doi:10.1029/2007EO130001.

Ramaswamy, V., O. Boucher, J. Haigh, D. Hauglustaine, J. Haywood, G. Myhre, T. Nakajima, G. Y. Shi, and S. Solomon (2001), Radiative forcing of climate change, in Climate Change 2001: The Scientific Basis-Contributions of Working Group I to the Third Assessment Report of the IPCC, edited by J. T. Houghton et al., pp. 239-287, Cambridge Univ. Press, New York. Rasmussen, R. A., and M. A. K. Khalil (1984), Atmospheric methane in the recent and ancient atmospheres: Concentrations, trends, and interhemispheric gradient, J. Geophys. Res., 89(D7), 11,599-11,605, doi:10.1029/JD089iD07p11599.

Reagan, M. T., and G. J. Moridis (2009), Large-scale simulation of methane hydrate dissociation along the West Spitsbergen Margin, Geophys. Res. Lett., 36, L23612, doi:10.1029/2009GL041332.

Rehder, G., R. Keir, E. Suess, and M. Rhein (1999), Methane in the Northern Atlantic controlled by microbial oxidation and 
atmospheric history, Geophys. Res. Lett., 26, 587-590, doi:10.1029/1999GL900049.

Rehder, G., P. W. Brewer, E. T. Peltzer, and G. Friederich (2002), Enhanced lifetime of methane bubble streams within the deep ocean, Geophys. Res. Lett., 29(15), 1731, doi:10.1029/ $2001 \mathrm{GL} 013966$.

Ridgwell, A. J., S. J. Marshall, and K. Gregson (1999), Consumption of atmospheric methane by soils: A process-based model, Global Biogeochem. Cycles, 13, 59-70, doi:10.1029/ 1998GB900004.

Rigby, M., et al. (2008), Renewed growth of atmospheric methane, Geophys. Res. Lett., 35, L22805, doi:10.1029/2008GL036037.

Ringeval, B., N. de Noblet-Ducoudré, P. Ciais, P. Bousquet, C. Prigent, F. Papa, and W. B. Rossow (2010), An attempt to quantify the impact of changes in wetland extent on methane emissions on the seasonal and interannual time scales, Global Biogeochem. Cycles, 24, GB2003, doi:10.1029/2008GB003354.

Riseborough, D., N. Shiklomanov, B. Etzelmuller, S. Gruber, and S. Marchenko (2008), Recent advances in permafrost modelling, Permafrost Periglacial Processes, 19, 137-156, doi:10.1002/ ppp.615.

Rothwell, R. G., M. S. Reeder, G. Anastasakis, D. A. V. Stow, J. Thomson, and G. Kahler (2000), Low sea-level stand emplacement of megaturbidites in the western and eastern Mediterranean Sea, Sediment. Geol., 135(1-4), 75-88.

Roulet, N., T. Moore, J. Bubier, and P. Lafleur (1992), Northern fens: Methane flux and climatic change, Tellus, Ser. B, 44, 100-105.

Sanderson, M. G., C. D. Jones, W. J. Collins, C. E. Johnson, and R. G. Derwent (2003), Effect of climate change on isoprene emissions and surface ozone levels, Geophys. Res. Lett., 30(18), 1936, doi:10.1029/2003GL017642.

Schimel, D. S., B. H. Braswell, E. A. Holland, R. McKeown, D. S. Ojima, T. H. Painter, W. J. Parton, and A. R. Townsend (1994), Climatic, edaphic, and biotic controls over storage and turnover of carbon in soils, Global Biogeochem. Cycles, 8(3), 279-293, doi:10.1029/94GB00993.

Schuur, E. A. G., et al. (2008), Vulnerability of permafrost carbon to climate change: Implications for the global carbon cycle, Bioscience, 58, 701-714, doi:10.1641/B580807.

Sclater, J. G., C. E. Corry, and V. Vacquier (1969), In situ measurement of the thermal conductivity of ocean-floor sediments, J. Geophys. Res., 74(4), 1070-1081, doi:10.1029/JB074i004p01070.

Scranton, M. I., and P. G. Brewer (1978), Consumption of dissolved methane in the deep ocean, Limnol. Oceanogr., 23(6), 1207-1213, doi:10.4319/lo.1978.23.6.1207.

Shakhova, N., I. Semiletov, and G. Panteleev (2005), The distribution of methane on the Siberian Arctic shelves: Implications for the marine methane cycle, Geophys. Res. Lett., 32, L09601, doi:10.1029/2005GL022751.

Shakhova, N., I. Semiletov, A. Salyuk, V. Yusupov, D. Kosmach, and Ö. Gustafsson (2010), Extensive methane venting to the atmosphere from sediments of the East Siberian Arctic Shelf, Science, 327, 1246-1250, doi:10.1126/science.1182221.

Shindell, D. T., B. P. Walter, and G. Faluvegi (2004), Impacts of climate change on methane emissions from wetlands, Geophys. Res. Lett., 31, L21202, doi:10.1029/2004GL021009.

Shindell, D. T., G. Faluvegi, N. Bell, and G. A. Schmidt (2005), An emissions-based view of climate forcing by methane and tropospheric ozone, Geophys. Res. Lett., 32, L04803, doi:10.1029/ 2004GL021900.

Shindell, D. T., G. Faluvegi, D. M. Koch, G. A. Schmidt, N. Unger, and S. E. Bauer (2009), Improved attribution of climate forcing to emissions, Science, 326, 716-718, doi:10.1126/science.1174760.

Shur, Y. L., and M. T. Jorgenson (2007), Patterns of permafrost formation and degradation in relation to climate and ecosystems, Permafrost Periglacial Processes, 18, 7-19, doi:10.1002/ ppp.582.
Sitch, S., A. D. McGuire, J. Kimball, N. Gedney, J. Gamon, R. Engstrom, A. Wolf, Q. Zhuang, J. Clein, and K. McDonald (2007a), Assessing the carbon balance of circumpolar Arctic tundra using remote sensing and process modeling, Ecol. Appl., 17, 213-234, doi:10.1890/1051-0761(2007)017[0213:ATCBOC] 2.0.CO;2.

Sitch, S., P. M. Cox, W. J. Collins, and C. Huntingford (2007b), Indirect radiative forcing of climate change through ozone effects on the land-carbon sink, Nature, 448, 791-794, doi:10.1038/ nature 06059 .

Sitch, S., et al. (2008), Evaluation of the terrestrial carbon cycle, future plant geography and climate-carbon cycle feedbacks using five Dynamic Global Vegetation Models (DGVMs), Global Change Biol., 14(9), 2015-2039, doi:10.1111/j.1365-2486. 2008.01626.x.

Sloan, E. D. (2003), Fundamental principles and applications of natural gas hydrates, Nature, 426, 353-363, doi:10.1038/ nature 02135 .

Sloan, E. D., and C. A. Koh (2008), Clathrate Hydates of Natural Gases, 3rd ed., CRC Press, Boca Raton, Fla.

Smith, S. L., M. M. Burgess, D. Riseborough, and F. M. Nixon (2005), Recent trends from Canadian permafrost thermal monitoring network sites, Permafrost Periglacial Processes, 16(1), 19-30, doi:10.1002/ppp.511.

Soja, A. J., N. M. Tchebakove, N. H. F. French, M. D. Flannigan, H. H. Shugart, B. J. Stocks, A. I. Sukhinin, E. I. Parfenova, F. S. Chapin III, and P. W. Stackhouse Jr. (2007), Climate-induced boreal forest change: Predictions versus current observations, Global Planet. Change, 56, 274-296, doi:10.1016/j.gloplacha. 2006.07.028.

Sowers, T. (2006), Late quaternary atmospheric $\mathrm{CH}_{4}$ isotope record suggests marine clathrates are stable, Science, 311, 838-840, doi:10.1126/science.1121235.

Steele, L. P., E. J. Dlugokencky, P. M. Lang, P. P. Tans, R. C. Martin, and K. A. Masarie (1992), Slowing down of the global accumulation of atmospheric methane during the 1980s, Nature, 358, 313-316, doi:10.1038/358313a0.

Stevenson, D. S., et al. (2006), Multimodel ensemble simulations of present-day and near-future tropospheric ozone, J. Geophys. Res., 111, D08301, doi:10.1029/2005JD006338.

Stocks, B. J., et al. (1998), Climate change and forest fire potential in Russian and Canadian boreal forests, Clim. Change, 38, 1-13, doi:10.1023/A:1005306001055.

Stokstad, E. (2004), Defrosting the carbon freezer of the north, Science, 304, 1618-1620, doi:10.1126/science.304.5677.1618.

Stott, P. A., G. S. Jones, J. A. Lowe, P. Thorne, C. Durman, T. C. Johns, and J.-C. Thelen (2006), Transient climate simulations with the HadGEM1 climate model: Causes of past warming and future climate change, J. Clim., 19(12), 2763-2782, doi:10.1175/JCLI3731.1

Sturm, M., C. Racine, and K. Tape (2001), Increasing shrub abundance in the Arctic, Nature, 411, 546-547, doi:10.1038/ 35079180 .

Tarnocai, C., and V. Stolbovoy (2006), Northern peatlands: Their characteristics, development and sensitivity to climate change, in Peatlands: Evolution and Records of Environmental and Climate Changes, Dev. Earth Surface Processes, vol. 9, edited by I. P. Martini, A. Martinez Cortizas, and W. Chesworth, chap. 2, pp. 17-51, doi:10.1016/S0928-2025(06)09002-X, Elsevier, Amsterdam.

Tarnocai, C., J. G. Canadell, E. A. G. Schuur, P. Kuhry, G. Mazhitova, and S. Zimov (2009), Soil organic carbon pools in the northern circumpolar permafrost region, Global Biogeochem. Cycles, 23, GB2023, doi:10.1029/2008GB003327.

Telford, P. J., et al. (2010), Effects of climate induced changes in isoprene emissions after the eruption of Mount Pinatubo, Atmos. Chem. Phys., 10, 7117-7125, doi:10.5194/acp-10-7117-2010. 
Turetsky, M. R., R. K. Wieder, and D. H. Vitt (2002), Boreal peatland $\mathrm{C}$ fluxes under varying permafrost regimes, Soil Biol. Biochem., 34(7), 907-912, doi:10.1016/S0038-0717(02)00022-6. Upstill-Goddard, R. C., T. Frost, G. R. Henry, M. Franklin, J. C. Murrell and N. J. P. Owens (2003), Bacterioneuston control of air-water methane exchange determined with a laboratory gas exchange tank, Global Biogeochem. Cycles, 17(4), 1108, doi:10.1029/2003GB002043.

Valdes, P. J., D. J. Beerling, and C. E. Johnson (2005), The ice age methane budget, Geophys. Res. Lett., 32, L02704, doi:10.1029/ 2004GL021004.

van Aardenne, J. A., F. J. Dentener, J. G. J. Olivier, C. G. M. Klein Goldewijk, and J. Lelieveld (2001), A $1^{\circ} \times 1^{\circ}$ resolution data set of historical anthropogenic trace gas emissions for the period 1890-1990, Global Biogeochem. Cycles, 15(4), 909-928, doi:10.1029/2000GB001265.

van der Werf, G. R., J. T. Randerson, L. Giglio, G. J. Collatz, P. S. Kasibhatla, and A. F. Arellano Jr. (2006), Interannual variability in global biomass burning emissions from 1997 to 2004, Atmos. Chem. Phys., 6, 3423-3441, doi:10.5194/acp-6-3423-2006.

Vogt, P. R., and W. Y. Jung (2002), Holocene mass wasting on upper non-Polar continental slopes-due to post-Glacial ocean warming and hydrate dissociation?, Geophys. Res. Lett., 29(9), 1341, doi:10.1029/2001GL013488.

Volodin, E. M. (2008), Methane cycle in the INM RAS climate model, Izv. Russ. Acad. Sci. Atmos. Oceanic Phys., Engl. Transl., 44, 153-159, doi:10.1134/S0001433808020023.

von Kuhlmann, R., M. G. Lawrence, U. Pöschl, and P. J. Crutzen (2004), Sensitivities in global scale modeling of isoprene, Atmos. Chem. Phys., 4, 1-17, doi:10.5194/acp-4-1-2004.

Wadham, J. L., M. Tranter, S. Tulaczyk, and M. Sharp (2008), Subglacial methanogenesis: A potential climatic amplifier?, Global Biogeochem. Cycles, 22, GB2021, doi:10.1029/ 2007GB002951.

Walter, B. P., and M. Heimann (2000), A process-based, climatesensitive model to derive methane emissions from natural wetlands: Application to five wetland sites, sensitivity to model parameters, and climate, Global Biogeochem. Cycles, 14(3), 745-765, doi:10.1029/1999GB001204.

Walter, B. P., M. Heimann, and E. Matthews (2001a), Modeling modern methane emissions from natural wetlands: 1. Model description and results, J. Geophys. Res., 106(D24), 34,18934,206, doi:10.1029/2001JD900165.

Walter, B. P., M. Heimann, and E. Matthews (2001b), Modeling modern methane emissions from natural wetlands: 2 . Interannual variations 1982-1993, J. Geophys. Res., 106(D24), 34,20734,219, doi:10.1029/2001JD900164.

Walter, K. M., L. C. Smith, and F. S. Chapin (2007), Methane bubbling from northern lakes: Present and future contributions to the global methane budget, Philos. Trans. R. Soc., 365, 1657-1676, doi:10.1098/rsta.2007.2036.

Wang, J. S., J. A. Logan, M. B. McElroy, B. N. Duncan, I. A. Megretskaia, and R. M. Yantosca (2004), A 3-D model analysis of the slowdown and interannual variability in the methane growth rate from 1988 to 1997, Global Biogeochem. Cycles, 18, GB3011, doi:10.1029/2003GB002180.

Wania, R. (2007), Modelling northern peatlands land surface processes, vegetation dynamics and methane emissions, Ph.D. thesis, Univ. of Bristol, Bristol, U. K.

Wania, R., I. Ross, and I. C. Prentice (2009a), Integrating peatlands and permafrost into a dynamic global vegetation model: 1. Evaluation and sensitivity of physical land surface processes, Global Biogeochem. Cycles, 23, GB3014, doi:10.1029/2008GB003412.

Wania, R., I. Ross, and I. C. Prentice (2009b), Integrating peatlands and permafrost into a dynamic global vegetation model: 2 . Evaluation and sensitivity of vegetation and carbon cycle processes, Global Biogeochem. Cycles, 23, GB3015, doi:10.1029/ $2008 \mathrm{~GB} 003413$.
Ward, B. B., K. A. Kilpatrick, P. C. Novelli, and M. I. Scranton (1987), Methane oxidation and methane fluxes in the ocean surface layer and deep anoxic waters, Nature, 327, 226-229, doi:10.1038/327226a0

Warwick, N. J., S. Bekki, K. S. Law, E. G. Nisbet, and J. A. Pyle (2002), The impact of meteorology on the interannual growth rate of atmospheric methane, Geophys. Res. Lett., 29(20), 1947, doi:10.1029/2002GL015282.

Weitemeyer, K. A., and B. A. Buffett (2006), Accumulation and release of methane from clathrates below the Laurentide and Cordilleran ice sheets, Global Planet. Change, 53, 176-187, doi:10.1016/j.gloplacha.2006.03.014.

Westbrook, G. K., et al. (2009), Escape of methane gas from the seabed along the West Spitsbergen continental margin, Geophys. Res. Lett., 36, L15608, doi:10.1029/2009GL039191.

Williams, P. J., and M. W. Smith (1989), The Frozen Earth: Fundamentals of Geocryology, doi:10.1017/CBO9780511564437, Cambridge Univ. Press, Cambridge, U. K.

Wolff, E. W., J. Chappellaz, T. Blunier, S. O. Rasmussen, and A. Svensson (2010), Millennial-scale variability during the last glacial: The ice core record, Quat. Sci. Rev., 29(21-22), 28282838, doi:10.1016/j.quascirev.2009.10.013.

Wuebbles, D. J., and K. Hayhoe (2002), Atmospheric methane and global change, Earth Sci. Rev., 57, 177-210, doi:10.1016/S00128252(01)00062-9.

Xu, W., R. P. Lowell, and E. T. Peltzer (2001), Effect of seafloor temperature and pressure variations on methane flux from a gas hydrate layer: Comparison between current and late Paleocene climate conditions, J. Geophys. Res., 106, 26,413-26,423, doi:10.1029/2001JB000420.

Yoshikawa, K., and L. D. Hinzman (2003), Shrinking thermokarst ponds and groundwater dynamics in discontinuous permafrost near Council, Alaska, Permafrost Periglacial Processes, 14, 151-160, doi:10.1002/ppp.451.

Zhang, Y. (2003), Methane escape from gas hydrate systems in marine environment, and methane-driven oceanic eruptions, Geophys. Res. Lett., 30(7), 1398, doi:10.1029/2002GL016658.

Zhang, Y., and Z. Xu (2003), Kinetics of convective crystal dissolution and melting, with applications to methane hydrate dissolution and dissociation to seawater, Earth Planet. Sci. Lett., 213, 133-148, doi:10.1016/S0012-821X(03)00297-8.

Zhuang, Q., et al. (2003), Carbon cycling in extratropical terrestrial ecosystems of the Northern Hemisphere during the 20th century: A modeling analysis of the influences of soil thermal dynamics, Tellus, Ser. B, 55, 751-776.

Zhuang, Q., J. M. Melillo, W. Kickighter, R. G. Prinn, A. D. McGuire, P. A. Steudler, B. S. Felzer, and S. Hu (2004), Methane fluxes between terrestrial ecosystems and the atmosphere at northern high latitudes during the past century: A retrospective analysis with a process-based biogeochemistry model, Global Biogeochem. Cycles, 18, GB3010, doi:10.1029/2004GB002239.

Zhuang, Q., J. M. Melack, S. Zimov, K. M. Walter, C. L. Butenhoff, and M. A. K. Khalil (2009), Global methane emissions from wetlands, rice paddies, and lakes, Eos Trans. $A G U, 90(5), 37-38$, doi:10.1029/2009EO050001.

Zimov, S. A., S. P. Davydov, G. M. Zimova, A. I. Davydova, E. A G. Schuur, K. Dutta, and F. S. Chapin III (2006a), Permafrost carbon: Stock and decomposability of a globally significant carbon pool, Geophys. Res. Lett., 33, L20502, doi:10.1029/ 2006GL027484.

Zimov, S. A., E. A. G. Schuur, and F. S. Chapin (2006b), Permafrost and the global carbon budget, Science, 312, 1612-1613, doi:10.1126/science. 1128908

O. Boucher, W. J. Collins, G. A. Folberth, C. E. Johnson, C. D. Jones, F. M. O'Connor, and J. Ridley, Met Office Hadley Centre, FitzRoy Road, Exeter EX1 3PB, UK. 
J. Chappellaz, Laboratoire de Glaciologie et Géophysique de I'Environnement, CNRS-University of Grenoble, F-38400 Saint Martin d'Hères, France.

R. Coppell, School of Geography, University of Leeds, Leeds LS2 9JT, UK.
P. Friedlingstein, College of Engineering, Mathematics and Physical Sciences, University of Exeter, Harrison Building, North Park Road, Exeter EX4 4QF, UK.

N. Gedney, Joint Centre for Hydrometeorological Research, Met Office Hadley Centre, Maclean Building, Crowmarsh Gifford OX10 8BB, UK. 